\title{
FORESTRY WORK
}

\section{W. H.WHELLENS}




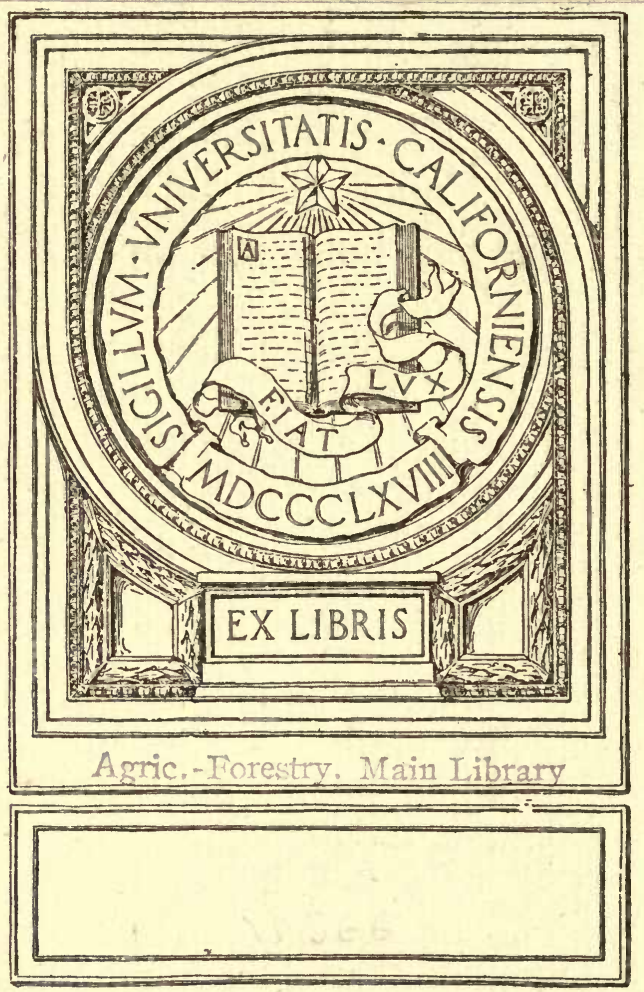




FORESTRY WORK 


\section{BOOKS ON FORESTRY}

Published by Mr. T. FISHER UNWIN

FUTURE FOREST TREES

Or, The Importance of the German Experiments in the Introduction of North American Trees. By A. Harold Unwin. Illustrated. Cloth, 7s. 6d, net.

CHINESE FOREST TREES

AND TIMBER SUPPLY

By Norman Shaw. Illustrated. Cloth, 103. 6d. net.

THE PRACTICE OF FORESTRY

Concerning also the Financial Aspect of Afforestation. By Percival Trentham M^w. Cloth, 17 \&. net.

T. FISHER UNWIN, LTD., LONDON 


\section{FORESTRY WORK}

BY

\section{W. H. WHELLENS}

LATELY HEAD FORESTER TO THE RT. HON. THE EARL MANVERS AT THORESBY PARK

WITH SEVENTEEN ILLUSTRATIONS

T. FISHER UNWIN, LTD

LONDON : ADELPHI TERRAGE 


\section{INTRODUCTION}

Mr reason for attempting to write of forestry work is that I feel there is need for a comparatively low-priced book giving a brief outline of the principles of sylviculture, and describing in more detail and in simple language the actual work, and the methods of arriving at certain facts and figures, which might serve as a stepping-stone to larger and more expensive works. Many young lads, when first entering the woods, cannot afford to buy expensive books, and are thus at a loss to know the proper way to do certain work, and the reason why it is done in certain ways. This small work may help to explain many of these things. It may also prove useful to older and more experienced men as a reference book, through the collection of tables at the end.

My sincere thanks are due to $\mathrm{Mr}$. R. Galloway (the Secretary of the Royal Scottish Arboricultural Society) for the encouragement he has given me, and for his kindness in reading through the MS. and making suggestions. 


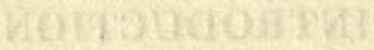

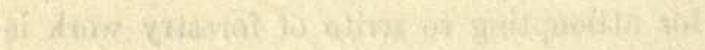

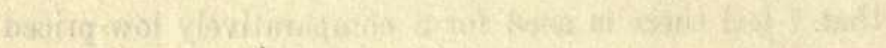

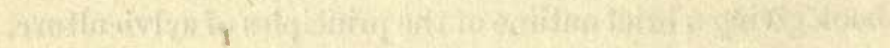

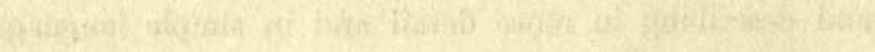

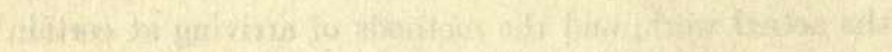

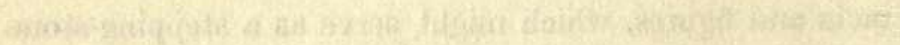

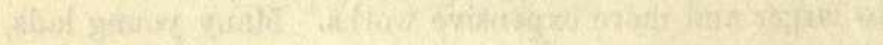

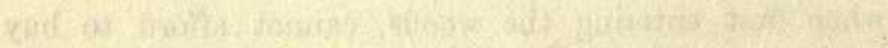

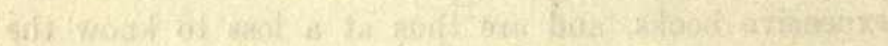

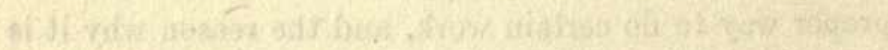

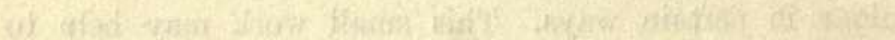

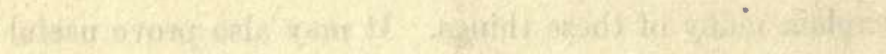

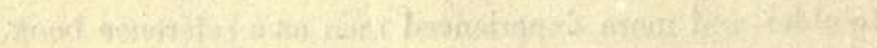

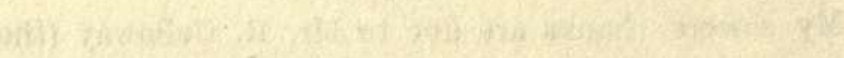

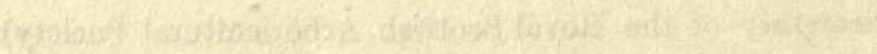

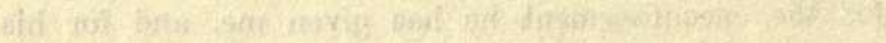

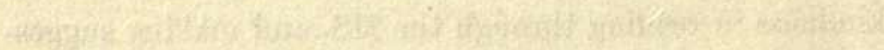
(2010is) 


\section{CON'TEN'TS}

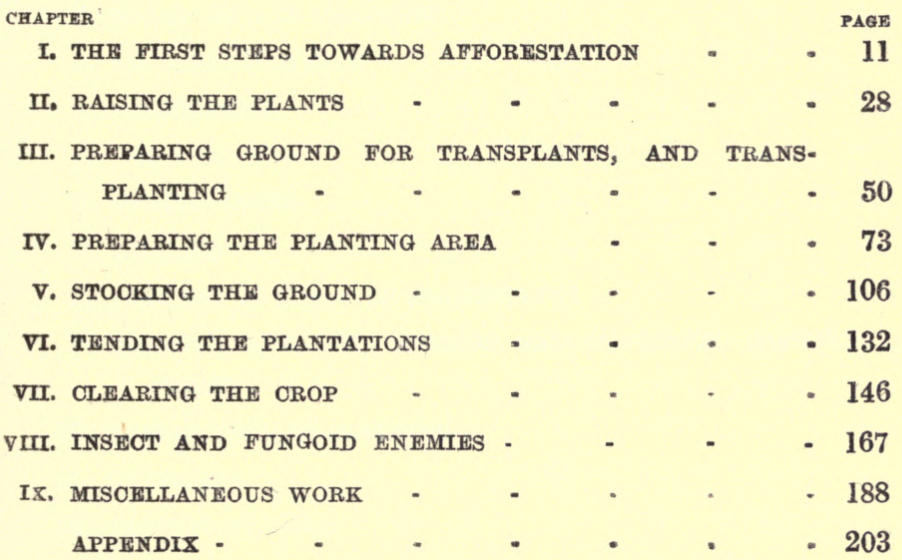





\section{LIST OF ILLUSTRATIONS}

FIG.

1. SHAPE OF NURSERY AND DIVISION INTO BEDS

2. TOOLS USED IN DRAINING

3. SFCTION OF TRENCH

- 23

4. SCARCEMENT

- 25

5. DRILL BOARDS

- $\quad 39$

6. SOWING-LATHS

- 40

7. DIBBLER

- 41

8. POSITION OF ROOTS OF TRANSPLANTS

- 61

9. CARDOT'S SEEDLING PRICKER AND SUGGESTED IMPROVEMENT

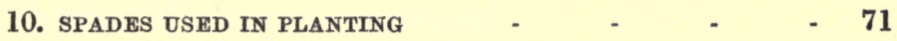

11. LEVELLING

$-82$

12. SECTION OF DRAIN

- 85

13. POST HOLDERS

- 92

14. A TREE "LAID IN" "AND "FACED" $\quad$ - $\quad$ - $\quad 149$

15. A, TOOLS USED IN BARK PEELING; AND B, BARK RACK - 155

16. HYPSOMETER (FAUSTMAN'S) - $\quad$ - $\quad$ - $\quad$ - $\quad-160$

17. plan of plantation to be measured $\quad-\quad+\quad 196$ 


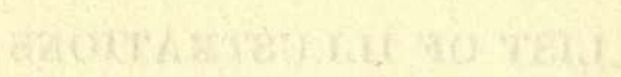




\section{FORESTRY WORK AND HOW IT IS DONE}

\section{CHAPTER I}

THE FIRST STEPS TOWARDS AFFORESTATION

Necessity of a working plan-Formation of a nursery-Advantages of a home nursery-Selection of site for a nursery-Size of nursery-Shape of nursery-Division of the nursery into beds-Soil preparation, draining, trenching-Making the roads and paths-Fencing the nursery-Hedges for nursery.

Necessity of a Working Plan.

A working plan for a period of years should form the basis of all forestry operations.

This period need not necessarily be equal to a full rotation, although a rough idea should be formed of the order in which the different woods and waste land will come into the scheme of felling and planting. The rotation may be a short one, as for pitwood, longer if for large coniferous timber, and still longer for such trees as Oak and Beech. The first point to be considered before deciding on the length of rotation is, What species will give the best return for money invested on the soil found on the area? and the second is, What class of timber is most in demand within a reasonable distance? If the 
soil on an estate varies greatly, a separate working plan should be drawn up for each class of timber grown, one each for hardwoods, conifers, copse woods, etc.

In drawing up a working plan, the area should be divided into as many sections as there are years in the rotation, adding one for the year of felling. The area of these sections should be based upon the yield expected. from them, so that the yearly income may be nearly equal. To base calculations on area alone would often result in very unequal yearly incomes, as the soil in some sections might be much better than others, and the yield of timber would consequently be better. After the rough plan has been drawn up for the whole rotation, a felling and planting scheme must be drawn up for a shorter period, as the larger plan may need revision from time to time owing to damage from windfalls, fire, fungi, or insects.

The smaller scheme should cover a period of five or ten years. If a five-year period is selected, another section can be added each year in the place of the one restocked, so that it may be possible at any time to tell what the income and expenditure will be for the next five years; also what plants and material will be reguired for each year. If the scheme is drawn up for ten years, it should be revised after five years.

In either case it should always be possible to look five years ahead, so that every detail from felling down to buying seed may be arranged for.

In the larger working plan all facts and figures regarding thinnings and their value and work done to each 
section should be noted. Notes should also be made of measurements, of their contents and yearly increment; in fact, everything likely to be of use or interest in future years should be noted.

From the smaller scheme it will be possible to tell what area is to be planted annually; the species, number, and size of plants that will be required for it, and the area of nursery that will be needed for rearing the plants.

\section{FORMATION OF A NURSERY.}

Advantages of a Home Nursery.

1. Whether the plants are bought as seedlings from nurserymen, or are raised from seed in the home nursery, they become acclimatized and accustomed to the soil in which they are to be planted, as the soil in the nursery should be representative of that on the greater part of the estate.

2. Attention can be given to the proper shape of the roots when transplanting the seedlings into lines.

3. The time that elapses between the lifting of the plants in the nursery and the planting in the woods is reduced to a minimum, as there is no need to lift more plants per day than can be planted.

4. The strongest seedlings can be selected for lining out, and later on only the best and straightest transplants need be sent out to the woods.

5. Plants can usually be grown more cheaply than they can be bought, unless too much time is spent on unnecessary work in the nursery. 
Selection of Site for a Nursery.

A nursery, to produce sturdy plants, should neither be too well sheltered nor too exposed.

The south-west wind is generally the strongest wind in this country, and the east wind the most bitter.

A certain amount of shelter is given against these winds by choosing a north-western aspect with a gentle slope.

Advantage may also be taken of an old wood to serve as shelter against the worst wind.

If extra shelter is needed for the most tender species, it should be provided artificially.

On a north-western aspect, growth starts later than on south or south-western exposures, thereby reducing risk of loss by late spring frosts.

Southern aspects on dry soil often suffer from drought.

The soil of a nursery should be fairly light and open, so that a fine tilth can be obtained for the seed-beds and for the young transplants, a sandy loam being best.

Sandy soils encourage the growth of fibrous roots more than stiffer soils. Nurseries should not be formed on stiff clays if this can possibly be avoided. It is better to have the soil too light than too heary.

The depth of the soil should be at least 15 inches, but it is seldom necessary to have it deeper than 20 inches.

The elevation of the nursery should never be too low, especially if plantations are to be formed on exposed hillsides; it should be rather higher than the average of the land to be planted. 


\section{FIRST STEPS TOWARDS AFFORESTATION 15}

Frosty situations should be strictly avoided.

A nursery that is open to air-currents will suffer less from frost than one too much enclosed.

As water is so necessary, the site must not be too far from a supply. It is better to lay the water on from a local reservoir than to make the nursery near a stream, where frosts are liable to be severe. The nursery should be as nearly as possible in the centre of the area on which planting operations are to be carried out.

\section{Size of Nursery.}

This depends on the area to be planted each year and the size of the plants to be used.

If 2-year 2-year plants of Scots Pine are to be used (i.e., plants that have stood 2 years in the seed-bed and 2 years in the nursery lines), enough ground will be required to hold plants for 3 years, in addition to the ground to be occupied by seed-beds.

At the end of the planting season the ground for the transplants will be divided thus:

One-third bare ground, from which 2-year 2-year plants have been lifted, and which is to be green-cropped.

One-third stocked with 2-year 1-year transplants.

One-third stocked with 2-year seedlings.

Taking a square acre to represent each third part of the area as an example, the number of plants that can be transplanted thereon can be arrived at in this way:

The acre is divided into 3 beds by paths 4 feet wide, with another path at the top and a cart-road 4 yards wide at the bottom. 
These paths will be each 200 feet long (approx.). Their total width will be 32 feet, making an area of 6,400 square feet to be deducted from the acre, leaving 37,160 square feet-say, 37,000 square feet.

If the plants are placed at intervals of 3 inches in lines 12 inches apart, each plant occupies 36 square inches of growing space, equal to a $\frac{1}{4}$ square foot, or 4 plants per square foot.

$37,000 \times 4=148,000$, the number of plants per acre.

If the lines are only 9 inches apart, each plant will occupy 27 square inches of space- $5 \frac{1}{3}$ plants per square foot, or approximately 197,000 plants per acre. Another way to arrive at the number of plants is to count the lines on each bed or break.

The latter will be about 192 feet long, and with lines 1 foot apart there will be 190 lines. Each line will be 63 feet long, and the number of plants 4 to each foot of length-say, 250 plants in each line. $250 \times 190 \times 3$ (the number of beds) $=142,500$, which is a better estimate than the former one, as it allows for the spaces left between the plants and the edges of the bed.

Allowing for 10 per cent. of culls or badly shaped plants, this leaves approximately 128,000 trees fit to plant out.

If the trees are to be planted at $3 \frac{1}{2}$ feet apart each wayi.e., about 3,600 plants per acre-there are enough plants for $35 \frac{1}{2}$ acres.

A certain percentage of the plants, however, must be reserved for beating up-i.e., replacing plants that have died in the plantation from drought, frost, etc. An 


\section{FIRST STEPS TOWARDS AFFORESTATION 17}

allowance of at least 10 per cent. should be made to spread over the time taken to establish the crop, usually two or three years. This leaves 115,200 , enough to plant 32 acres.

Thus it will be seen that to plant annually an area of 32 acres, 3 acres of ground are needed for transplants alone.

To this figure must be added sufficient ground for seed-beds and for other trees that may be needed apart from the plantations.

Another acre should be left for this, making 4 acres in all, equal to one-eighth of the area to be annually planted.

If the lines are only 9 inches apart, about one-third less ground for transplants will be needed. (The advantages and otherwise of this are discussed under " Lining Out," Chapter III.)

If the plants are to be twice transplanted to encourage the growth of fibrous roots, another acre will be needed, unless they are replaced upon the same beds from which they are lifted.

Hardwoods and Larch require more growing space in the lines than the majority of conifers, so if all or a proportion of these plants are to be used, a corresponding addition must be made to the size of the nursery.

When ploughed ground or very clean old woodland is to be planted, 2-year 1-year or 1-year 1-year transplants or 2-year seedlings may be used. In these cases the area of nursery can be reduced accordingly. 


\section{FORESTRY WORK}

The Shape of the Nursery.

A rectangular piece of ground, especially a square, requires less fencing and is more easily divided into beds than an irregularly shaped area.

If it is to be oblong in shape, the long sides should run horizontally along the face of the slope.

Division of the Nursery into Beds.

A square nursery of 4 acres may be divided thus:

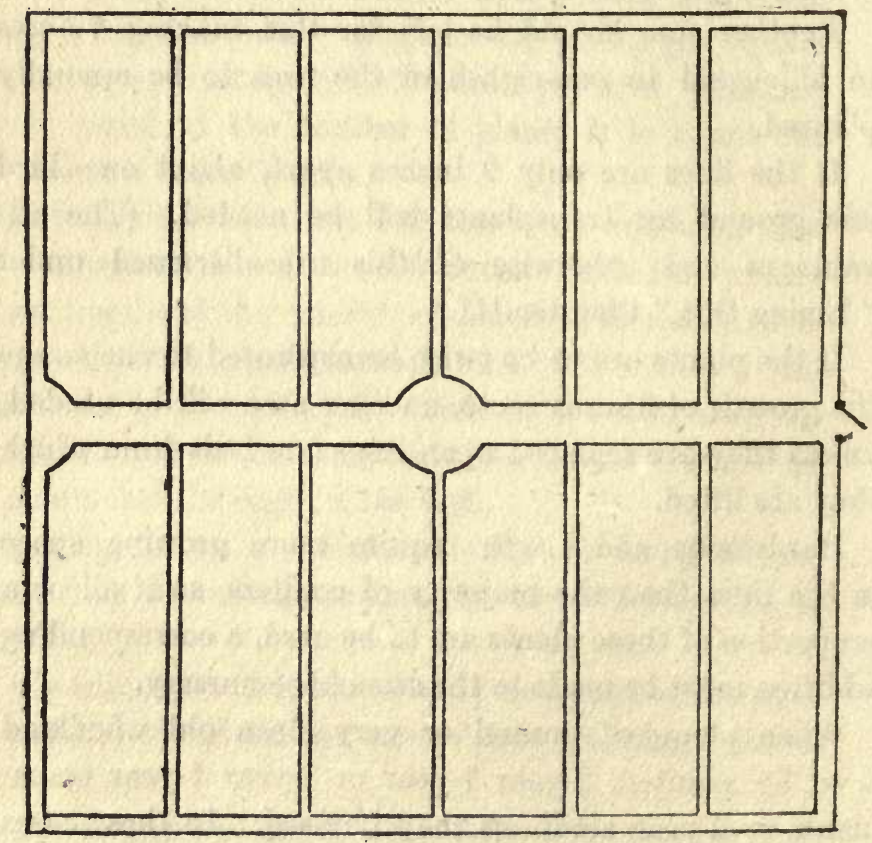

Fig. 1.-Plan of 4-Acre Square Nursery.

Beds, 21 feet wide; dividing paths, 4 feet wide; cart-road, 12 feet wide. 


\section{FIRST STEPS TOWARDS AFFORESTATION 19}

A cart-road 12 feet wide should run horizontally through the centre of the square, and each half of the nursery be divided into 6 equal beds 21 yards wide by paths 4 feet wide, leaving a path 6 feet wide at either side. Paths 4 feet wide at the top and bottom should also be made. A space for a cart to turn should be left in the centre and at the end of the road farthest from the gate.

The beds may be subdivided by paths running horizontally if necessary, but it is a mistake to take up too much space with paths.

Soil Preparation: Draining.

If the soil contains any excess of water, the nursery must be drained. A main drain should be cut along the bottom side of the nursery, and made to discharge either into any existing main drain or watercourse or into a well, so that the water may be utilized for watering in the nursery. An overflow pipe to carry the surplus water to the nearest outlet should be laid a few inches lower than the inlet pipe. The feeders or small drains should run straight up the slope, with a slight bend at the mouths in the direction of the flow of water in the main drain.

The distance apart and depth to cut the side drains can be seen from the following table:

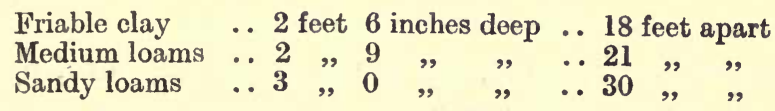

The main drain should be 3 inches deeper in each case, and the side drains mouthed or jointed into the top of 
the tiles in the main. It is a mistake to drain too deeply and so lower the water-level too much.

By capillary attraction a drain will draw water from a depth below the drain almost equalling the depth of the drain itself. The size of the main-drain tiles and pipes depends on the area to be drained. The old rule-ofthumb-viz., 1 inch per acre-holds good where there is no great excess of water. To arrive at this the diameter of the pipe is squared and multiplied by 7.854 to find its area. For instance, the area of a 3-inch circle is $3 \times 3 \times$ $7 \cdot 854=70 \cdot 686$ in. Therefore, a 3 -inch pipe will drain 7 acres and a 4 -inch pipe $12 \frac{1}{2}$ acres. Where the pipes are likely to become choked with sand or iron ore, it is cheaper to use pipes of a larger size, rather than have to lift and clean smaller ones every few years. The pipes in small drains should never be less than $2 \frac{1}{2}$ inches.

In cutting the drains for a nursery or any agricultural land, the methods are different from those employed when making open drains in woods (see Chapter IV.).

When pipes are to be laid, it is not necessary to slope the sides, but to cut thern perpendicular, allowing only enough room between them for a man to move along while grading the bottom or laying the pipes; 15 inches is usually enough.

In the case of very deep drains or when the pipes are very large, the drains must be made wider.

The turf and first spade depth of soil are thrown out with an ordinary digging spade, but below that a draining spade, or "graff," is used. It is a long, narrow, and tapering tool, very strongly made to stand leverage. 
The blade is about 18 inches to 24 inches long (the longer length for deeper drains), 6 or 7 inches in width at the tread, tapering to 3 inches at the point, and is slightly convex in shape (Fig. 2).

For throwing out the loose soil and for grading the bottom of a drain, the tools used are either a narrow curved shovel on a long handle or a long curved scoop.

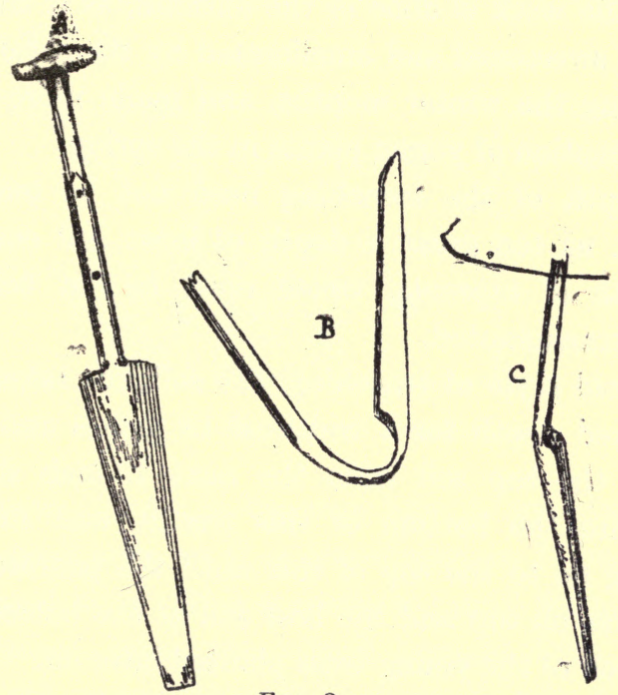

Fig. 2.

$A$, Graff ; $B$ and $C$, Grading tools.

Either tool is very good, but where the bottom is soft the latter is better, as the user by working backwards up the drain avoids treading on the prepared bed. A tool for laying the tiles in soft places is similarly shaped, but having a steel rod in place of the scoop. A pick is generally necessary where the soil is hard or stony. 


\section{Trenching the Ground.}

All soils are benefited by trenching, even where they are of good depth and where the subsoil is not hard and impervious to water. Trenching makes dry soils retain moisture longer, and aids drainage on stiffer soils, making them more easily worked.

When the work is done in the autumn, as it should be, the soil is sweetened and ameliorated by the action of the frost during the winter months, and made more suitable for the reception of young plants in the spring.

The depth of the trenching need not be more than 20 inches, as too great a depth of loose soil encourages the growth of taproots, which must be cut before the trees are transplanted.

In the old style of trenching, the soil was taken out to the required depth for a width of 18 inches and laid on one side, the top soil from the next 18-inch strip was thrown into the bottom of this trench, and succeeding layers dug on to the top of this until the poorest soil, or subsoil, was on top and the best soil at the bottom, right out of reach of the young trees planted later on.

The newer and more approved method of trenching, commonly called " bastard trenching," is carried out in the following manner: At one end of the bed to be trenched, a strip 18 inches wide is marked off, and the top soil, which will contain a certain proportion of vegetable matter or humus, is taken off and barrowed to the opposite end of the bed, and deposited in heaps for use in filling up the last trench made. The depth of this soil will vary, but 


\section{FIRST STEPS TOWARDS AFFORESTATION 23}

to make explanation more simple the top half will be considered as vegetable soil and the bottom half as subsoil.

The subsoil, which usually contains little or no humus, is then taken out and barrowed to the opposite end. This leaves an open trench, say 20 inches deep.

Another strip 18 inches wide is marked off, and the top soil is again barrowed away and placed with that from the previous strip. The shape of the trench will then be similar to Fig. 3.

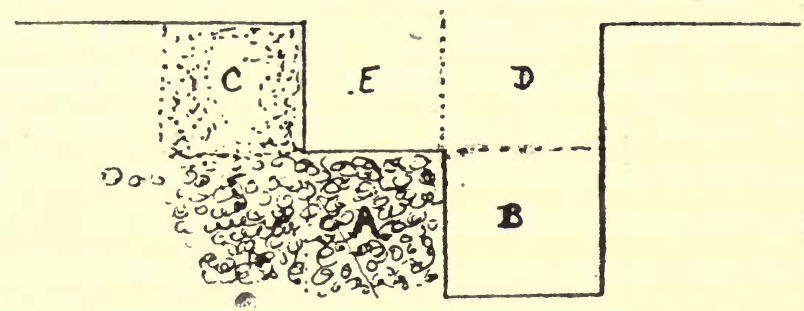

Fig, 3.-Sketch of Trench.

The subsoil from $A$ is dug over into $B$, and the top soil from the next strip at $C$ is transferred to $D$ on the top of the subsoil at $B$. This is continued until the end of the bed is reached, when the subsoil brought from the first trench is put in to replace that removed from $A$ and the barrowed top soil used to fill up $D$ and $E$. If there is turf to be disposed of, it should be chopped up finely with a spade and placed between the subsoil and the top soil, where it will rot and so enrich the soil.

In trenching, all large stones must be taken out and any irregularities in the surface of the bed made level.

The absence of large stones makes subsequent opera- 
tions much easier. The stones taken out can be used in making the cart-road in the nursery. The tools used in trenching are the common spade, shovel, and pick, with a mattock if roots are present.

\section{Making the Roads and Paths.}

The roads which are to bear the traffic of loaded carts must be made fairly solid. This can be done by taking off the top soil to the depth of 5 or 6 inches and filling up the space left with the larger stones taken out in trenching the nursery, or with any rough rubble or broken brickwork that may be within easy carting distance. These should be well rolled and given a covering of the smaller stones from the beds, cinders or gravel to a depth of 3 inches, and rolled till firm.

The road should have sufficient camber, or curve, to throw off rain-water, otherwise it will never be solid in wet weather. Drains with open gratings and soil-traps to intercept the water should be made at intervals on either side, and mouthed into the drains that drain the nursery.

The paths should preferably not be metalled, as they are then difficult to keep clean with the hoe, and it is dangerous to the young plants near the paths to use weed-killer. Fine gravel may be used to keep them from becoming dirty in wet weather.

To prevent the soil from the beds breaking down on to the paths, edgings of creosoted boards or of stones and brick are used; but the latter need constant attention to keep them neat and tidy, while the former incurs a large initial expense. 


\section{FIRST STEPS TOWARDS AFFORESTATION 25}

To make a board edging, boards 5 or 6 inches wide by 1 inch in thickness and at least 9 feet long will be needed.

Stakes 18 inches long by 2 inches square, or 2 inches by $2 \frac{1}{2}$ inches, are driven in to the required depth and fairly close together, to prevent the boards warping. The latter are sunk into the ground about 2 inches, leaving either 3 inches or 4 inches above the paths, according to the height of the soil in the beds. They are then nailed securely on to the stakes. To make an edging of old bricks, the latter are sunk into the ground to about half their length, and laid in a slanting direction in the line of the edging.

The cheapest and also the neatest form of edging is made simply by firming the edge of the bed for a width of about 4 inches with the back of a spade. A line is stretched the full length of the bed, and the edge cut down on the slope and patted firm, the top being firmed in the same way, making a "scarcement" as shown in sketch.

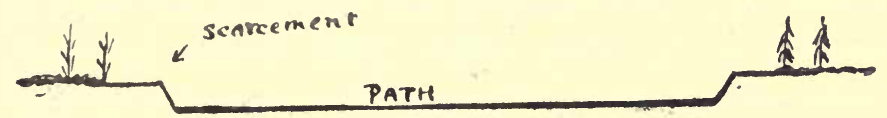

Fig. 4.-SCARCEMENT.

This edging, of course, will be made after the beds are stocked with young plants, and will need renewing every time the beds are planted. A live edging of box or prive $\theta_{t}$ is sometimes planted, but it is more ornamental than economical. 
Fencing the Nursery.

Unless the ground chosen for the nursery is already fenced, and farm stock have to be guarded against, it will be necessary to erect a substantial fence.

A 6-wire fence, with iron standards and straining-post, is both very efficient and economical.

If the nursery needs protection from rabbits and hares, the wire-netting 4 feet high can be erected on this fence.

If ground game only is to be kept out, the wire-netting should be erected upon shorter standards with a wire or two to support it. Details of fencing, with mode of erection, will be found in Chapter IV.

Hedges for Nursery.

If the nursery is very exposed it will be wise to plant a hedge inside the ring-fence, to serve as a protection to the young plants from the most severe winds.

It should be at least 4 feet away from the fence, to prevent cattle from reaching and nibbling it, and to make brushing or switching easier. Holly hedges are both strong and close and give great shelter, especially if mixed with Beech, Hornbeam, or Quickthorn. They are also highly ornamental if properly cared for. (The planting and care of hedges is explained in Chapter IX.) They should never be allowed to grow higher than about 4 feet 6 inches or 5 feet, nor allowed to become too wide.

For the protection of seed-beds or the more tender species of trees, other hedges may be needed. These need not be so big and heavy, and can be formed of oval-leaved 


\section{FIRST STEPS TOWARDS AFFORESTATION 27}

Privet alone or mixed with Beech or Quick, Beech for preference, as when they are trimmed annually they retain their leaves throughout the winter and serve better as a protection. It is a mistake to have too many hedges in a nursery, and to allow them to grow too high and wide, as they serve as a harbour for rats, mice, and other vermin, which are often difficult to exterminate from these places. Hedges serve as nesting-places for a few useful birds, but also for destructive ones as well. 


\section{CHAPTER II \\ RAISING THE PLANTS}

Collection of seed-Extraction of seed-Storage of seed-Buying seed-Germinative capacity of seeds-Seed tests-Size of seed-beds-Making the beds-Methods of sowing-Protection of beds against vermin, frost, and drought-Other methods of propagating trees-Weeding the seed-beds-Lifting the seedlings.

Collection of Seed.

Seeds must be collected only from well-shaped, healthy trees of middle age. The seed of young trees is usually weak and immature, while the plants grown from the seed of old trees are generally very inferior in vitality.

Unhealthy trees often bear a very heavy crop of seed, but this should never be collected. Trees grown from seed of diseased trees are weak and predisposed to infection by the same disease, even if they do not actually inherit it.

The collection of seeds of trees such as Oak and Beech entails very little work. They can be gathered or swept up from under the trees and passed through a riddle or sieve with large enough mesh to allow the seeds to drop through, but small enough to stop leaves, small sticks, etc. The seeds of many trees, such as Scots Pine, Larch, Alder, and Birch, must be picked from the trees; but if 
a forester intends collecting his own supply of seed, he should pick it from the best trees only, which, theoretically, should have long, clean boles with heads so high up that the work of collecting by the use of ladders would be impossible, and by the use of tree-climbers very difficult and dangerous. The only other way is to fell the trees. Therefore, if there are any good trees of the species required bearing seed on any area that is to be felled, they should be left until their seed is ripe, then felled, and their seed collected.

Where climbing or the use of ladders is possible, the collector takes with him a canvas bag slung over his shoulders, and a light pole at the end of which is a projectlng hook, with which he can pull branches towards him, or, in the case of conifers, can pull off cones, which can be picked up from the ground later.

Some seeds are very difficult to collect, those of Abres nobilis, for instance, the cones of which, when ripe, shatter to pieces at a slight touch. If unable to reach them easily, so as to place a basket or other receptacle beneath, a canvas bag with a stout wire ring round its mouth and fixed to a light pole may be used. This is held under the cone and the bough shaken, when the shattered cone will fall into the bag.

The times when the seeds of the more common trees should be collected are:

June - Elm.

October-Ash, Alder, Birch, Beech, Maple, Sycamore, and Horse-Chestnut (also Spanish Chestnut in the South of England). 
November.-Oak, Larch, Spruce, Silver Fir, Hawthorn, Holly; also Beech and Ash, if late in ripening.

December to February.-Scots Pine, Corsican Pine, Austrian Pine.

(These dates apply principally to England. In Scotland the seeds are usually from a fortnight to a month later in ripening.)

Except for the more easily collected seed, it is usually cheaper to buy a supply from a good nurseryman.

Foreign seeds of Larch, Spruce, Corsican, Austrian, and Weymouth Pines, and Spanish Chestnut, to name a few of the more common varieties, are usually superior to home-grown seed.

Extraction of Seed.

On very few estates is there a seed-kiln for extracting seeds of conifers, and unless a large quantity of any particular conifer seed, such as Scots Pine, is annually required, the expense of erecting a kiln is not warranted. It is better to send the seed collected at home to a nurseryman to extract and clean.

When a small quantity of seed from any particular tree is to be extracted, use can be made of an ordinary hot-air incubator. A tray made of laths with wire-netting at the bottom is used to hold the cones.

The heat required to extract the seeds from the cones of Scots Pine-namely, $110^{\circ}$ F.- or for Larch (105 F.) is easily regulated by anyone who understands an incubator. 
The cones on the tray are turned every two or three hours, and the seed that has fallen through the netting is collected and taken out. It takes from twelve to fifteen hours at $110^{\circ}$ F. to extract Scots Pine seed. Higher temperatures may extract the seed more quickly, but the germinative power of the seed is impaired.

Weymouth Pine and Silver Fir seed is extracted very easily. If the cones are placed in a sunny position and turned occasionally, the seeds fall out of their own accord. Larch cones, however, even when opened, will often not part with their seed, and must be thrashed to pieces with a flail and the seed sifted from the débris.

\section{Storage of Seed.}

The best place to store seed such as Acorns and Spanish Chestnut is in a loft or granary, through which there is a free current of air, but where it is not too dry or light. The seeds should be spread on the floor, not deeper than 3 or 4 inches, and should be turned frequently. If there is danger from severe frosts, canvas mats or straw should be laid over them.

Chestnuts also keep very well if "pied down" like potatoes, but in layers with dry straw between and with plenty of ventilation holes. Beech-nuts can also be stored in this way or mixed with sand. The seeds of Ash, Thorn, Holly, and Hornbeam, do not germinate until about sixteen or eighteen months after they are ripe, and must be mixed with sand and stored in "pies" or "clamps" for that time to allow the outer covering of the seed to rot. 


\section{Buying Seed.}

When buying seed, guarantees should be obtained from the vendor as to their germinative capacity, and the country or district from which they are collected.

There is no Scots Pine seed to be bought better than that collected from the forests in the North of Scotland. The germination is better than that of foreign seed, and the resulting plants are usually sturdier. Native Larch seed, as a rule, is poor, and the liability to disease is greater in plants raised from home-grown seed than that obtained from the Tyrol.

British Oak, Beech, and Common Ash, cannot be beaten.

Many large firms of seedsmen have collectors in all parts of the world, and it is, as a rule, wiser to buy seed collected in the country in which the tree is indigenous.

Germinative Capacity of Seeds, etc.

The table (p. 33) gives a few particulars as to the number of seedlings that may be expected from 1 pound of seed of the more common species of trees.

The majority of the figures in the percentage column and that for strong seedlings are the results of tests which I have made at different times; only the very best seedlings were counted when they were lifted. The seeds were tested by the damp-flannel method. The percentage for Japanese Larch is low, but the seed may not have been so good as usual in the years that it was tested, as it varies considerably. Other figures given have been taken 
from the table of germinative capacity in Nisbet's "Forester."

Germinative Capacity of Seeds.

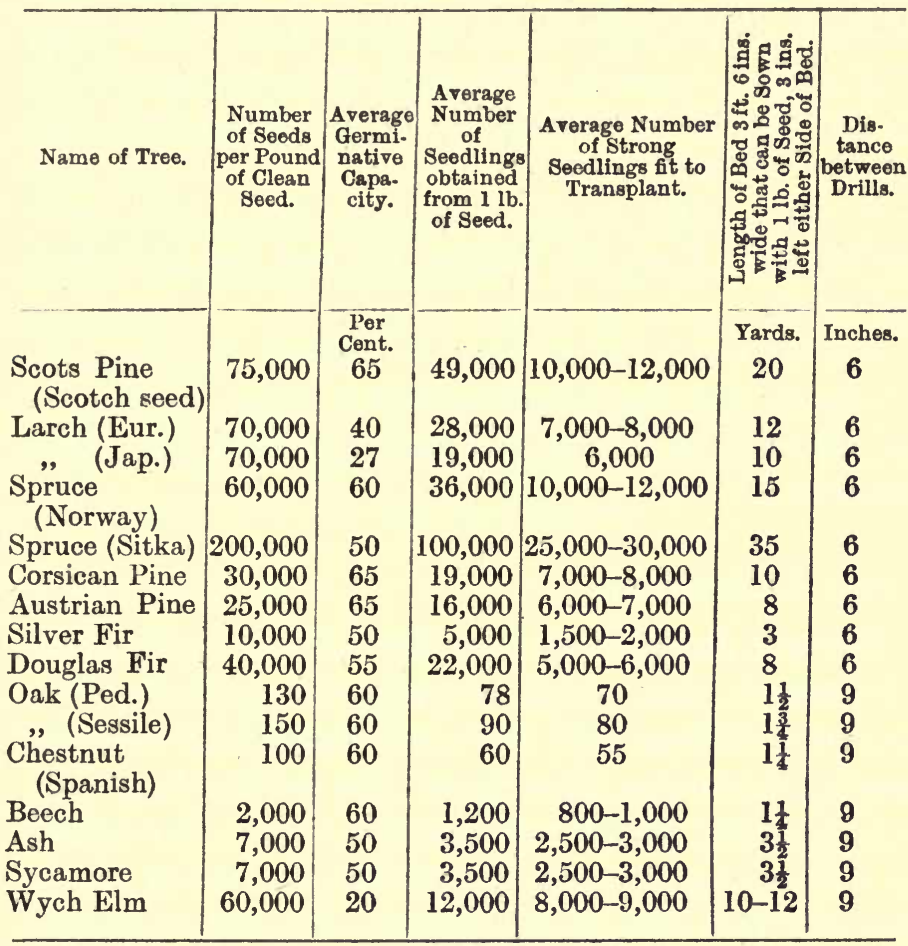

The figures in the sixth column are calculated for sowing $i_{n}$ drills. For broadcast sowing about 25 per cent. must be added to the quantity of seed sown per square yard.

Seed Tests.

The method of applying the damp-flannel test is to count out a number of seeds (not selected)-say 100, or 
multiples of 100 -soak them for twenty-four hours in tepid water, then place a piece of good thick flannel upon a tray or plate, thoroughly soak it, and place the seed upon it. Cover them with another piece of flannel, and keep them in a fairly warm place, such as a greenhouse or frame heated to about $65^{\circ}$ to $70^{\circ} \mathrm{F}$. The flannel must be kept constantly damp.

In three weeks or so every good seed should have germinated. These are counted out and the percentage arrived at.

The seeds may also be sown in ordinary flower-pots to germinate; but the flannel method is better, as there is no difficulty in finding and counting those that have germinated.

Size of the Seed-Beds.

The beds should be no wider than about 3 feet 6 inches from edge to edge, so that the persons hand-weeding them can reach halfway from either side comfortably, without treading or leaning upon them. The length of the beds can be roughly judged from the table above. The figures in this column are based upon the number of plants expected from each pound of seed. For most coniferous seeds 4 yards in length by 1 yard in width, or 4 square yards per 10,000 plants expected. On beds 3 feet 6 inches wide, with lines 6 inches apart, 7 to a bed. This works out at 360 plants per lineal yard of drill, or 10 plants per lineal inch, or about 2 plants per square inch of ground.

The width of 3 inches on either side of the beds will not 
be sown, so that the seedlings will occupy 1 yard of the width.

If 1 pound of Scots Pine seed is sown in drills 6 inches apart, and 49,000 seedlings are expected, or say 50,000, a bed about 20 yards long will be needed. Corsican and Austrian Pine and Silver Fir require rather more space than this.

For hardwoods one square yard per 1,000 plants expected should be allowed; the thinner the seed is sown, the greater the number of plants there will be fit to transfer to the nursery line.

The beds should be divided by paths about 18 inches wide, so that the weeders may kneel comfortably without sticking their toes into the adjoining bed.

\section{Making the Beds.}

The site of the beds should be on ground that has been manured and green-cropped during the previous year. It is a mistake to manure the beds just before sowing the seed, as it tends to force the growth of the seedlings and make them weakly and drawn up. Well-decayed leaf soil may be added, to serve both as a source of plant food and to prevent the soil from caking.

This should be dug in during the autumn after the green crop has been taken off. The digging should be left rough, so that as much of the soil as possible may be exposed to the action of frost.

A day or so before the seeds are to be sown, the beds should be marked off and again well dug, care being taken to pulverize any lumps and to remove as many stones as 
possible. By the time the seeds are sown, the beds will have settled down.

They should be well raked just before sowing, first with a heavy rake having iron teeth 2 inches to $2 \frac{1}{2}$ inches long, and afterwards with a finer one, to make the tilth as mealy as possible for the reception of the seed. The paths between the beds should be trodden firm, as by doing so the latter are left raised about 2 inches or so above the paths, which makes subsequent operations more easy, especially when using drill-boards or rollers, as explained later.

\section{Methods of Sowing Seed-(1) Broadcast.}

To open the beds for sowing broadcast, a tool called a "cuffing-board" is used, which is in shape similar to a rake, but with a solid board in place of the toothed head. Working from each side, the soil is pushed back from the centre to the edges of the bed, leaving a smooth level surface. The depth of the soil pushed back depends upon the size of the seed.

T'he seed is then scattered over the prepared surface, either by allowing it to run between the fingers or by sprinkling it from a round tin, about 3 inches in diameter, with the lid perforated with holes large enough only to allow the seed to pass through one at a time. The seed can be more evenly distributed in this way than by hand. After the seed is sown, it is usually rolled lightly. To replace the soil, the cuffing-board is again used by placing it at the back of soil that has been pushed aside, given a sharp pull, which shoots the soil back over the bed. 
A skilled man can spread the soil very evenly, but this work should never be entrusted to beginners, especially when very fine seed, such as that of Sitka Spruce, is being sown. They should practise until proficient upon a dummy bed or a bed of Acorns or Chestnuts, although these seeds are now seldom sown in such beds.

A safer way of distributing the covering soil is to sift it over the bed by means of a $\frac{1}{4}$-inch mesh riddle.

A great drawback to broadcast sowing is that those trees in the centre of the beds, especially when left for two years or more, have not sufficient root room and do not develop so well as those on the edges of the beds, where the roots are not cramped for space. This can be obviated to a certain extent by thinning out the weakest plants at the end of the first year, by cutting them off with scissors, not by pulling them out, as doing so will loosen the others in the soil. Line-sowing allows equal room for the majority of seedlings to develop their roots.

(2) Sowing in Lines running the Length of the Beds.

For the seed of most conifers the lines should be about 6 inches apart, unless the seedlings are to be lifted at one year old, when 4 inches is sufficient. For cleaning purposes the former width is better. The seed of hardwoods should be sown in lines 9 inches apart.

A line is stretched from end to end of the bed at distances marked off, and a small drill made with a hoe to the depth required. A good rule to follow is to bury the seeds at a depth equal to the length of the seed. Scots Pine and Larch will thus be buried about $\frac{1}{4}$ inch deep, 
Spruce and Silver Fir $\frac{3}{4}$ inch, Acorns about $1 \frac{1}{2}$ inches, Chestnut 2 inches, Beech $\frac{3}{4}$ inch, Maple and Ash $\frac{1}{2}$ inch, while such seed as Birch, Cupressus, or Thuja gigantea, should only be given the slightest covering. (A slight allowance for subsidence of the soil is made in the depth of Acorns and Chestnuts.)

Another method of making the drills is to use a roller with raised ridges upon its surface, which press into the soil when the roller is drawn along the bed. A local blacksmith will make hoops of iron that can be nailed or screwed on to a wooden roller at the widths required.

The seed may be sown in the lines either by hand or by means of the sowing horn, a contrivance much used in Germany for sowing conifer seeds. It is fitted with five nozzles of different sizes to regulate the quantity sown.

A light machine drill made by the Planet, Junr., firm can be used for sowing seed, but the objection to this is that the man using it must walk on the beds, which should be avoided.

(3) Sowing in Lines across the Bed.

To make the drills across the bed a wooden roller may again be used, but with the bars running from side to side instead of encircling the roller. These can be made of wood to the width and thickness required to make a drill deep enough for the size of seed to be sown. Another contrivance that is being used more now in England is the Bavarian drill-board. It consists of a board about an inch thick, that has been well seasoned so as not to be liable to warp, with projecting pieces of wood running 
lengthwise screwed on to it. The width of the board depends upon the distance between the drills. If for 6-inch drills, a 12-inch board will be required, and the strips of wood will be screwed on at 3 inches from either edge. These strips are 1 inch wide and deep enough to make the drills sufficiently deep for each kind of seed. A groove running down the centre of the strip helps to distribute the seed more evenly.

The length of the board should be 6 inches longer than the width of the bed, so that they may be more easily handled.

It is more satisfactory to use two boards, so that after the first has been placed across the bed and pressed in, the second one can be placed by its side and pressed in before the first is lifted. The latter is then lifted across and placed at the side of the one in position. This is continued until the bed is finished. The drills can be kept more parallel than if only one board is used.

To make the contrivance lighter, the strips of wood can be screwed on to the three cross-pieces.

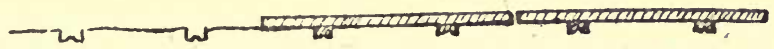

Fig. 5. -Drill Boards in Position on Beds showing Shape OF DRILL.

The seed is sown either by hand, from a flat tin box, by the use of sowing-horn, or by means of a sowing-lath. The latter is a piece of wood about $1 \frac{1}{2}$ inches square with a groove running from end to end, and fitted with a sliding lid.

Sufficient seed for each drill is placed in the groove, and 
the lid slid into place. The whole is turned over exactly above the drill and the lid withdrawn, allowing the seed to fall into place.

The lid may be made in two parts, so that half may be withdrawn either way. Sometimes it will be found that the lids carry the seed to the end before releasing it. To remedy this the lids may be hinged to the sides, and made to open downwards, so that when they are released the seed will fall straight into the drills.

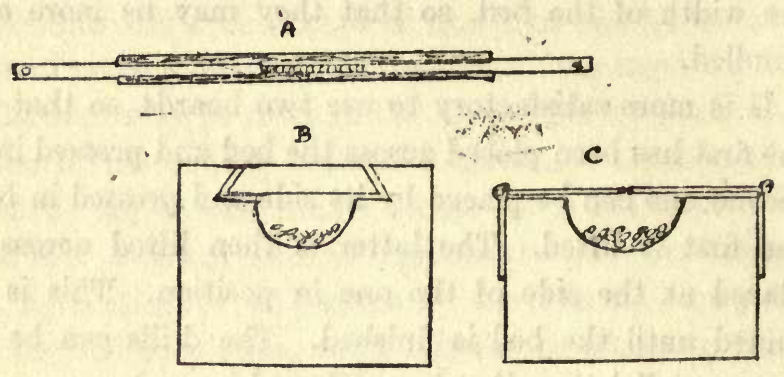

FIG. 6.

$A$, Sowing-lath with sliding lid.

$B$, Sowing-lath with sliding lid, end section.

$C$, Sowing-lath with hinged lids, end section.

To cover the seeds it is better to sift soil on to the beds through a small-mesh riddle or sieve. This should be fitted on to an old spade handle, so that it may be easily held over the bed.

The soil may be taken from between the beds, and mixed with fine leaf-soil and wood ashes.

Care must be taken not to sift on more soil than will fill the drills when the bed is finished off by levelling with the back of a light rake. Seed buried too deeply will 
either not germinate at all, or will lie dormant until the next year.

Acorns, Chestnuts, and other big seeds, are often dibbled in. A contrivance to make several holes at once is usually used. It consists of a board 3 feet long by 2 inches by $1 \frac{1}{2}$ inches, with projecting pieces of the required depth screwed on at 2 inches apart and fitted with a wide handle, so that two men, one on each side of the bed, may use it.

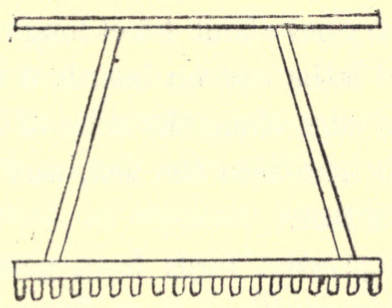

Fig. 7.-ACORN DibBLer.

If the seeds are soaked in tepid water for twenty-four hours before being sown, the germination is considerably hastened and the danger from birds and mice is reduced.

The danger from late frost is rather increased by soaking unless protection is given to the beds by use of mats.

To prevent birds and mice eating the seeds, they should be coated with red lead. The seed should be well damped, if it has not been previously soaked, and put into a box, and the powdered red lead sprinkled upon it. By stirring with a stick the red lead is evenly distributed. They should be allowed to dry thoroughly before being sown. 
Protection of Beds against Vermin, Frost, and Drought.

As mentioned above, where the nursery is very exposed, shelter from bitter winds may be given to the seed-beds by hedges, but against frost and vermin some other protection is needed.

A most useful and handy form of screen is made of ordinary plasterers' laths nailed to two cross-pieces, one at 2 inches from each end of the laths. The latter are 1 inch apart on frames about 4 feet long.

The frames of laths rest on boards 6 inches by $\frac{1}{2}$ inch, which are set on edge along the sides of the beds, sunk to the depth of an inch into the soil, and nailed to stakes driven in every 4 feet.

These frames prevent birds from getting in, and also shelter the young seedlings from frost, and shade them from the sun, which after frost does more harm than the frost itself.

The moisture is drawn by the action of the frost from the cells (which when young are very full of water) into the spaces between them. Here the water is frozen, and in all probability, when the sun is strong, as in late spring, it evaporates this before the cells can reabsorb it. In support of this theory, if a dull morning follows a frosty night little damage is done, and if the trees are sprayed with water before the sun gains strength it is practically nil, so that it seems to point to a rapid thaw and equally rapid evaporation being the cause of death, as much as the frost.

This is one of the chief reasons why a good supply of 
water should be available. If water is not laid on in pipes all over the nursery, or there is not sufficient force, a knapsack sprayer or one on wheels can be used.

Instead of laths, the frames are sometimes covered with 1-inch mesh wire-netting as a protection against birds. At night a covering of canvas or straw mats should be placed over them to guard against frost.

The lath frames protect the young seedlings from the direct rays of the sun, and prevent the beds from becoming too dry, but during a long spell of dry weather the beds should be watered from a fine rose fitted to a tube or watering-can. The watering must not be too heavy, otherwise the ground will cake and the watering will have been almost useless, as eapillary attraction is more rapid when the surface soil is caked, the moisture all being drawn to the top, where it is evaporated quickly by the sun.

Mulching with leaf-soil will reduce evaporation to a minimum and help to conserve moisture. The leaf-soil, which must be free from weed seeds, should be carefully scattered by hand between the rows of seedlings. Hoeing between the drills is a good preventative of excessive evaporation, and should be done in preference, or in addition, to watering.

Spruce or other boughs are sometimes stuck upright between the beds to shade them from the sun, and often Birch transplants are used for the purpose.

Mice and voles will often do a great deal of damage to seed-beds, and must be kept down.

Hedge bottoms should always be kept clear of leaves, 
weeds, etc., that serve as shelter and nesting-places for these rodents. They will eat Acorns, Beech, Chestnut, and other seeds, often when coated with red lead. They nibble off young seedlings, either for food or from pure wantonness. Older plants will be nibbled from top to bottom. The common field vole is a good climber, and will often go to the tops of trees 6 feet or more in height. The wood mouse and field mouse do not climb, but do most damage to seeds and seedlings. Traps baited with cheese or poison mixed with oatmeal or flour are often successful in combating these pests.

Barium carbonate is the safest poison to use, as it is very rapid in action and has no effect on other animals or birds if they eat the dead bodies. Mix with oatmeal into a stiff paste, and place small pieces in holes or in drain-pipes near the beds.

Squirrels sometimes do considerable damage. As they are difficult to trap, they should be shot.

Shooting, too, is the only way with destructive birds. To put down poison would result in killing useful birds as well.

On damp soils slugs and snails are common, and should be trapped, either by trenches filled with lime or heaps of moist bran. The latter attracts the slugs, which can be collected and destroyed. A line of soot and fine cinders, which they will not cross, may be laid round the seed-beds.

Cockchafer grubs often destroy whole beds of seedlings and plants. They may be trapped by putting down pieces of turf, grass side downwards, in shallow trenches. The turf under which the grubs collect should be examined 
every morning and the grubs destroyed. The mature beetles may be shaken down from trees on bright days in early autumn. A dressing of gas-lime given to the beds six or eight weeks before sowing a green crop will often destroy the grubs.

Other Methods of Propagating Trees.

The quickest and most useful way of raising Poplars and Willows is from cuttings or slips, which will vary much in size according to the class of tree to be raised. In the nursery Poplar cuttings, as a rule, are about 12 to 15 inches long and are cut from wood three or four years old. There should be four or five buds on each cutting, two or three of which should be below the surface of the ground when the slip is inserted, leaving two buds above the ground, from which the best shoot is selected to remain.

In plantations in frosty localities cuttings from 5 feet to 6 feet long with a terminal bud are sometimes used, the object being to keep the leading shoot above the frostline and to obtain a big tree in the shortest possible time.

Tree Willows, too, are generally started from large cuttings, often from 10 to 15 feet high and 2 inches or more in diameter at the butt.

The Cricket-Bat Willow is nearly always raised in this way.

Osier cuttings are about 12 inches long, and either allowed to take root in the nursery or placed direct into osier beds.

Small cuttings should always be cut with a sharp knife 
in a slanting direction, and large cuttings with a sharp bill-hook, so as to cause as little damage as possible to the bark.

For this reason, too, the cuttings should never be forced into the ground, but a hole made with a dibbler for the smaller slips or a crowbar for the larger ones. It may often be necessary to dig holes 2 feet 6 inches deep for the larger cuttings.

The best way to treat small cuttings in the nursery is to line them out in a trench in the same way as transplants, and, unless present in considerable quantities, sand should be added to the layer of soil next the cuttings, as they start root growth much quicker in sharp soil. All cuttings must be made firm in the soil.

Spring is the best time to take cuttings of most trees, just before the sap rises, and they should be set as soon as possible after they have been cut. Cuttings of many shrubs, Privet, Laurel, etc., are taken from the young shoots in early autumn.

English Elm, whose seed does not ripen in this country, and Lime amongst forest trees, besides many shrubs, are usually propagated from root suckers. These are cut away from the parent trees and placed in nursery lines for a year or two.

Layering in connection with sylviculture is usually confined to coppice woods and hedges, but many shrubs that do not seed well in this country are propagated in this way.

In layering, a low branch is bent over into a little trench about 3 inches deep, pegged down securely, and the soil 
replaced. The layer should either be notched with a sharp knife between the stool and the pegs or given a twist to arrest the flow of sap from the parent stool. After the layer has taken root (often in the first year) the layer should be detached. In the nursery the layers should be transplanted in the following season, but in the coppice woods they are left where they are. On dry soils the layers should be well watered. In nurseries stools of some species are kept specially for propagating by means of layers and cuttings.

\section{Weeding the Seed-beds.}

One of the disadvantages of broadcast-sown seed-beds is that they cannot be hoed, whereas when sown in lines, either along or across the beds, the spaces can be so treated, which work will keep down the weeds and help to conserve moisture by breaking up the surface of the soil.

Even in lines, of course, there will be weeds that cannot be displaced by the hoe, and these must be carefully pulled out by hand.

The weeders should place the fingers of one hand on the soil above the roots of the seedlings near the weeds, to prevent them being pulled up when the weeds are removed.

The latter must never be allowed to attain any size, as their roots sometimes spread over a large space, and the danger of pulling up seedlings is greatly increased.

For hoeing between lines running lengthwise, a 3-inch or 4-inch dutch hoe is better than the draw-hoe, as the soil is not trodden on again after being broken up. When 
using the dutch hoe, the user, who works backwards, must be careful to avoid treading on the young seedlings. There is no danger of this when the lines run across the bed.

\section{Lifting Seedlings.}

An ordinary digging fork or a one-handed garden spud may be used for loosening the plants, the tool being inserted to full depth 3 or 4 inches away from the lines, and then levered gently back until the plants are lifted above the surface of the bed. They should be kept in this position until all the best and strongest plants are sorted out from the rest, as the earth falls away from the roots and the plants are extracted more easily than when the soil is allowed to fall back into place.

Small and weakly plants, or "culls," should never be planted out in lines, as the majority of them will be from seed of weak germinative power, and the remainder will be those that have been suppressed by the stronger ones, and will never make good plants.

Twenty-five per cent. of strong plants is a fairly good average for Scots Pine or Larch, while with such plants as Spruce and Silver Fir, which even in the seedling stage are not so easily suppressed, 40 per cent. to 50 per cent. is often obtained.

The seedlings should be lifted at the same time as the transplanting work is being done and not before, only enough plants being at one time "sheued" or heeled in to serve for two or three lines in advance of the planters. They should be assarted into different sizes, so that those 


\section{RAISING THE PLANTS}

of each size may be placed in separate lines, or even on different beds, and so make the latter more uniform. Such plants as Oak or Ash that have long taproots should have these pruned, but it is a mistake to cut them too short; only enough should be taken off to stop their downward growth.

Root pruning encourages growth of fibre, and the more of the taproot that can be left the more fibre there will be. 


\section{CHAPTER III}

\section{PREPARING GROUND FOR TRANSPLANTS, AND}

TRANSPLANTING

Greencropping-Manuring and cleaning crops-Preparing ground for the reception of plants-The time for transplanting - Lining out seedlings and larger transplants-Keeping the plants clean -Pruning nursery plants-Lifting transplants in nursery.

\section{Green Cropping.}

When land is continually cropped with trees without a break it becomes impoverished, owing to the trees absorbing all or most of the available plant food, without returning it annually with a fall of leaves such as takes place in a forest. The supply must therefore be replaced for the use of future crops. This is done either through the medium of a green crop or by applying farmyard manure and growing a root crop before again lining out transplants.

Leguminous plants have the power of extracting nitrogen from the air and of giving it off to the soil in a form available as plant food by the aid of bacilli present in the little wartlike tubercles on their roots.

For this reason they are often used as green-crops in a nursery to enrich soil that has been impoverished by continual cropping of trees. Lupins, lucerne, and tares, are the plants most commonly used for the purpose. 


\section{PREPARING GROUND FOR TRANSPLANTS $\mathbf{6 1}$}

After the transplants have been taken off, the ground should be carefully forked over if there is much couchgrass, convolvulus, or other perennial weeds, care being taken to get out as much as possible, because the smallest piece that has a joint left in the ground will grow again.

The ground should then be ploughed, and the seed drilled, not sown broadcast, as then it is possible to keep annual weeds down by hoeing between the lines until such time as the green crop is high enough to suppress them.

The times for sowing and the quantities of seed required per acre are:

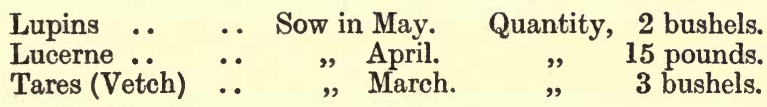

The crop should be ploughed or dug in while the stalks are still soft, and not left until they become " woody."

By the time the ground is wanted again for transplants, the crop will have decayed and added a good supply of humus to the soil.

\section{Manuring and Cleaning Crops.}

Instead of growing a green crop to be dug in as manure for the beds, they may be given a fair dressing of farmyard manure and a root crop grown upon them. There is an advantage in growing root crops, because the constant hoeing needed for them cleans the land. For this reason they are often called " cleaning crops."

A crop of potatoes is the best to grow, as by the action of their roots and tubers the soil is more broken up than 
by turnips or mangolds. The work of forking or harrowing between the rows and in " earthing " or " ridging" them up all helps to improve and clean the soil. A variety with a good amount of haulm should be chosen to suppress annual weeds.

It is a mistake to manure nurseries too heavily; this should never be done unless a crop is taken off before seedlings are lined out, as it encourages too rapid growth, which results in weak plants, not able to stand planting out in the poorer soils generally given up to planting. On the other hand, it is also a mistake to let the soil become too poor, so that the plants become starved and stunted; for a tree stunted in early life never grows into good timber.

If no green or manuring crop is to be grown on the bed before it is restocked with transplants, it should be given a good dressing of leaf mould or soil from the compost heap.

Farmyard manure should never be used unless there is to be a cleaning crop.

On most estates leaves are raked up in the private grounds, and these should be secured by the forester for use in the nursery. They should be carted to a convenient place in the woods near the nursery, or to a corner of the nursery itself, and left for at least two years, decomposition being aided by sprinkling with slaked lime and turning the heap twice every year.

The compost heap should be in a corner of the nursery, and all annual weeds and leaves taken from the beds should be placed there to rot. Perennial weeds should be 


\section{PREPARING GROUND FOR TRANSPLANTS 53}

burnt, and the ash, with all other available wood ash, added to the heap.

The heap should be sprinkled with lime and turned frequently to hasten decomposition.

Lime also helps to destroy weed seeds, or forces them to germinate before the compost is ready for application.

It should be sparingly used, especially if the compost or leaf-soil is to be spread on the beds upon which Douglas Fir, Weymouth Pine, Spanish Chestnut, or Sycamore, are to be planted, as an excess of lime will check growth and injure their vitality.

Other trees, such as Beech, Ash, Larch, and Corsican Pine, thrive well on limy soil.

On soils deficient in lime-very sandy soils, for instance -it may be applied direct if there is a good supply of humus, as lime is not only a plant food in itself, but also sets free from humus several other useful and necessary plant foods, such as nitrogen and ammonia, and neutralizes humic and other deleterious acids, thus sweetening the soil. On clays its action sets free potash and other salts, and also makes the soil friable and more easily worked.

It should preferably be applied on the fallow ground with the leaf-soil or other manures.

The use of too much lime will in time impoverish the soil, unless a good supply of vegetable matter is added.

Basic slag, a by-product of steel manufacture, is often used, and as it contains a good percentage of lime, besides other compounds useful as manures, it is as good a form as any in which to apply lime as manure. Gas-lime is of 
little use as a manure, if not, indeed, injurious to plant life, owing to the sulphur present in it.

As a grub destroyer it is very good, and should be ploughed deeply into the soil six or eight weeks before a manuring crop is sown. It also helps to kill seeds of weeds present in the soil. Other artificial manures should seldom be used, the best way to supply plant food being by manuring crops, as described above.

Preparing Ground for the Reception of Plants.

After a leguminous crop has been ploughed or dug in, the ground will be left fallow until the following spring, when seedlings are to be lined out; but when a potato crop has been taken off, the area must be cleared, the dead haulm being taken off and burnt. This is the safest way to dispose of it, especially when disease is present.

When crops of turnips or mangolds are taken off, the leaves should be left lying on the ground, to be dug in, and so add to the vegetable matter in the soil.

If there are many perennial weeds still in the ground they must be forked out, as it is easier to get them out whole with a fork than with a spade or by ploughing and harrowing.

The whole area should then be ploughed deeply or dug over, the earth being thrown up roughly to expose as much as possible to the action of frost.

The Time for Transplanting.

This varies a great deal with the locality. Some parts of England and Scotland are subject to a spell of cold and 
dry east winds during March and April, and in these places it is wise to get transplanting done in February or the early part of March, when the weather is favourable, so that they may get the benefit of the early spring rains; otherwise a large percentage may be killed by the cold, dry winds. Where these are not prevalent, transplanting should be left until the latter end of March or the beginning of April, so that as little time as possible elapses between their transference from the seed-beds and the time when growth begins. This is particularly the case with seedlings of Corsican Pine and Maritime Pine, and in a lesser degree with Douglas Fir.

Hardwood plants are not so difficult to deal with, and may be transplanted at any time in good weather during the late autumn or winter months.

\section{Lining out Seedlings and Larger Transplants.}

As mentioned above, 2-year seedlings are often used direct from the seed-beds for planting up very clean land, but where rougher ground is to be planted larger plants are needed.

To allow them to grow larger, they must be given more space, and to do this they are transplanted into the nursery lines. Transplanting not only allows them to grow, but also encourages the growth of fibrous roots or root hairs, which are the organs through which plants absorb their nutriment from the soil.

Plants plentifully supplied with root hairs will stand transplanting in the poorer soils of the woodlands better than those with few. Seedlings of some species-Spruce, 
for instance-are usually very poorly supplied, and benefit greatly from transplanting.

The distance apart at which to transplant seedlings depends upon the species, the age of the seedlings, the length of time they are to remain in the lines, whether they are to be once or twice transplanted, and the ultimate size of plants required.

In explanation of the terms used below-

1-year 1-year plants are those that have been trans. planted as 1-year seedlings and have stood for 1 year in the nursery lines.

2-year 1-year, 2 years in the seed-beds and 1 in the lines.

2-year 1-year 1-year, 2 years in the seed-beds, transplanted in their third year and again in their fourth year-i.e., twice transplanted.

2-year 2-year, 2 years in the seed-beds and 2 years in lines-once transplanted.

Hardwoods and Larch require more space than the majority of conifers. Some species-for instance, Corsican and Maritime Pines-should be transplanted more frequently than other conifers.

1-year 1-year 1-year and 1-year 1-year 2-year plants are usually better rooted than 2-year 1-year or 2-year 2-year respectively, and will be more likely to survive when planted out in the woods.

1-year 1-year transplants are usually better provided with root-hairs than 2-year seedlings, although they are often not as large, as they have not fully recovered from transplanting. 
1-year 2-year are better than 2-year 1-year, as the plants have recovered from the disturbance due to trans. planting, and have put on growth above ground.

2-year 2-year plants are the ones usually used, and although 2-year 1-year 1-year are better, the expense of transplanting more than once adds too much to the cost of the plants. Twice transplanting, as a rule, is not necessary, unless in the case of the species mentioned or when very large plants are required for any special purpose.

Even then a cheaper, though by no means as good a method is to cut the roots with a sharp spade. This is often useful when planting operations have been delayed, and a proportion of the plants that should have been planted out have to be left in the lines for another year. The spade, which should be very sharp, is inserted about 5 inches from the plants, and forced into the soil at an angle sufficient to cut the roots 6 or 7 inches below the surface.

This should be done on both sides, or, preferably, there should be a man at either side of the row.

After the spade is driven in to its full depth, it is gently levered back, lifting the plant slightly out of place, the spade withdrawn, and the plant again made firm in the soil.

This pruning and disturbance of the roots promotes the growth of root-hairs, but checks the upward growth of the plant.

Transplanting, however, is much to be preferred to this makeshift method, which should not be practised unless time is very pressing. 
If 1-year 1-year transplants of conifers are required, the seedlings should be dibbled in on beds about 4 feet wide, and the growing space allotted to each should be about 6 square inches - that is, 3 inches by 2 inches, or $2 \frac{1}{2}$ inches by $2 \frac{1}{2}$ inches, or, for convenience in weeding, 4 inches by $1 \frac{1}{2}$ inches.

Hardwood seedlings should have 9 or 10 square inches of growing space-3 inches by 3 inches or 5 inches by 2 inches.

1-year 2-year, 1-year 1-year 1-year, or 2-year 1-year conifer transplants should have 21 to 24 square inches, and be placed 3 inches apart in lines 7 inches or 8 inches apart.

Hardwoods of the same age require 36 inches to 48 square inches, 12 inches by 3 inches or 12 inches by 4 inches.

Lines of conifers 2-year 2-year old should seldom be closer than 9 inches, with 3 inches between the plants, although some foresters advocate giving them the same growing space by planting them farther apart, in lines that are closer together, but the difficulties of cleaning and the danger of damage when hoeing are increased.

In fact, the work of cleaning is more quickly done when the lines are 10 inches or 12 inches apart, and the plants are usually stronger and more robust than when they are too crowded.

One advantage of making the rows closer is that more plants may be grown per acre, thereby reducing the size of the nursery, and incidentally the cost per 1,000 plants.

Two-year seedlings of hardwoods should be planted 
about 4 inches apart, in lines 14 inches apart, and Larch 4 inches in lines 12 inches apart.

Spruce and Silver Fir, being slower growing, should, if transplanted at two years, be given the same growing space as Larch if they are to be left for three years in the lines.

There is no special preparation needed for the beds to be occupied for one-year seedlings, but a path 12 inches to 15 inches wide must be left about every 4 feet or between every ten or sixteen lines, so that weeding is made more easy.

The beds should be thoroughly dug over, all clods being broken up and the surface smoothed down either with a rake or the back of a spade. A garden line is stretched along the bed at the required distance from the edge, and the plants dibbled in with an iron-shod dibbler. They are firmed in by inserting the dibbler about 2 inches away, and the soil pushed towards the plants and the second hole filled up. The plants should not be firmed with the foot, but if the soil is very loose in texture they may be firmed by a slight pressure of the fingers. Care should be given to the depth at which the plants are inserted, otherwise, if planted deeper than they stood in the seedbeds, they are liable to choke and will decay just below the soil.

Seedlings of this age may also be treated in the same way as described below for larger plants, but owing to their small size they are more difficult to deal with.

The method employed for lining out two-year seedlings or larger transplants is as follows: 
Starting at one end of a bed or break, a trench is taken out of a spade's width and depth and the soil barrowed to the opposite end. The next " spit" of soil is dug over into this, and digging is continued until there is a smooth piece of ground of the required width from the edge of the path-say 12 inches.

A garden line is stretched along the bed at this distance, and held in place by pegs every 5 yards or so.

A narrow trench is then made by inserting the spade vertically along the line and drawing the soil towards the undug ground.

The depth of this trench must be as deep as the length of the roots of the plants. The latter may be placed in position by hand or by the aid of a notched seedling pricker.

When it is done by hand, the plants are held in position with the left hand, and a handful of soil placed against it with the right to keep it in place. This work is usually done by women or boys.

The diggers then turn the next spit of soil into the trench, and, when larger plants are being lined out, a slight pressure is given with the foot to firm the plant. Seedlings should be firmed with the fingers, if necessary.

Digging is then continued until the required width is again reached, the surface smoothed down with the back of the spade, not patted, and the former operations repeated.

Care should always be taken to make the trench deep enough to allow the roots to hang straight down, otherwise the roots are doubled up or bent at right angles, 
which, although very handy for $\mathbf{L}$ or $\mathbf{T}$ notching, is not their natural position, and is often a cause of stunted growth and want of stability in trees.

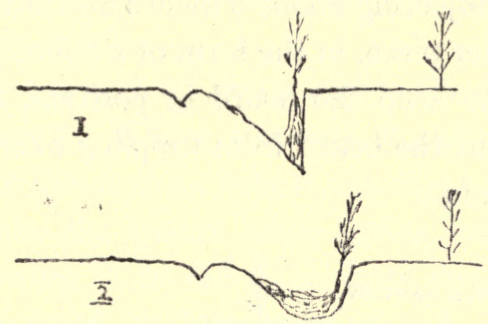

FIG. 8.

1, The right way to transplant seedlings.

2, The wrong way.

Cardot's notched seedling pricker is thus described by Nisbet in "The Forester": "It consists of a piece of wood about 4 feet long notched at every inch or inch and a half to hold seedlings, which are kept in place by another (movable) piece of wood. The seedlings are inserted into the notches at the required distance, 3,4 , or 6 inches, in such a way that only the roots appear under groundlevel in the seed-bed; and when the perpendicular-sided trench has been opened out, the instrument charged with seedlings is laid along the edge of the trench with the rootlets close against the side, and the loose earth is filled into the trench again, when the upper piece of wood is first removed and the notched lower piece then withdrawn towards the planter."

This contrivance is extremely useful, but may be improved upon by making it wider. If it is too narrow, 
it is apt to break down the vertical edge of the trench; 6 inches is a good width. Two narrow strips of wood or iron should be screwed on to the back of the board, one at each end, projecting about 3 inches upwards and downwards, the latter piece, in the form of a spike, being forced into the soil to keep the board in position, and both of them to prevent the board from toppling over while being filled with plants.

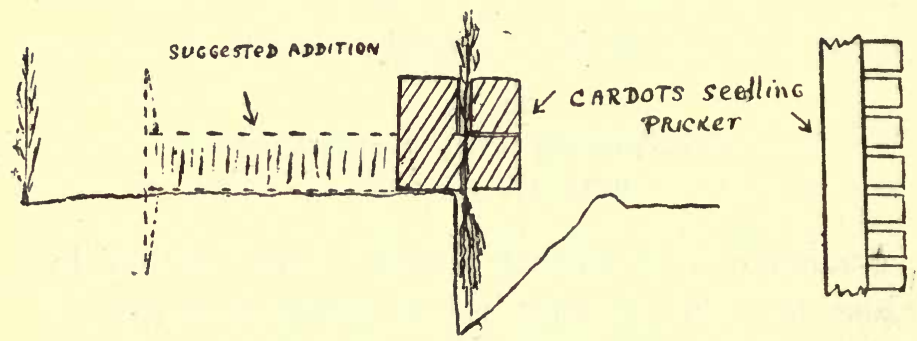

FIG. 9.

Two sets of these boards should be made, each long enough to do a whole line, as one can be in position while the other is being refilled with plants. There is thus no delay. One advantage of using these boards is that they are easily filled by women or boys, who do the work away from the lines and out of the way of the diggers.

The following few hints in regard to digging may be useful:

Never use too big a spade or take too wide a spit of ground. A man using a smaller spade or taking a smaller spit will work much easier and faster than a man using a larger spade, and the digging will be better. A No. 2 
spade is large enough for the majority of men, and a 5 -inch or 6-inch spit enough soil to take at once.

The soil should be thrown well up on to the edge of the dug ground, and all clods broken by a smack with the back of the spade.

If they are too stiff to break easily, the soil is not fit for transplanting. Where the soil is naturally stiff, a good plan is to loosen it up behind the diggers by inserting a fork or spade, the former being better, levering up the soil, and allowing it to fall back into place. The men while digging tread on this loosened soil, which action helps greatly to pulverize it and make it suitable for the insertion of young plants.

The tools used in transplanting are spade, fork, rake, garden line, foot-rule or measuring sticks, barrow or skeps (rough baskets) for carrying weeds or stones off the beds, and two sets of seedling prickers.

The measuring sticks may be 8 or 9 feet long, marked to the width of the lines, and laid down along the edges of the bed.

Keeping the Plants Clean.

Such weeds as couch-grass and convolvulus can only be dealt with effectively when the nursery ground is bare, but annual weeds can be kept under by means of hoeing and hand-weeding.

The latter is the only way to get rid of weeds on beds where the seedlings have been pricked out 3 inches by 3 inches or so. Where they have got a very strong hold on the ground, as they will do during a spell of wet but 
warm weather, aid may be obtained in loosening them by means of an ordinary weed fork (sometimes used for eradicating daisies from lawns), which tool may also be used to loosen or lighten up the soil between the plants.

Between lines of plants 5 inches or more apart, hoes can be used. For use where the weed growth is light, the dutch hoe is better than the draw hoe, as it is easier to use, and the user, working backwards, does not tread on the ground after the soil has been loosened up. This is a great consideration, as the loosening up of the soil often does more good than watering.

In a dry spell of weather it is often wise, especially amongst young transplanted seedlings, to hoe the ground, even if there are few or no weeds, to prevent it from caking and to conserve the moisture, for, as explained above, evaporation is very rapid from caked surfaces. When heavy weeds are to be removed from paths, etc., the draw hoe is perhaps best, as more force can be applied and the weeds chopped out (not chopped off).

For quick work the Planet, Junr., wheeled hoe is very good. With this tool a man can hoe almost as fast as he can walk. It is made on the principle of a horse hoe, and the hoes, two in number, can be set at various widths from 6 inches to 12 inches.

If the soil is light the hoes can be driven at a steady pace through the soil, but where the soil is stiffer the machine should be used with a sawing motion, the man moving it backwards and forwards as he walks.

The worst defect is that the man walks on the hoed ground, but otherwise for efficient and rapid work the 
tool is hard to beat. It can be fitted with grubber teeth, rakes, or even a small plough, which is used to turn a small furrow back on to the roots of the plants that may have become deprived of soil during hoeing and handweeding. Other types of machines have been made that will hoe three or four lines at once, but in my opinion there is quite enough to do in hoeing one line at a time, to do it properly and see that the plants are not injured. Another useful tool for light weeds and for loosening the top soil is made with three triangular hoes on spring arms, and is used in the same way as a draw hoe.

As little raking of the surface as possible should be done after hoeing, as it tends to consolidate the ground. If the hoeing is done in dry, hot weather, the weeds will lose their vitality in a short time; but if showers are frequent and there are many weeds, it is wise to rake them off or pick them up when hand-weeding between the plants in the rows, and then again hoe between the lines.

The weeds on the main cart-roads in the nursery should be destroyed by the use of weedkiller, but the paths should be hoed, because, no matter how carefully the weedkiller is applied, there is always a danger of some of it reaching the roots of young trees, especially if a thunderstorm or a heavy shower should fall soon after it is used. On the main road, water-tables and drains will prevent it reaching the beds.

While hoeing, great care should be taken not to injure the young plants, as there is always a great risk of spores (frequently miscalled seeds) of fungi obtaining a lodgment in the wounds. 
This is particularly so in the case of Larch, which is attacked by the canker fungus, Peziza Willkommii.

At the end of the growing season, or when too damp for hoeing, another method of suppressing weeds is to "point" the ground between the lines. Pointing is really shallow digging.

The top 3 inches or so of soil is dug or, rather, shovelled over, and all weeds buried. Those between the plants can be drawn with the point of the spade or pulled by hand and placed in the shallow trench, where they are buried by the next spadeful of soil.

The work is slower than that of hoeing, but does not need doing so often, and is the better method where there are many weeds in damp weather. The loosening of the soil, too, is of great benefit to the plants.

\section{Pruning Nursery Plants.}

As explained before, seedlings of Oak and Ash, amongst others, have strong taproots, often longer than the portion of the plant above the ground. If these are allowed to grow untouched for two or three years in the nursery lines, the plants will be very difficult to lift and also to transplant in the woods. In lifting they would probably be injured by spades. An excessive length of taproot is not necessary, so, as suggested before, they should be pruned back after being raised from the seed-beds, so that the downward growth may be checked and the growth of the smaller roots thereby encouraged.

When roots are injured during the operation of lifting, they should be pruned back as far as the injury, care 
being taken not to cut any of the rootlets from the uninjured parts.

Among hardwood transplants there are usually a good percentage with double tops. The strongest and straightest of these should be selected to remain as the leader, and the other cut off flush with the stem. When the leader has been killed or damaged, a side-shoot may be tied up to the stem and trained to take its place. This is seldom done with the commoner forest trees, but is useful when a new leader is required on more expensive ornamental trees.

Forest trees without leaders should be discarded, as, except in a few cases, they seldom recover in time to maintain a high growth equal to those with perfect leaders.

Ash, Sycamore, and Oak amongst the hardwoods acquire a new leader very readily, while Larch and Menzies Spruce are the best of the conifers for this.

When roots of hardwoods have been pruned, the branches should also be slightly pruned, to restore the balance between the root system and the top; otherwise there may not be enough moisture absorbed by the remaining roots for the sustenance of the leaves or young shoots, some of which will die off. In other words, the tree will prune itself in the endeavour to restore the balance.

In any case, it is better to shorten all straggling branches to about half their lengths, and to prune off close to the stem any that look like becoming too strong for the shade of other trees in the plantation to kill before they produce knots in the timber.

All pruning should preferably be done with a sharp 
knife, and the cuts made in a slanting direction; and always made from the direction of the roots towards the extremities of branch or stem, never downwards, otherwise a fracture of the remaining wood will result, allowing water to find its way in and causing rot.

Hand seccateurs or pruners are very handy, especially for shortening branches, but the cut can never be made flush with the stem, and, unless they are kept very sharp, the branches are pinched or bruised off rather than cut.

When pruning young hardwood standards-i.e., trees that have been kept in the nursery until 5 to 10 feet high for use as ornamental trees or specimens-all branches should be taken off from the bottom to within half their height.

If the branches are too thick for cutting with a knife, a broad chisel may be used. The branch is first cut off about 1 foot away from the tree to relieve it of weight, and the chisel placed against the bough flush with the stem and given a sharp blow with a mallet. All widespreading side-branches should be shortened and the crown made uniform and shapely.

\section{Lifting Transplants in Nursery.}

When the plants are to be notched in the plantations, or where the cartage is too excessive for lifting them with balls of earth, they must be lifted with naked roots, for which work an ordinary strong digging spade is used.

The tool is inserted in the ground about 5 inches away from the plants, and pushed in at an angle sufficient to get under the roots, to avoid, if possible, any damage to 
them. The spade is levered back and the plant, if then loose in the soil, lifted out.

If it is not loose, a spadeful of earth must be taken out and another application of the spade made, deeper.

Plants should never be pulled out, as the roots will be broken and the root-hairs torn off.

If the plants are very deeply rooted, a trench should be dug along the line, so that the spade may be placed right under the roots and the plants levered up clear of the soil. It is better always to have a man at either side.

The plants, when lifted, should be root pruned, as explained above, counted, and tied up in convenientsized bundles of 25,50 , or 100 , according to their size. The material for tying the bundles should be thick and strong, yet soft.

Faggoting band answers very well, and does not injure the plants so much as the coarser makes, such as binder twine, which is often used. The cords should be looped at one end, through which the other end is passed and pulled tight. They may be used over and over again. The foot should never be used to compress the bundles, but, if necessary, a slight pressure from the knee may be applied. The plants should be "sheued" or heeled in until they are carted to the planting area, when they should again be heeled in until required, to protect them from air, frost, and sun.

To do this a trench is opened, and the bundles placed in far enough apart to prevent heating if they have to be left in the trenoh for some time, owing to an unexpected 
ohange from open weather to frost or snow. The soil is then replaced over their roots.

If a change is expected, the work of lifting should be stopped, and those plants that are already lifted should be taken out of the bundles and heeled in thinly in rows.

If the nursery is near the area to be planted, or when the plants are in a temporary nursery on the site, they should be lifted with balls of earth by the use of either the cylindrical or semicircular spades. The plants may be then either planted in prepared pits or in holes made with similar spades.

This method of lifting and planting prevents any great disturbance of the root system, and should be practised whenever the conditions are suitable. In very sandy soil the earth will not adhere to the roots during the journey to the woods. Plants with naked roots, then, must be used. To lift plants with a cylindrical spade, it is placed round the plant, which is allowed to pass through an opening in the spade. The tool is forced into the soil, given a half turn either way to out any side roots that might adhere to the ground, and then lifted out, bringing the plant and ball of earth with it. The plants may then be released by pressure being put upon the bottom of the ball of earth. The plants should be loaded carefully on a horse trolly, or, if the nursery is on the site, upon a hand-barrow carried by two men.

The semicircular spade is inserted first on one side of the plant and then on the other, or by a man on either side, and the plant lifted out with a conical-shaped ball 
of earth. This spade is most useful for the larger transplants that are to be pitted.

When lifting still larger trees-i.e., standards or ornamental trees and shrubs-a trench should be dug round the tree from 1 to 2 feet from the stem, according to the size and spread of the roots and to the full depth of the side-roots. The ball of earth is then undermined and all deep descending taproots cut.

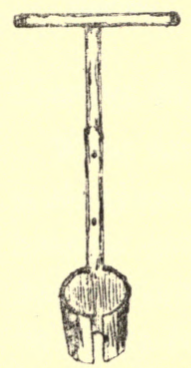

Cylindrical spade.

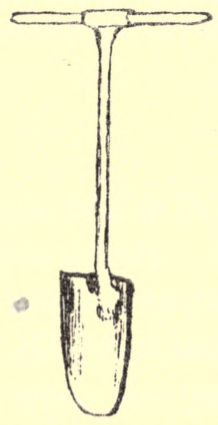

Semi circular spade

Fig. 10.

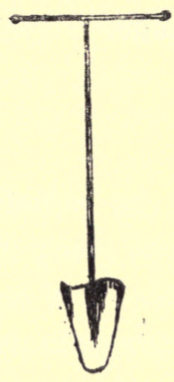

Spiral spade.

All roots that have been cut or injured by spades should be pruned by a clean cut from the knife.

The tree is then lifted up or gently levered over, and a mat or piece of sacking is placed under the ball of earth, the ends being brought up and tied round the stem of the tree. It can then be lifted up and carted away without fear of losing much of the soil.

With very large standards the trenches should be dug, and the taproots and wide-spreading side-roots pruned 
back in the spring previous to the time when they are to be removed, and the trench refilled with compost or leaf-soil.

This root pruning and manuring encourages the growth of fibrous roots, and the trees suffer less after preparation in this way than when they are transferred at once to their new quarters. Smaller plants may be prepared by a sharp spade being used to cut the roots on all sides without disturbing the soil, or by the use of the cylindrical spade. 


\section{CHAPTER IV}

\section{PREPARING THE PLANTING AREA}

Clearing the ground-Preparation of the soil: pitting, ploughing, stripping off turf and draining-Fencing and maintenance of fences-Laying out of drives and division of area into compartments.

\section{Clearing the Ground.}

When an area of waste land is to be planted up, there is always some preparation needed. Rough grass, bracken, heather, gorse, or other rough growths, must be eliminated. Also, in some cases, on old forest land such oleaning must be done; for instance, when the previous crop has been very thin, allowing undergrowth to grow profusely, or when the area has been left for three years after felling, as should be done when attacks of Pine weevil are to be feared. Usually the quickest way to destroy this rubbish is to burn it as it stands, during the winter months, in dry weather with little or no wind. Great care must be exercised if there are young plantations near. Burning should always take place against the wind, fire being set to a narrow strip on the leeward side of the area, and allowed to burn out before setting fire to another strip farther back. The line of fire should then be allowed to burn gradually against the wind, as by so doing the 
roughness is burned more thoroughly than when fire is started on the windward side and allowed to rush over the ground. If the fire burns badly, succeeding strips may be fired, the draught thus caused making the flames draw together and burn much better. Any coarse growths, brambles, elder-bushes, etc., should be cut and burned in heaps before the whole area is burned.

Bracken is often the most difficult to get rid of. It does not burn well at any time, and if it gets broken down in a wet season it is impossible to burn it in situ. The best plan is to mow it before it falls.

In some districts there is a ready market for bracken as bedding for pigs and horses, where the price obtained for it will replay the cost of cutting and harvesting. Cottagers and farmers will often do this work themselves.

\section{Preparation of the Soil.}

On clean old forest land on light soils, small transplants or two-year seedlings may be notched in without soil preparation; but where the soil is heavy or covered with a thick mat of turf, some preparation is needed.

There are several ways in which this difficulty may be overcome-viz., by-

1. Pitting.

2. Ploughing the whole area.

3. Ploughing strips.

4. Stripping the turf with plough, spade, or mattock.

5. By use of the spiral spade.

6. By preparing mounds for mound-planting. 


\section{Pitting.}

On heavy soils some preparation is absolutely necessary, and this is the method most often used. If the pits are dug properly and at the right time of the year it is better than any other method, because the turf is done away with, by either turning it over grass downwards at the sides of the pits or by chopping it up in the bottom of the hole out of the immediate reach of the young roots, where it will rot and become available in the form of humus as a supply of plant food. (If allowed to remain in contact with the roots, it is apt to heat them.)

The pits should be dug in the early autumn months, so that the soil taken out may be exposed to frost and sun, thus being sweetened and made more friable.

The young rootlets of the plants have a much better opportunity of finding their way through the soil than when the clay is just taken out, the tree inserted, the soil put back again and rammed down, thereby enclosing the roots between layers of impervious soil.

When the soil is not properly weathered, cracks appear between the lumps in hot seasons, allowing an excess of air to penetrate to the roots, and often killing the plants.

The pits should be at least 15 inches in diameter for the usual size of plants that are used, but a good rule is to allow 3 inches or so beyond the spread of the roots to give them some weathered soil in which to start growing. The roots of a plant should never be made to fit the hole, but the hole made to fit the roots.

In digging the pits the soil should be taken out to the 
depth of a foot, the top layer, which will be better quality than the lower, being kept apart from the latter. The soil at the bottom of the hole should be loosened up for a spade's depth. If the sides are undercut, it will allow more growing space for the roots.

If the turf is to be chopped up and placed in the holes, they must be made correspondingly deeper.

Where the herbage is likely to grow fast enough to smother the plants, it is an advantage to strip the turf off a spade's width all round the hole, turning it downwards on the next strip. These little details add to the initial cost of planting, but the benefit is noticed when the plants have to be oleaned. In fact, there is often little to do in this way when the turf is stripped off 15 inches or so all round the plants, and there is no fear of herbage suppressing them.

Ironpan or moorpan, if met with, should be broken through by the use of crowbars.

Measuring sticks should be used to keep the proper distance between the pits.

\section{Ploughing the Whole Area.}

On land that is free from big roots or boulders this operation is fairly simple, but one difficulty often presents itself. The turf will be turned over, but where it is thick it will still form a soft spongy layer above the firm soil, and into this layer it will be difficult or impossible to firm the plants sufficiently to withstand the wind. The ploughed area should either be fallowed to allow the turf to rot, or cropped, preferably with leguminous plants, such 
as lupins, lucerne, or tares, which would enrich the soil. The crop would not be heavy on most forest land and would not pay as a farm crop, but the soil would be improved, the turf rotted, and the operation of planting by any method made easier. The benefit of the nitrogen provided by the crop will be noticeable in the growth of the plants, and will repay the cost of seed, labour, and rent.

There are three methods of disposing of the crop-viz.:

(1) It can be fed off by sheep in the case of tares or lucerne.

(2) It can be ploughed in.

(3) It can be allowed to die down and form a layer of humus on the top of the soil.

The latter is perhaps the best method, as the soil will still benefit from the humus without the cost of ploughing.

Where shallow moorpan or ironpan is met with, it can often be dealt with by horse-drawn subsoil ploughs, but when it is too deep for this it is necessary to use steam subsoil ploughs, or to break it through by cutting drains about 12 feet apart and throwing the soil taken out on to the spaces between them to raise the level of the soil.

The advantage obtained from ploughing is that smaller plants can be used, and notched in the case of conifers, the initial cost of plants and planting thus being greatly reduced, and the cost of cleaning plants reduced to a minimum.

Hardwoods transplants should still be pitted; but as smaller plants will be used, the pits will be smaller and more cheaply made, either with the common or cylindrical spades. 


\section{Ploughing Strips.}

To save the expense of ploughing the whole area, strips 3 or 4 furrows wide may be ploughed every 4 feet or so, in which to plant the trees. They should be left for a year to allow the turf to rot and settle down if it is very thick.

\section{Stripping off the Turf-(1) By Ploughing.}

This is simply done by ploughing across the ground and then coming back in the same furrow, thus throwing a strip of turf on either side and leaving a strip of bare soil 14 inches to 18 inches wide, according to the size of the plough.

The overturned turf will also serve to keep the herbage from encroaching on the plants for a year or two.

The trees may then be planted by any method-viz., pitting, notching, dibbling, etc. Where the turf is thick and springy, it will often fall back into the furrow, and to prevent this a man should follow the plough and tread it down.

A plough can be made, however, to cut the turf clear, with two coulters and a base-plate fixed to the bottom of the plough and carried up in a slanting direction. This lifts the turf clear of the soil, and the "turn-furrow," which should be slightly longer than on ordinary ploughs, and should have a more exaggerated curve, will throw the turf clear of the edge and prevent it falling back.

Ploughed strips are especially useful on hillsides, because they serve to catch the rain-water as it runs down the 
slope, thus conserving for the use of the plants a great deal of moisture that would otherwise be lost to them. To secure this advantage strips must be ploughed horizontally along the face of the slope, and must be as level as possible, otherwise the water will rush to the lowest points and escape.

(2) By the Use of Spade or Mattock.

Where it is impossible, owing to roots, etc., to strip the turf by means of ploughing, but the soil is light enough for successful notching or dibbling, it should be taken off with a spade or chopped off with a mattock.

The principal reasons for stripping the turf are-(1) That it prevents herbage from smothering the plants; (2) that it ensures the rootlets of small plants reaching the mineral soil; (3) that it allows the rain to percolate to the roots.

The mattock is perhaps better than the spade for removing the turf, as by it the soil may be loosened up at the same time, thereby reducing evaporation, which takes place freely from the smooth surface usually left when a spade is used. It is also a very useful tool to loosen very stony soil and to remove large stones before planting with the planting hoe.

\section{The Use of the Spiral Spade.}

This tool may be used with advantage to prepare small patches for the insertion of small transplants or seedlings on the strips or squares from which the turf has been removed.

The spade is forced into the ground after the manner 
of an auger-viz., with a screwing motion. The soil is thus churned up and made more suitable for the insertion of the plants. These patches may be prepared at any convenient time during the winter months or just previous to planting (Fig. 10, p. 71).

Preparing Mounds.

A plan adopted largely on wet land in Belgium, but seldom practised in this country, is mound-planting.

The turf is taken off, a mound of soil made on the spot, and the turf replaced grass downwards on the sides of the mound, to hold it together. The plants, preferably those lifted with balls of earth, are then inserted in the top of the mound. This method prevents the plants being killed by any excess of water before becoming established, but it is expensive, and it is usually cheaper in the end to drain the ground thoroughly. Planting on upturned turf is sometimes done with success, but unless the roots of the plants are long enough to reach the mineral soil, this method should not be adopted.

The turves are either cut in squares and turned over on a different spot, or are those taken off when draining and placed in position. The plants are notched through these into the turf below by means of a grubbing iron or a straight notching spade.

\section{Draining.}

Agricultural land is drained by the use of pipes or tiles laid in ditches that are filled up again after the pipes are laid. If this method of draining were adopted for forest 
land, the drains would soon become choked with roots, unless they were too deep down, when they would be useless to drain the land. So recourse is had to open drains or ditches.

A large percentage of the land given up to forestry operations is too heavy and waterlogged to grow farm crops. This condition may arise from different causes. There may be a layer of moorpan or the subsoil may be impervious to water, the mineral soil may be covered with a layer of peat varying in depth, or the area may be affected by flood water from a river or by springs.

In the first two cases the use of subsoil ploughs may remedy the fault, and no further draining may be necessary.

The first thing in draining is to find a convenient outlet for the main drain in some existing watercourse. From this point the line of the main drain should be marked out, following the lowest ground on the area. If this is not easily discernible to the naked eye, a spirit-level must be used.

Very accurate work in levelling is not perhaps so necessary with open drains as it is with field drains, but nevertheless it should be carefully done. The levelling instrument, which is fixed upon a stand and made level by means of screws, is set up midway between two points $A$ and $B$ on the line to be levelled, the distance between these points being measured and a peg driven in flush with the ground at each point, and the instrument correctly set by means of the levelling screws. A staff marked in feet, tenths and hundredths of a foot is held perfectly 
upright on the peg at $A$ (the level of the water in the stream), and a reading is taken from the staff and booked. Other intermediate readings may be also taken from the same stand, if necessary.

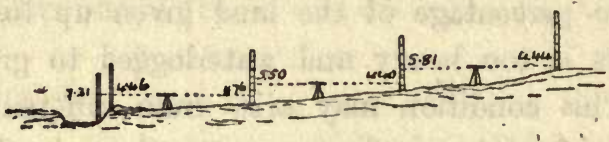

FIG. 11.

The difference between the two readings shows the rise or fall of the ground. The instrument is then moved and set up again midway between the points $B$ and $C$ and readings again taken, the rise and fall being added or subtracted from the previous rise or fall.

A simple and efficient method of booking is as follows :

\begin{tabular}{|c|c|c|c|c|c|c|}
\hline Point. & - & $\begin{array}{c}\text { Staff- } \\
\text { Reading. }\end{array}$ & $\begin{array}{c}\text { Reduced } \\
\text { Level. }\end{array}$ & $\begin{array}{l}\text { Height } \\
\text { of Colli- } \\
\text { mation. }\end{array}$ & Distance & Remarks. \\
\hline A & Backsight & $7 \cdot 31$ & 10.00 & $17 \cdot 31$ & - & $\begin{array}{l}\text { Level of } \\
\text { water in } \\
\text { stream }\end{array}$ \\
\hline Al & Backsight & $4 \cdot 46$ & $12 \cdot 85$ & - & - & Peg on bank \\
\hline B & Foresight & $4 \cdot 71$ & $12 \cdot 60$ & - & 50 yds. & Peg. \\
\hline $\begin{array}{l}\text { B } \\
\text { C }\end{array}$ & $\begin{array}{l}\text { Backsight } \\
\text { Foresight }\end{array}$ & $\begin{array}{l}5 \cdot 50 \\
4 \cdot 40\end{array}$ & $\overline{13 \cdot 70}$ & $\frac{18 \cdot 10}{-}$ & $50 \overline{\mathrm{yds}}$ & Peg. \\
\hline $\begin{array}{l}\text { C } \\
\text { D }\end{array}$ & $\begin{array}{l}\text { Backsight } \\
\text { Foresight }\end{array}$ & $\begin{array}{l}5 \cdot 81 \\
4 \cdot 44\end{array}$ & $\overline{15 \cdot 07}$ & $\begin{array}{c}19 \cdot 51 \\
-\end{array}$ & $50 \overline{y d s}$ & $\begin{array}{l}\text { Peg. } \\
\text { Junction } \\
\text { of side- } \\
\text { drain. }\end{array}$ \\
\hline
\end{tabular}


The reduced level is the height of the point levelled above an imaginary level line called a datum-line, in this case 10 feet below the starting-point.

The line of collimation is the height of the line of sight at each change of the instrument above the datumline.

The object in making the datum-line below the startingpoint is to avoid having minus figures. It may be made so many feet above when working downhill.

In the above booking $\mathbf{1 0 . 0 0}$ feet is taken as the reduoed level at $A$. The staff reading (backsight) at $A$ (the level of the water in the stream) is $7 \cdot 31$. This reading is added to the reduced level, giving the height of collimation-lineviz., $17 \cdot 31$.

The next reading, 4.46 , on the top of the bank at $A$, is subtracted from this, leaving 12.85 as the reduced level for this point-i.e., 2.85 feet above the water-level.

The instrument is turned round and a reading taken from the staff at $B$ (foresight) which is 4.71 . This, too, is subtracted from the height of the collimation, giving 12.60 as the reduced level at $B$. After setting up the instrument midway between $B$ and $C$, a reading (backsight) is taken from staff at $B$. This is $\mathbf{5 \cdot 5 0 \text { . }}$

To find the new collimation-line this figure is added to the last reduced level, viz., 12.60, making 18.10. The staff is then moved to $C$, and a foresight reading made, 4.40. This is subtracted from the new height of collimation, leaving 13.70 as the reduced level.

The height therefore of any point above $A$ may be read direct from the reduced level column. 
Explained briefly, the rules are:

To find reduced level, deduct staff reading from height of collimation.

To find difference between two points, find difference of the reduced levels. When changing stand of level, add first sight after change to last reduced level for new line of collimation.

To find gradient, divide the total distance in feet between two points by the difference in height.

For instance, if the drain at $C$ is to be 2 feet 6 inches= 2.50 , and the point $C$ found by reference to the reduced level column to be 3.70 feet higher than $A$, the difference between the level of the bottom of the drain at $C$ and $A$ is $3.70-2.50=1.20$ feet. The distance between these two points is 100 yards $=300$ feet. Therefore, 300 feet must be divided by 1.20 , which gives 250 as answer. That is, 1 foot fall in 250 feet=the gradient of the drain.

After finding the gradient of the whole length, to find out how much fall there is in each section of the length, multiply total fall by length of section and divide by whole length.

$$
\frac{1.20 \text { feet } \times 50 \text { yards }}{100 \text { yards }}=\frac{1.20 \times 150 \text { feet }}{300}=\frac{180 \cdot 00}{300}=\cdot 60 .
$$

On the other hand, given a gradient, we must find the depth at each point.

Suppose a drain with a gradient of 1 in 250 is required, the depth of the drain at each point is found by dividing the section by the length of fall for one foot.

Thus the fall in 50 yards $=150$ feet will be $\frac{150}{2} \frac{0}{5}=\cdot 60$.

Add this to the previous reduced level, and subtract the total from the ground level. 
Therefore the height of the drain above the datum-line at $B 50$ yards from $A$ will be $10 \cdot 00 \times \cdot 60=10 \cdot 60$. The level of the ground at $B$ is $\mathbf{1 2 \cdot 6 0}$. The difference between $12 \cdot 60$ and $10 \cdot 60=2$ feet $=$ the depth of the drain.

$C$ is 50 yards from $B$, so .60 must be added to $10 \cdot 60$, making 11.20.

Ground level at $C=13.70$. Difference between 13.70 and $11 \cdot 20=2 \cdot 50=2$ feet 6 inches $=$ depth of drain at $C$.

A section of the drain is made thus:

The datum-line is drawn corresponding with the length of the drain on a scale of, say, 1 inch per 50 yards.

The distances of each point must be marked off on this line and perpendiculars set up at each point (the scale of depths may be 1 inch per 10 feet), the figures for each point marked off on them, and the points of each line joined.

\begin{tabular}{|c|c|c|c|c|c|}
\hline $\begin{array}{l}\text { Level of the ground } \\
\text { above datum-line } . .\end{array}$ & $10 \cdot 00$ & $12 \cdot 85$ & $12 \cdot 60$ & $\begin{array}{c}C \\
13 \cdot 70\end{array}$ & $15 \cdot 07$ \\
\hline & $10 \cdot 00$ & & $10^{\circ}$ & 11 & \\
\hline Depth of dra & & 2 & . & 2. & \\
\hline
\end{tabular}

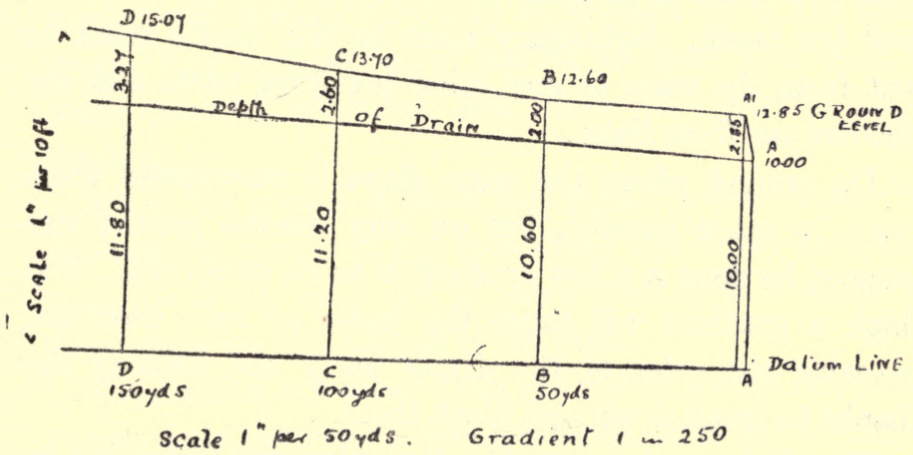

Fig. 12. 
When the proper course of the main drain is found it should be marked out and the figures respecting the depth given to the man in charge. A good average depth for the main drain is 2 feet 6 inches, with a top width of 2 feet 6 inches and a bottom width of 10 inches. The average angle of a slope for the sides will be about 72 degrees, which is enough for stiff soils. In lighter soils the slope should be greater-viz., from 60 to 65 . The small drains or feeders should be 6 inches shallower, with a top width of 2 feet in stiff soils to 2 feet 6 inches in sandy soils. A bottom width of 9 inches allows sufficient room for a spade or shovel to be passed along easily when cleaning them.

When the quantity of water is greater, it is better to widen the main drain rather than deepen it; for although water will run better in a narrow drain, it is apt to cut into the sides and break them down. The gradient should not be more than 1 in 300 , if possible to avoid it.

A wide drain is more easily kept clean than a deep one, and it is often a mistake to lower the water-level in the soil too much. Subsidiary main or side drains must be cut from the main to any other low-lying parts and the feeders cut from these.

On ground where the same slope is maintained these may be made parallel, but on very uneven ground this cannot be done if a low gradient is to be preserved. Too high a gradient will cause the water to rush downhill, wearing the sides of the drains away and causing the banks to break down and block them.

The distance between the feeders varies according to 
the nature of the soil and the quantity of water to be coped with. On heavy and wet soils they may be needed as close as 12 feet, while in lighter soils they may be 30 feet or more apart. They must be made to enter the sidedrains at a sharp angle, so that there is no check to the water, otherwise damage may be done to the larger drains at the points of entry.

The principal point is to cut the feeders in the direction in which they will intercept most water running through the soil.

Draining deep peat is a rather more difficult job, as peat shrinks very considerably when the water is drained off.

The work should be spread over two or three years instead of making the drains as deep as will be finally necessary in one year. For instance, the ditches may be made 18 inches deep in the first year. After the water has drained out of this layer they may be only about 15 inches or even 12 inches deep. Another 18 inches is taken out in the second year, which, allowing for shrinkage, should leave the drain 30 inches or 24 inches deep. If needed still deeper, they may be finished off in the third year. This method saves having to deal with such a large quantity of water, and allows the peat to settle gradually.

When the peat is shallow the whole operation may be done in one year. If the underlying soil is not naturally wet, the drains need not be more than from 3 inches to 6 inches below the bottom of the peat.

The mineral soil taken from the drains should be spread evenly over the spaces between them, or it can be left in 
heaps at the side of the drains and mixed with the peaty soil at the time of planting. This will help to aerate the peat and to set free nitrogen by hastening the decay of the raw humus.

When very deep moorpan is met with, that cannot be reached by subsoil ploughs, the drains must be cut deep enough to enable it to be smashed by crowbars.

\section{Fencing.}

Fences round plantations should be cheap, but strong and lasting. To erect a very expensive fence or to spend a lot on subsequent repairs is to reduce the profit on the timber at the end of a rotation. For economical reasons, too, as large an area as possible should be fenced at one time, even if it is not possible to plant all the ground in one year; for the larger the area, the cheaper will be the cost per acre.

For instance, 1 square acre requires approximately 280 yards of fencing and 4 acres, 560 yards. Thus it will only cost twice as much to fence four times the area.

At one time drystone and turf dykes were erected, and although very useful as shelter, these fences cost too much to erect and maintain. For the same reason ironbar fences are seldom erected round plantations.

The principal fences in use at present are-

Post and rail morticed fencing.

Driven stob and rail fencing.

Driven stob and wire fencing.

Iron standards and wire fencing.

Wire-netting fences. 
Although this small book is only intended to describe the work and not the cost of material or work, a few figures relating to the cost of the various fences and the length of time they are likely to last may not be out of place. (Pre-war prices given.)

4-hole morticed post and rail, Scots Pine, 1s. 8d. per yard; at 20 years will need renewing.

4-inch $\times 3$-inch driven post and rail, Scots Pine, $1 \mathrm{~s}$. per yard; at 15 years will need renewing.

3 inches $\times 3$ inches driven post and 6 wires, $7 \mathrm{~d}$. to $10 \mathrm{~d}$. per yard; at 15 to 20 years will need renewing. Iron standards and 6 wires, $9 \mathrm{~d}$. to $1 \mathrm{~s}$. per yard; at 15 to 20 years will need rewiring.

Woven wire fencing, 8 wires, 4 feet high, 1s. $3 \mathrm{~d}$. to

1s. $6 \mathrm{~d}$. per yard; at 15 to 18 years will need rewiring. 4-foot wire-netting (wooden stobs), $9 \mathrm{~d}$. per yard; at

15 years will need renewing.

The price for the wire fences varies according to whether long, straight stretches are available or not.

In exceptional cases the material will last longer, while near smoky towns or the seashore the wire may need renewing more often; but the above figures are fair averages.

On some soils the iron standards will rust away more quickly than on others.

\section{Post and Rail Morticed Fencing.}

These fences may have either three or four rails, but where big stock is to be guarded against, the former is not high enough. 
The posts for the four-hole fence should be at least 5 feet 6 inches long for stiff soils and 6 feet for looser ones, and 5 inches by 3 inches in section.

Holes are morticed for rails 9 feet 6 inches by 4 inches by $1 \frac{1}{4}$ inches at the following distances:

The centre of the top mortice 5 inches from the top of the post. No. 2 mortice 18 inches from the top; No. 3, 29 inches; No. 4, 40 inches. This leaves 9 inches between the two top rails, 7 inches between the others, and 6 inches between the bottom rail and ground. This makes a fence 45 inches to the top of the rail.

Corner posts must be morticed both ways.

The end of the rails are slanted so that they overlap one another in the morticed hole, forming a splice.

In setting the fence, a narrow hole is dug deep enough to leave the fence the required height, and wide enough only, after the post is in, to admit of the use of a rammer to firm the soil.

The next hole is dug 3 yards away (allowing 6 inches for the overlapping of the rails in the mortice), the post placed in (but not firmed), and the rails fitted in. The post is then firmed up. This procedure is continued until the length of fencing is finished.

Two middleheads, or pegs-i.e., light posts 5 feet 6 inches by 3 inches by $1 \frac{1}{4}$ inches-are driven in at 3 feet apart between each two posts on the side away from stock and the rails securely nailed to them.

Sometimes nails are driven into the big posts to secure the rails, but if these are fitted properly there should be no need of this. 


\section{Driven Post and Rail Fencing.}

For this style of fence the rails are usually $\mathbf{1 2}$ feet long by $3 \frac{1}{2}$ inches by $1 \frac{1}{4}$ inches, and for a fence 3 feet 9 inches above ground the posts should be 5 feet 6 inches long for stiff soils or 6 feet for loose ones. The section of these may be either 3 inches by 3 inches or 4 inches by 3 inches, the latter being better, as there is more room to joint the rails upon. The ends of the rails may be spliced or made to fit square in the centre of the post.

The posts or stobs are pointed at the lower end to make driving more easily done.

In erecting the fence a hole is first punched by the use of a crowbar, which is driven in and worked about until a hole is made large enough to admit the point of the stob. The latter is then driven in to the required depth by means of a "mall," or driving hammer. In some districts a very heavy hammer is used (20 to 28 pounds), the user standing in a barrow, lifting the hammer up and allowing it to drop on to the post, but few of these are to be seen in use now. The work of lifting this heavy weight is not compensated for by the force it strikes the post.

The most useful hammer is one weighing about 14 or 16 pounds.

With a heavy hammer it is not possible to put any strength, or " pith," behind the blow, while with a very light one too much strength is required. To use the mall to the best advantage and least waste of strength, it should first be rested on top of the stob, and from this 
position, with a light pull, swung in a circle, the swing lifting the hammer to the top of the circle. Thus most of the strength applied in using it is reserved for the downward stroke.

A good steady swing should be maintained, and the face of the hammer brought down flush on the top of the stob, as one good blow is worth half a dozen bad ones.

The man holding the stob should keep it perfectly upright and square with the line of the fence. To help in this a tool made of iron to the shape and size of the posts is used, and supplied with a handle, so that the posts may be held true. It should be made either hinged or open on one side, otherwise it will be difficult to get off if the head of the stob is battered. The hinged holder can be used at the top of the stob to prevent this.

If the stob should be split or badly battered, it should be trimmed up with a bill or sawn off below the battered place.
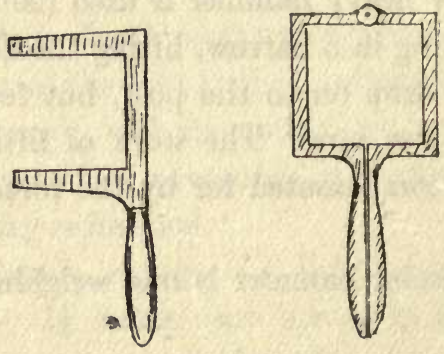

Fig. 13.-Post HolderR.

The stobs are driven in either 3 or 4 feet apart, the former if against heavy stock, and the rails nailed on, leaving spaces about the same width as for the previous style of fencing. 
To avoid jointing all four rails on one post, they may be jointed on alternate ones. This prevents the weakest spots of each rail being in one place. Nails long enough to clench at the back of the posts should be used.

Driven Stobs with Wire Fences.

In addition to the stobs, which should be 6 feet long by 3 inches square, heavy posts 7 feet long by 8 inches in diameter are required. These should be of Oak, and should have their tops sawn to a point to prevent water from lodging there and causing rot.

The intermediate stobs may be of Larch or creosoted Scots Pine. In a straight line of fence there should be a heavy post every 200 yards or so, from which to strain the wires.

When the shape of the fence is angular, there must be one at every corner. Also, when the surface of the ground is very irregular, a heavy post should be placed in the bottom of every hollow, with a sole board nailed securely on to the base of the post, otherwise the strain of the wires may lift the stobs out of the ground.

When erecting the fence, the straining posts should be fixed first, in the same way as the posts in the first fence described.

A post-hole spade and a foot pick or light crowbar are needed for getting out the soil. The spade has a long handle, and is bent sharply outwards from it, so that it will hold soil more easily. The foot pick is practically a light crowbar slightly bent at the end and fitted with a foot tread and a cross handle. The ordinary pick and 
spade are almost useless for the deep and narrow holes needed for posts. After the hole has been dug to the proper depth, the post is set in place and the soil filled in, every layer of 3 or 4 inches being well rammed. Each post must be set upright and stayed on the side from which the strain will come. Corner posts need staying in both directions.

Posts in the middle of a long, straight stretch do not need a permanent stay, a temporary one being used when straining on the first side; afterwards the strain of these wires will hold the post when the wires on the other side are strained. The stays should be 7 feet long, fitted into a notch in the post between the top and second wires, and well secured by nails. The lower end should be sunk in the ground about 1 foot and fitted with a sole board or braced against a flat stone.

The stays are often fitted underground, but the extra work entailed is not repaid by any superiority in strength, as so much soil is taken out that it cannot be replaced as firmly as it formerly was. The posts should be bored with holes at the distance apart at which the wires are to be. For a six-wire fence, the top wire should be 2 inohes from the top of the post and the spaces between the wires 10 inches, 9 inches, 8 inches, 6 inches, 6 inches, leaving 6 inches between the bottom wire and the ground. This makes the fence 3 feet 9 inches high.

The bottom wire should then be stretched tight between the strainers, to serve as a guide when driving in the intermediate posts. These are driven in 6 or 7 feet apart if droppers are not to be used, otherwise they may be 
from 9 to 15 feet apart with either two or three droppers. The latter are light pieces of wood about 2 inches by 1 inch in section, and long enough for all the wires to be stapled to them. They are apt to get shoved about by cattle, leaving the wires slack. The difference in the cost does not warrant their use.

After the stobs are all driven in, the places for the wires should be marked upon them, always starting from the top of the post. The wires are then run out and fixed to the stobs by staples, not driven home, but leaving enough room for the wires to run through easily. The old method of straining the wires with levers and straining machines and then stapling the ends securely to the straining posts is to be deprecated, as it entails so much extra labour when repairs are made or when the wires need tightening or slackening.

Heat expands and cold contracts, and wire (especially plain wire) is much affected by extremes of heat and cold. In summer the wires of a fence will slacken, making it quite easy for sheep to get through, and in winter become so tight that they often break.

When screwed eye-bolts or winding brackets are used, the wires can be easily slackened or tightened as required.

Straining machines are still necessary when eye-bolts are used, the wire being stretched and the loose end passed through the eye and fastened. The bolt is passed through a hole in the post and secured by a nut, with which the wire is tightened, a washer preventing the nut cutting into the post.

When winding ratchets are used, they are fixed to the 
back of the post with flat-headed nails or screws, the wire pulled fairly tight by hand, passed through the hole in the post and the one in the barel of the ratchet, and the latter wound up by means of a lever or a screw wrench. After the wire is fixed and strained, the fence should be levelled off by driving down any stobs that may be too high.

The wires should not be fully stretched until the whole fence is finished, because the strain on each succeeding length will have some effect on the length previously stretched. Each length should be strained gradually, and the whole looked to again before finishing the work.

To prevent stock rubbing against the fence, the top wire should be barbed. The next two wires may be either No. 7 galvanized strand wire or No. 6 plain galvanized, and the three bottom wires No. 8 strand or No. 7 plain. Strand wire, although higher in price, is much stronger, No. 7 being at least as strong as No. 6 plain; and as there are 546 yards in 1 ewt. of No. 7 strand against 393 yards in 1 cwt. of No. 6 plain, the difference in cost per yard of fence is practically nil. At pre-war prices No. 6 plain cost $\cdot 38$ d. per yard, No. 7 galvanized strand $\cdot 42$ d. per yard.

To guard against deer a fence 6 feet high with nine or ten wires will be necessary.

To join two lengths of plain wire the ends are brought together and held with clams, and each alternately twisted round the other four or five times. This can be done very neatly by hand, but a knotting tool is usually used. For strand or barbed wire the latter is necessary, as it 
is not so easy to tie. A loop should be made at one end of strand wire, the other end being passed through and looped back by means of the knotting tool.

Wire, when drawn off the coils direct, will loop and twist about unless it is put upon a turn-table; but if this is not available a very good plan is for the man attending to the uncoiling to hold the roll upright and allow, say, six coils to pass off, then turn the roll round and allow the coils to pass off on the other side. This action straightens the wire and prevents it getting into knots.

If the ground is too hard or stony for the stobs to be driven in, holes may be dug or blasted for them.

\section{Combination of Rail and Wire Fencing.}

This style of fencing is often seen in hunting countries, and is very useful. There are two rails at the top of the fence, 10 inches apart, with three wires below. The top rails prevent any accident while hunting, owing to their being easily seen, while the wires reduce the cost of the fence. The stobs are placed 6 feet apart, so slightly stronger rails are needed if heavy stock are to be kept out.

The tools necessary for wire fencing are iron mall, pick, crowbar, spade, hammer, saw, knotting tool, pliers, wirecutters or cold chisel, clams, post-holder, screw wrench.

Iron Standards and Wire Fences.

As a rule all the materials of this fence are of iron, although sometimes the straining pillars are of wood. The iron pillars, however, are much neater and last longer. These are either "batted" into stone blocks or are fitted 
with foot-plates fitted on to the bottom and stayed to the post. The latter are much more convenient to handle, and make the fence more secure.

The standards are often batted into stone, but those driven in, and provided, when necessary, with thrust plates, are much more cheaply erected and will last longer.

The winders or ratchets are slipped on to the posts and fastened by means of keys, and are worked in the same way as those fitted on to wooden posts.

At the requisite intervals the standards are punched with holes, through which the wires are passed, the only fixing required being for the top barbed wire, which is secured by clips; or if this is not used, the second wire is keyed to the standards to prevent the latter from being pushed out of perpendicular. They are fixed after the wire is strained, and must be removed before any strain is put upon the wires when tightening them at any time.

Each pillar and standard is punched with holes, to which stays may be fixed. The standard stays are used on curves, but curves should be avoided if possible.

When the iron is not batted into stone, the fence is erected in the same manner as the driven stob and wire fence, the winding posts being sunk in the ground and the standards, usually $\mathbf{T}$ or $\mathbf{H}$ iron, driven in at 7 feet apart. If no barbed wire is used, or where the ground is soft, it is necessary to fix earth-plates (thrust plates) 8 inches by 6 inches to the standards. These are made to slip down the standard, gripping the edge, and are driven into the ground to their full depth-viz., 6 inches. The material for these fences can be bought ready for 
erection from any of the leading firms, but an estate blacksmith can buy the bar and plate iron and make the straining pillars much cheaper than they can be bought. The standards and winding ratohets may be bought ready-made. All iron before erection should either be dipped in boiling tar or given a coat of black varnish.

Where the soil is too stony or too shallow for driving in standards, it is necessary to use the fence with the iron posts and standards batted into stone.

Holes must be dug or blasted out for the posts large enough to accommodate the blocks of stone.

To batt the iron into the stone, a hole is first drilled in the latter slightly larger than the width of the standard or post. Ordinary rock drills are used for this work.

The iron is placed in position and fixed by pouring in either molten lead or sulphur, which when set will hold the iron firmly in place. It is long, tedious, and expensive work, and should never be attempted unless no other fence can be erected.

A lighter and cheaper fence is made by placing the standards farther apart, 9 to 12 yards, and fixing droppers to the wire every 6 or 8 feet, to hold the wires at proper distances apart. The droppers are fixed by means of clips or wedges.

A fence of this sort requires more attention than those with closer standards, as more stress is put upon the latter, and the droppers, which are not fixed in the ground, are apt to work loose and cattle push them out of place, leaving slack places in the fence through which sheep can get. 


\section{Woven Wire Fencing.}

The straining posts for these fences are the same as described for the other wire fences, either wood or iron, but the standards, or stobs, are not required so close together, 18 to 20 feet usually being close enough.

The woven wire, which is practically wide-meshed wirenetting of No. 8 and 9 gauge, is strained in the same way by means of winding ratchets, or by a special straining machine which pulls on all wires equally and at the same time. These machines, which are usually lent by the manufacturers, vary according to the makes of wire. It is much easier to fix the wires to ratchets and strain them gradually.

\section{Wire-Netting Fences.}

Very few plantations can be formed without protection from rabbits or hares.

When other fences are erected for protection against stock, wire-netting may be attached to these by staples or string wire.

On morticed posts it is better to run a strand wire along the outside of the posts, otherwise the netting will be pulled out of shape if stapled to the rails. On driven stob and rail fencing it may be so fixed.

On the wire fences it must be secured by means of string wire to one of the wires of the fence. One or two of the wires may be dispensed with when netting is added to these fences, thus reducing the cost. In every case the bottom 6 inches of the netting must be placed 
below the ground, to prevent rabbits from burrowing beneath.

A trench 3 inches deep is taken out and the wire-netting inserted, the bottom 3 inches being doubled outwards from the fence and the soil or turf replaced.

Where hares are numerous, the height of the netting should be 3 feet 6 inches above ground, but 3 feet is usually enough to prevent rabbits entering a plantation if the ground is fairly level.

The gauge of the wire should be No. 18, or even No. 17 if likely to be required for a long period, as when protecting hardwoods. The mesh must not be larger than $1 \frac{1}{4}$ inches. Small rabbits have even been known to get through this.

When there is no fence upon which to erect the netting, straining posts about 6 inches in diameter should be put in as for ordinary stob and wire fencing, but the stobs for netting alone need only be placed every 4 or 5 yards. Neither are such strong stobs necessary, $2 \frac{1}{2}$ inches by $2 \frac{1}{2}$ inches being sufficient.

A wire is stretched between the straining posts at 2 inches from the top to hold up the netting, which is fixed to it by string wire. Another wire should be stretched about 1 foot from the ground, to which the netting is also secured. This prevents the wire sagging and giving rabbits a landing-place from which to climb the fence. If the stobs are driven in a slanting direction, leaning outwards, the fence is made more difficult to climb.

With the same object in view, the top of the netting may be bent outwards by means of brackets attached to the top of the stobs. Light iron standards are also used 
for wire-netting, and although they cost more than the wooden ones may be used again elsewhere after the netting is done.

\section{Maintenance of Fences.}

Fences of all kinds should have constant supervision, as rails or wires get broken, and if not repaired at once stock may get through into young plantations and do incalculable damage by eating the young top shoots of small trees or nibbling the bark of older ones.

In summer, when wires get slack, men supplied with screw wrenches should visit all the wire fences and tighten the wires, or in winter slacken those that seem too tight.

When wires are broken in the centre of a long stretch, Page's wire-strainer is most useful. Repairs should always be made midway between standards, otherwise the knots, being unable to pass the standard, may, when the wire is strained in summer, pull the standard out of place. Wire-netting should be attended to weekly. If there are holes under the wire, these should be blocked with stones and covered. If the netting is holed it must be patched, or if too bad either taken down altogether or replaced with new.

If there are many rabbits in a thick young plantation it is better to have no netting at all than to shut them in, as rabbits will do less damage if they run in and out than when they are prevented from doing so.

A rabbit-catcher, who should be attached to the woods staff, should be constantly employed clearing the plantations. 
A device which is often successful in clearing rabbits out of a netted plantation is to place two or three light poles in a sloping direction from the ground to the top of the corner posts, and cover them with turf. Rabbits seeking their way through the wire-netting from the inside will run along close to the fence and up this pathway and will jump off at the top to the outside of the plantation.

Iron standards and posts should be tarred every three years or so.

\section{Plantation Gates.}

In plantation fences against stock, gates equally strong must be hung; but where wire-netting alone is used, ones of lighter make are sufficient.

A strong stock gate, 9 feet long overall can be made with the back post or heel 5 inches by 4 inches, and the front post or head 4 inches by 3 inches morticed to hold four rails. The top rails taper from 4 inches by $2 \frac{1}{2}$ inches at the heel to 3 inches by $2 \frac{1}{2}$ inches at the head, the other three rails being $3 \frac{1}{2}$ inches by $1 \frac{1}{4}$ inches.

The diagonal and two upright supports are of the same thickness. The head, heel, and top bar are of Oak, the remainder being either of Larch or Scots Pine (creosoted).

An all-iron gate, with head, heel, and top bar of $1 \frac{1}{4}$ inches $T$ iron and the other bars of $1 \frac{1}{4}$ inches flat iron, is both cheap and efficient. All bars are riveted together, making it strong and rigid. With a barbed wire on the top bar to prevent cattle from rubbing against it, this gate will outlast most wooden gates. Made by local blacksmiths, it cost about 18s. (pre-war price). 
For wire-netting fences a gate made entirely of rails $3 \frac{1}{2}$ inches by $1 \frac{1}{4}$ inches is strong enough. The posts for stock gates should be of Oak, Larch, or cresoted Scots Pine. The hanging post, 7 feet 6 inches long by 8 inches by 8 inches, should be fitted with a board across the front just below the soil and another at the side on which the gate opens. These boards add greatly to the stability of the posts.

The shutting or slapping post may be 7 feet by 7 inches by 7 inches.

For the lighter gates posts 6 inches by 6 inches wil be strong enough.

Laying Out of Drives and Division of Area into Compartments.

The principal rules to be observed in laying out drives are to obtain as easy gradients as possible and to keep them on the dryest ground.

They must be marked out before planting or even fencing begin. The width of the main drives should be 7 yards and the smaller ones 5 yards. A drain should be cut on either side of all drives where the soil is at all wet, so as to keep them as dry as possible.

Although it makes dragging and carting easier to have a large number of drives, it is a mistake from an economical point of view to leave a large percentage of the ground lying idle in the shape of drives. A 200 -acre plantation should not be divided into more than eight compartments. Even then nearly 6 acres will be lying idle.

If necessary, smaller dragging rides may be cut when 


\section{PREPARING THE PLANTING AREA 105}

the trees arrive at a size when they are too heavy for men to carry out during thinning operations. One, or at the most two, lines of trees can be cut out to allow horses to be used for dragging the poles out.

The trees must not be planted too near fences, otherwise it is often difficult to repair the fences in later years. A space of at least 6 feet should be left. 


\section{CHAPTER V \\ STOCKING THE GROUND}

Decisions to be arrived at as regards stocking-Species for different soils-Pure or mixed plantations-Shade-bearing qualities of trees-Soil-improving qualities of trees-Suppression of sidebranches-Rapidity of growth-The advantages and disadvantages of pure plantations-Advantages and disadvantages of mixed plantations-Trees to plant pure-Methods of mixing -Mixing in uneven-ages woods-Mixtures-Methods of stocking the ground-Broadeast sowing-Drill sowing-PlantingShelter belts-Rotation of crop-Underplanting-The time to plant or sow-Size of plants and distance apart at which to plant-Advantage of a temporary nursery.

Decisions to be arrived at as Regards Stocking.

The first and prinoipal point to decide is what species will grow to best advantage on the soil and in the situation of the area to be stocked. The next is whether these species will grow better or produce better timber if planted pure or if mixed with others. Other point $t_{\mathrm{s}}$ are, the best method of stocking (by sowing or planting), the time to plant, and the rotation on which the trees should be grown to pay the largest percentage of profit on the money invested.

On the decisions arrived at on these points depend the number of plants or the quantity of seed per acre, the size of the plants, and the method of planting. 


\section{STOCKING THE GROUND}

If the trees are raised from seed in the home nursery, these decisions must be arrived at several years before the ground is to be stocked. It is for this reason that a planting scheme should be drawn up for at least five years ahead (from which it will be possible to answer all such questions).

Species for Different Soils.

The first thing, then, to consider is what soil will suit each individual species.

To plant a tree on soil totally unsuited to its requirements is to court disaster.

When Larch was first introduced into this country it was often planted on any or every class of soil, with the result that in many cases its vitality was lowered and it became more predisposed to attacks of the canker fungus, Peziza Willkommii.

The best loams are seldom given up to forestry operations, but any small area of this class that may be found in the woodlands should be reserved for growing Ash, which will only grow at its best on these soils.

Oak, Spanish Chestnut, Larch and Douglas Fir, also require good soil to grow to the best advantage.

On Stiff Clays: Pedunculate Oak and Spanish Chestnut should form the main crop.

On Milder Clays: Oak, Spanish Chestnut, Sycamore, Maple, Beech, Elm, and Ash, with Alder, Black, White, and Black Italian Poplars where there is more water in the soil. Also Larch, Norway and Sitka Spruces, Douglas 
Fir, Thuja gigantea, and Cupressus Lawsoniana. Pines will do well on a short rotation.

Medium Loams and Loamy Sands: Practically all trees will grow well on these soils, but the main crop should be Oak, Spanish Chestnut, Sycamore, Elm, Douglas Fir, or Larch.

Sandy Soils: The Pines (Scots, Corsican, and Austrian), with Birch.

Gravels: Beech, Sycamore, Maple, Sessile Oak. Where there is a good supply of moisture, Douglas Fir, Larch, Poplars, and Willows.

Chalky Soils: Birch, Beech, Larch, Silver Fir, and Thuja gigantea. (Spanish Chestnut, Sycamore, and Weymouth Pine, should seldom, and Douglas Fir never, be planted on limy soils.)

Peaty Soils: Wych Elm, Beech, Larch, Scots, Corsican, and Austrian Pines. As a rough guide it may be said that heavy soils should be planted with hardwoods and sandy soils with conifers.

Frosty Hollows: The Scots Pine is our hardiest conifer, and the most frosty places should be planted up with this tree. The other pines are also fairly hardy. Birch, Hornbeam, Poplars, amongst the hardwoods, stand frost best.

Trees suffer most from frost in the early autumn, before the young shoots are properly ripened, and in late spring, when they are beginning to shoot.

Frost does most damage in those places where the air-cuirrents have not free play, such as in valleys or

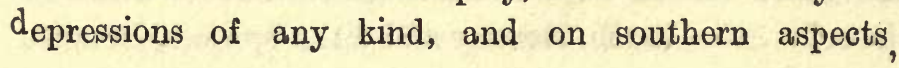


where growth usually starts earlier than on northern slopes.

After a spell of dry weather the damage is more likely to be severe than during wet weather. The damage, too, varies on different soils, moist sands being much worse than clay.

Pure or Mixed Plantations.

There are several things to be considered before this point can be decided. Some trees are shade-bearing; some will endure shade from light-foliaged trees such as Larch; others are light-demanding.

Shade-bearing Qualities of Trees.

Shade-bearing Trees: Norway Spruce, Sitka Spruce, Silver Fir, Hornbeam, Beech.

Trees tolerant of Light Shade: Spanish Chestnut, Sycamore, Lime, Douglas Fir, Thuja gigantea, Corsican Pine, Weymouth Pine, Alder.

Light-demanding Trees: Larch, Scots Pine, Oak, Ash, Elm, Poplars, Willows, Birch.

Soil-improving Qualities of Trees.

Some trees improve the soil by their heavy fall of leaves and protect it by their heavy shade.

Beech, Hornbeam, and in a less degree Sycamore, Maple, Spanish Chestnut, are soil-improvers, while the same trees, with Spruce, Silver Fir, Douglas Fir, by their density of foliage, are soil-protectors.

Larch, Oak, Ash, with others, allow too much light 
and air to reach the soil, drying up leaves, which are thus prevented from decaying and so becoming available as a source of plant food.

Suppression of Side-Branches.

To produce the highest quality of timber, the sidebranches of the trees must be suppressed or killed off before they produce large knots in the bole.

The side-branches on, shade-bearing trees are very persistent, and can only be suppressed by closely adjoining trees of equal density. Some light-foliaged trees grow the side-branches too strongly, spoiling the quality of timber, and these can be suppressed only by mixing with trees of greater density.

Rapidity of Growth.

Some trees naturally grow more rapidly than others, and consequently in a mixture by single trees those that grow more slowly are suppressed by the rapid growers. The same result follows in similar mixtures made on a soil suited to one species only-those that the soil does not suit will be suppressed.

\section{The Advantages of Pure Plantations.}

They are more easily planted and tended, and the trees all reach maturity at the same time.

With heavy-foliaged, shade-bearing trees, the sidebranches are suppressed more readily than if mixed with light-foliaged trees. 
Disadvantages of Pure Plantations.

Crops of pure light-foliaged trees admit too much light, and allow the soil to deteriorate.

Danger from fire is greater in pure coniferous woods than where there is an admixture of hardwoods, and the risk of damage by insects or fungi is greatly increased.

Advantages of Mixed Plantations.

The soil is protected and improved when soil-improvers are mixed with light-foliaged trees.

The side-branches of a light-foliaged main crop are rubbed off better if shade-bearers are mixed with them than in pure light-foliaged woods, and the timber is consequently of higher value.

The more expensive trees can be planted at wider intervals, thereby reducing initial expense, and the intervening spaces filled up with cheaper varieties, which may be more valuable as thinnings at an early age than those of the main crop.

If the principal species fails, there will be another left to take its place as the final crop.

Deeper-rooted or more hardy species can be planted as nurses to protect the main crop against frost or storms, and hardwoods introduced into coniferous plantations as a protection against fire.

\section{Disadvantages of Mixed Plantations.}

They are most difficult to manage. The different species seldom reach maturity at the same time. 
Trees to plant Pure.

Shade-bearing trees such as Spruce, Silver Fir, Donglas Fir, Beech, and Hornbeam, should be grown pure where their timber is most in demand and the soil is most suited to them, because no other trees grown in mixture with them would prune them sufficiently to produce highclass timber. Mixtures of two or more shade-bearers are seldom satisfactory, as their height growth is so unequal.

Light-foliaged trees may be planted and allowed to remain pure for a number of years, and then heavily thinned, and underplanted with some shade-bearing and soil-protecting tree.

\section{Methods of Mixing.}

There are three main methods of mixing-viz., (1) By single trees; (2) by groups or patches; (3) by strips.

1. Trees such as Oak or Chestnut are planted from 12 to 15 feet apart and the intervals filled up with nurses, that will be removed as thinnings. Two or more varieties may be mixed singly in the lines.

2. Small groups or patches of light-foliaged trees may be planted, and the spaces between filled up with soilimprovers. Variations in the soil, too, may be taken advantage of to plant species to which each class is suited.

3. Strips from 5 to 20 lines wide may be planted alternately with light-demanders and shade-bearers. The strips should run from east to west, so that the 
shade of the heavy-foliaged trees may benefit as large an area as possible. The heavy leaf-fall of the shadebearers will spread over the intervening spaces, and water will carry the plant food in solution from one place to another in draining through the soil.

The two latter methods are especially to be advocated when there is danger of one species suppressing another. The advantages of both systems are obtained to a certain degree with few of their disadvantages. They are pure groups in a mixed plantation and may be treated as such.

\section{Mixing in Uneven-Aged Woods.}

As suggested above, light-foliaged trees are planted pure and allowed to remain so for a period-Larch from 25 to 30 years, Oak from 40 to 50 years. A heavy thinning is then taken, leaving from 300 to 350 trees per acre, and the wood is underplanted with some soil improving species, such as Beech, Sitka Spruce, or Douglas Fir, under Larch; and Beech or Douglas Fir under Oak.

Spruce, although it stands shade well, should not be planted unless there is a very good supply of moisture, as it transpires too much water, to the detriment of the Oak.

\section{Mixtures.}

Douglas Fir and Sitka Spruce: A fairly good mixture, but too expensive at the present time.

Douglas Fir and Larch: A good mixture in uneven. aged woods, and also in groups or strips. 
Douglas Fir and Oak: Good in uneven-aged woods. Underplant the Oak at 40 years, and both species will then arrive at maturity together.

Douglas Fir and Scots Pine: Not a good mixture in even-aged woods, as the fir grows too fast.

Larch and Silver Fir: Good in uneven-aged woods.

Larch and Spruce or Sitka Spruce: Fairly good in uneven-aged woods where there is a good supply of moisture.

Larch and Scots Pine: Fairly good on soil suited to the Pine. The soil is apt to deteriorate, when either species may be taken out and the other underplanted at about 30 years.

Larch and Corsican Pine: On moist sandy soils this mixture is good, even height growth being maintained. Very good for pitwood.

Spruce and Scots Pine: Not a good mixture, as the Scots Pine will suppress the Spruce in early life, while if Spruce are in greater number the Scots Pine will be dominated later.

Scots Pine and Beech: Fairly good mixture if protection is given to the Beech while young. Beech does well as an undercrop to Scots Pine under a light canopy.

Beech and Oak: A good mixture on soil suited to the Oak, but is better in uneven-aged woods.

Scots Pine and Corsican Pine: Good mixture on moist sandy soils, especially for pitwood. A percentage of the Scots Pine can be left, and underplanted with Beech and Douglas Fir. 
Oak and Larch: A bad mixture, both being lightfoliaged. The Larch will overgrow the Oak, and the latter will not be pruned.

Oak and Ash: Another bad mixture. The Oak will be outgrown, and both species will be branchy.

Beech with Ash and Chestnut or Sycamore: Very good in groups, strips, or uneven-aged woods.

Birch on almost any soil and Poplars may also be mixed with the most tender species as nurses. If there is a growth of self-sown Birch on the ground, it should be thinned, sufficient being left to serve as nurses.

\section{Methods of Stocking the Ground-Sowing.}

Where conditions are favourable, woods may be stocked by sowing the seed direct on to the land. Also, in places where the soil is very shallow, as on hillsides, sowing may be a surer method of producing a crop than planting.

When it is possible to plough the whole area, or strips, sowing may be adopted on land suitable to the growth of Scots Pine, Larch, Spruce, or any of the cheaper seeds.

The ploughed land should be lightly harrowed, to prevent seeds from falling down between the furrows and being lost.

The seed, which should be soaked, to hasten germination, and red-leaded, as described in Chapter II., may be sown either broadcast or by a drill. The latter is better, as the seed required is much less and it is more evenly distributed. 
Broadcast Sowing.

The table of germination shows that 1 pound of Scots Pine seed should produce at least 10,000 strong seedlings. These would be more than sufficient to stock an acre if they were planted, but the difficulty in broadcast sowing is to get 1 pound of seed to cover an acre. As seed is cheap compared with plants, it is advisable to use plenty of it to ensure the ground being properly stocked.

To avoid sowing too thickly, it should be mixed with some other substance, such as coarse sawdust, care being taken to mix it well. A method adopted in some parts of the Continent, and which should succeed in this country, is to mix and sow the seed with Oats. The crop of corn springing up protects the young seedlings for a time, and keeps down any rough growth.

The corn is cut fairly high, so that the young seedlings escape the knives of the machine or scythes.

During harvesting operations many young plants will bo killed, but enough will be left to stock the ground.

The value of the Oat crop, even if only a poor one, will help to repay the initial oost of stocking the ground.

With this method only 2 or 3 pounds per acre need be used, whereas if it were sown by itself from 5 to 6 pounds of Scots Pine seed would be required.

In broadcast sowing by hand, the sower has a curved tin hung round his waist, supported by a strap over the shoulders. From this, with either hand alternately, he takes a small handful of seed, and, keeping time with his stride, throws the seed in a sweeping curve. The amount 
of seed sown is regulated by the size of the "handful " taken each time and by the length of the stride. The longer the latter is, the thinner will the seed be sown.

In some parts of the country a small machine called a "fiddle" is used for broadcast sowing. This is hung round the waist, and the distributing wheel worked by drawing a cord, fitted to a stick, to and fro, in the same manner as the bow is used when playing a violoncello, the cord acting as a driving belt.

Sowing is sometimes done on unploughed land where the herbage is not rank, as on hillsides, where it is not advisable to disturb the soil covering for fear of having the soil washed away.

A light harrowing should be given to make lodgmentplaces for the seed, which is left for the rain to wash into the soil.

On ploughed land the seed should either be lightly rolled or bush harrowed.

Sowing in Drills.

This method is usually adopted when sowing on pre pared strips, and may either be done by hand, by sowinghorn, or by the use of a machine drill.

When the seed is sown in the two former ways, the drills are made with a hoe, the seed sprinkled in thinly in a continuous line or a few dropped every foot or so, and lightly covered by hand. Acorns, Chestnuts, or other large seeds, are usually dibbled in about 1 foot apart, use being made of a similar tool to that described for nursery work. 
When the seed is to be sown in drills on ploughed land, an ordinary turnip drill can be adapted for the purpose by dispensing with some of the cups in the revolving bar.

A very useful machine is made by the Planet, Junr., firm, which will either sow seed in lines or will deposit a small quantity of seed at intervals of 2 inches, 4 inches, 8 inches, 12 inches, or 24 inches. Although it is really intended for garden seeds, of sizes varying from beans to carrot seed, it can be regulated to place about four Scots Pine seeds in each heap. The seed must be very clean, otherwise a small stick will block the aperture through which the seed passes.

If it is set to place four seeds every 12 inches in lines 2 feet apart, there will be roughly 88,000 seeds sown per acre. As there are 75,000 seeds in 1 pound of Scots Pine seed, this works out at nearly $1 \frac{1}{4}$ pounds per acre. If there is only one strong seedling in each clump after germination, this will mean 22,000 plants per acre. The struggle for existence will begin at an early age, and the weaklings in each group soon suppressed.

The machine can be set to bury seed at any depth down to 2 inches, and has a small roller behind to firm the soil slightly.

This method of sowing can be adopted in combination with the sowing of Oats, but the latter must be sown broadcast first.

A combination of sowing and planting is sometimes practised with success. Acorns and Chestnuts are sown on prepared strips 14 or 15 feet apart, and the spaces 
filled up with transplants as nurses, Scots Pine, Larch or Spruce being used.

When turf has been ploughed off in strips, small patches can be prepared on the bare soil by means of the spiral spade (Fig. 10), and seed sown upon them.

\section{Planting-In Prepared Pits.}

When sowing is impossible, the ground must be stocked by planting, of which there are three methods, -viz., pitting, notching, and dibbling. The making of pits having been explained under "Preparation of Soil," Chapter IV., it remains to show the way to plant the trees. The soil left in the bottom of the pits must be made into a mound in the centre of the pit, sufficiently high to prevent the plants being inserted too deeplyviz., not more than $\frac{1}{2}$ inch deeper than they stood in the nursery lines. This $\frac{1}{2}$ inch allows for a slight subsidence of the soil. If the plants have naked roots, these must be placed in a natural position round the mound, and a small quantity of the best or top soil, which was laid aside from the bottom soil, placed over then. The plants should then be lightly shaken up and down to encourage the soil to get between the roots. More earth may then be added and the plants again shaken. This should be continued until the pit is nearly full. If there is a boy helping the man to plant, he should continually move the plant up and down while the man fills in the soil.

If the soil is shaken well amongst the roots, the plant will be almost as firm as if it had been trodden, and the danger of lifting by frost is considerably diminished. 
When the pit is nearly full, the soil must be firmed by treading, preferably starting at the edge of the hole and working inwards. The pit can then be filled and trodden firm. The tree should then be able to withstand any wind.

The last few scrapings of soil or any leaf-mould that is handy should be scattered loosely over the top of the pit, to reduce evaporation and as a protection against frost.

Treading, if started before the roots are sufficiently covered, will damage the roots, and on clay soils undo all the good done by the weathering of the soil, by puddling it and making it too stiff for the young rootlets to start growing in.

When plants with balls of earth are used, the hole is partly filled, leaving a depression in the centre into which the ball is placed. More soil is added and firmed round the ball, care being taken not to tread on the latter, otherwise the earth will be broken away from the roots.

When standard trees of large size are being planted, the pits are prepared beforehand as for forest trees, and the trees prepared a year before, as described under "Transplanting in Nursery," Chapter III. A good supply of leaf-mould or compost should be brought to the side of the pit, and some of it mixed with the soil left in the bottom. The pit is filled up to the height required, a depression being left, to receive the ball of earth. The tree is then gently lowered into place, and the sacking or mat removed. Sufficient soil is added to make the tree fairly firm, and then either two or three 
stout stakes driven in about 6 to 9 inches away from the tree on different sides, and the tree secured to these.

A rope of straw or a piece of thick matting must be twisted round the stem to prevent the cords from injuring the bark.

The cord must not be tied tight to the tree, but looped round, so as not to compress the bark too tightly.

After the tree is properly staked, the remainder of the soil and leaf-mould is filled in and trodden firm, and the turf, if necessary, replaced.

\section{Notch Planting.}

There are several kinds of notches, the ones mostly in use being the $L$ and $T$ notches made with an ordinary digging spade, and the straight notch made with the straight planting spades and the heavy grubbing iron.

The L notch is made by inserting the spade to its full depth, withdrawing it, and then inserting it at right angles at one end of the previous cut, making the two cuts in the shape of the letter $L$. The spade is then levered back, lifting the soil sufficiently to admit the roots of the plant. These should be put well down, the spade withdrawn, allowing the soil to fall back into place, and the plant drawn carefully upwards to the required depth. This helps to straighten the roots. The ground must be trodden firm round the neck of the plant and along the slits.

The $\mathbf{T}$ notch is an adaptation of the previous method. The upright slit is made first, the soil levered up after the cross-slit is made, and the plant placed in the upright 
part of the notch and trodden firm. With this notch the blade of the spade often interferes with the proper arrangement of the roots.

Small plants should be used when these methods of planting are adopted, as the roots of larger trees are apt to be bent about, to their detriment.

The straight notch is perhaps the best method of notching where there is a good depth of soil and the roots of the plants are in a natural form and not bent about by careless work in the nursery.

The most handy tool for this work on light soil is that placed on the market as the "Mansfield" spade. Its blade is $\mathbf{1 1}$ inches long and perfectly straight, the sides tapering from $6 \frac{1}{2}$ inches at the shoulder or tread to 3 inches at the point.

On heavier soils the grubbing iron is sometimes used, but it is a great mistake to notch plants on these soils, because the roots are pressed flat between two sides of stiff soil, made stiffer by the working of the tool, and giving no chance for the young rootlets to start growth.

In planting with the Mansfield spade, it is inserted to its full depth and worked to and fro until a V-shaped hole is made large enough to admit the roots of the plant. These are pushed well down and then gradually drawn up to straighten them, the spade being used to assist. The latter is then inserted about 3 inches away, pulled sharply back to close the bottom of the hole, and then pushed toward the plant to close the top. The ground is then made firm round the plant and along the notch, and the second hole filled in. 
In working with the grubbing iron, it is punched into the soil and worked about to make the hole into which the plant is inserted, the hole being elosed and the soil trodden firm as with the Mansfield spade.

Planting with the Dibbling Iron.

On very clean land where small plants such as twoyear seedlings can be used, planting with the dibbling iron or planting stick is a very useful and cheap method.

The dibbler is made either solely of iron or of wood shod with iron. The blade is about $2 \frac{1}{2}$ inches wide at the top, tapering to a point, and is about 6 or 8 inches long. The shaft, about 6 inches long, is fitted with a cross-handle.

It is used in a similar way to the Mansfield spade, the blade being pushed into the soil, the plant inserted deeply, then drawn up to the required height, the hole olosed by another insertion of the dibbler, and the plant firmed up. This tool can be used for planting on the small patches prepared by the use of a spiral spade.

\section{Planting with the Planting Hoe.}

After the mattock has been used to strip the turf and loosen the soil, the planting hoe is a handy tool to use. It is made with a long, narrow blade about 3 inches wide, fitted to a short handle about 1 foot long.

When naked-rooted plants are used, it may be used as a dibbler, the blade being pushed into the soil, which is dragged aside, the plant inserted, and the hoe withdrawn, allowing the soil to fall back over the roots. 
When ball-plants are used, a hole can be scraped with the hoe, and the soil pushed back after the tree is placed in position. As this method is chiefly used on stony soil, it is advisable to cart some better-class soil or leafmould, to be added at the time of planting.

\section{Planting with the Cylindrical and Semicircular Spades.}

The use of these tools prevents any great disturbance of the root system of the plants, but where the latter have to be carted from a nursery a long distance away, the cost of cartage is increased, and the soil will get shaken off, especially if it is light in texture. When a temporary nursery has been made on the site, the method is a good one.

With the cylindrical spade, holes are made at the required distance apart by pressing it into the soil and giving it a half turn. The spade is then lifted up, bringing with it the soil, which is placed at the side of the hole. The plants, having been lifted with spades of the same size, are carted to the area, lifted from the carts or trolleys, and placed in the holes. A small quantity of the soil taken out of the hole is spread over the surface and the plant firmed up. If the ball has lost much earth, it must be replaced by that taken out of the hole.

If naked seedlings are used, they are placed in the hole, and the soil filled with a trowel and firmed up.

This spade is very useful for filling up thin places or blanks on a sown area, the plants being lifted from places where they are too thick and transferred to holes made in the thin places. 
Planting with the semicircular spade is very similar, holes being made and plants, which have been lifted by the same spade, inserted and made firm.

Shelter Belts.

On exposed areas it is always wise to give protection to the main crop, especially if it is composed of shallowrooted or the more tender species. The shelter belt, which should be from 20 to 30 feet wide, should be planted, if possible, two or three years before the rest of the area.

The trees most useful for the purpose are those with deep roots and strong side-branches, such as Scots Pine, Austrian Pine, and Sycamore. The two latter are perhaps the best, and when mixed afford splendid protection to the trees behind. They should be planted from 5 to 6 feet apart, to encourage side-growth, and should be kept thin.

The two outside rows may be pure Austrian Pine, with the two species mixed equally in the other rows.

Against sparks from railway-engines, coniferous plantations should be protected by a wide belt of hardwood trees.

\section{Rotation of Crop.}

Local demands will help to a great extent to enable the landowner or forester to come to a decision on this point, dependent, of course, upon the quality of soil, as poor soil will not support a crop for such a long rotation as one of better quality. 
If pitwood is in greatest demand, Scots and Corsican Pines, Larch or Spruce, can be profitably grown on rotations from 35 to 45 years, according to the size of props required.

Some pits use short props, which need not be very thick; others use very long and strong ones. Forty years is a good average rotation for pitwood. If the butts are too big for props, they may be sawn for other uses at the pits, such as sleepers or used for estate purposes. For larger timber the following rotations are usually considered most profitable on soils suited to the different species:

Oak, 120 to 150 years.

Beech, 100 to 120 years.

Ash, Spanish Chestnut, Sycamore, Elm, 70 to 80 years. Scots Pine, Larch, Douglas Fir, Spruce, and Silver Fir, 70 to 80 years.

Poplars and Willows, 40 to 50 years.

On soils less suited to their requirements, a rotation shorter by 10 to 15 years may be more profitable.

If exceptionally large timber is in demand, a proportion of the final crop may be left standing at the end of the first rotation, and the area restocked, using shadebearing and soil-improving trees near the standards, and leaving the more open spaces for light-demanding trees.

\section{Underplanting.}

Soil improving and protecting trees not only provide a heavy leaf-fall, but their dense shade keeps the leaves damp, hastens their decay and the formation of a layer 
of humus on top of the mineral soil, from which water carries the plant foods in solution to the roots of the trees.

Under a light-foliage crop, however, too much light is admitted, and the leaves are dried up and do not decay. The soil therefore deteriorates, and in time becomes so poor that the trees cannot obtain sufficient nutriment. To improve and protect the soil for the benefit of a proportion of the trees, the crop should be heavily thinned, leaving only the best stems, to the number of about 300 to 350 per acre for Oak at 50 years, and 350 to 400 per acre for Larch or Scots Pine at 25 to 30 years; and shade-bearing trees introduced as an undercrop to improve the soil.

Beech is by far the best tree for the purpose, as it not only bears shade well, but its leaves contain a greater percentage of plant foods than those of any other tree. Hornbeam comes next as a soil-improver, while Silver Fir, Spruce, Sitka Spruce, Douglas Fir, are splendid soilprotectors. Weymouth Pine and Thuja gigantea are also often used with success.

These trees may all be notched or dibbled in, as they will have the protection of the older crop and the ground will be fairly clean. Underplanting will not only improve the soil and stimulate the growth of the overcrop, but, if not left till too late, will help to keep the trees from becoming too branchy.

The time to underplant is when a falling off in increment is noticed. Underplanting, too, is used as a method of repairing the ravages of the Larch disease. 
It has been very successfully tried on Sir Ronald Munro-Ferguson's estate at Novar in Ross-shire, and is described at some length by Mr. W. McKenzie in the "Transactions of the Royal Scottish Arboricultural Society" for January, 1910, vol. xxiii., part 1, page 35:

"The Larch are planted pure. When they reach the age of from 12 to 15 years the diseased stems are cut out, leaving only the soundest and healthiest, which usually number from 350 to 600 per acre.

"They are underplanted with two-year seedlings, dibbled in at the rate of about 2,000 per acre. The species used are Sitka Spruce, Thuja gigantea, Tsuga Albertiana, Abies grandis, Cupressus Lawsoniana, C. macrocarpa, C. Sempervirens, Abies nobilis, A. Concolor, Norway Spruce, Silver Fir, Douglas Fir, and Beech."

When a small proportion of a crop is to be left for a second rotation, the ground is planted up, with shadebearing trees under the direct shade and drip of the standards, and groups of light-demanding trees in the more open spaces.

The Time to Plant or Sow.

In districts that are subject to a dry, cold spell during April and May, it is better to start planting in autumn, so that the plants may get the advantage of the winter rains and snows.

Hardwoods, as a rule, should be planted in autumn, as their rootlets will grow during any open spell during the winter, and the trees start into growth more readily than when planted in the spring. 
Conifers, whose roots remain dormant throughout the winter, should in moist situations be planted in the spring, so that as little time as possible elapses between lifting in the nursery and the time when growth begins. This applies particularly to those trees which take unkindly to transplanting.

On light soils, thaw following a severe frost is liable to throw young plants right out of the ground; in this case planting should be deferred until the danger from heavy frosts is past.

Sowing should, as a rule, be done in April with seeds of most conifers, so that as little time as possible elapses between sowing and germination.

Large seeds may be dibbled in the autumn, but risk of loss through mice and birds is increased.

The seeds of some trees-Birch or Wych Elm, for instance-should be sown as soon as ripe, as they soon lose their germinative power.

Size of Plants and Distance at which to Plant.

The size of the plants must depend on the class of land to be planted. On old forest land or ploughed land, seedlings may be used; where coarse grass covers the ground, plants from 1 to 2 feet will be needed, and where bracken is present 2 to 3 feet will not be too large. Different trees arrive at these sizes at different ages.

Larch, Sycamore, or Alder, for instance, being quickgrowing, will reach the latter height as 2-year 1-year plants; others, sueh as Silver Fir, Spruce, Oak, or Beech, may require three or even more years in the nursery 
lines. In any case trees as small as possible should be used, consistent with the class of soil-covering, as smaller plants start growth more readily than older ones, and are not so easily blown about by the wind.

The distance apart depends also upon the species. Such trees as Scots Pine or Oak, which develop strong side-branches, should be planted from 3 to $3 \frac{1}{2}$ feet apart. Larch, whose branches are more easily killed, may be planted at 4 to 5 feet apart, or even more. If Jap Larch are being planted, 6 feet is not too much to leave between the plants, as this not only reduces expense, but in my opinion produces sturdier trees, which will be less liable to be bent or twisted by snow.

Seedlings are eheaper than transplants and are more cheaply planted; it is therefore advisable to plant them more closely.

Although Oaks should be planted closely, a pure plantation of them would mean a great expense. To avoid this, they may be planted 12 to 15 feet apart and the spaces filled up with nurses, as suggested under "Methods of Mixing."

The number of plants required per acre at different distances apart will be found in the table at the end of the book.

\section{Advantage of a Temporary Nursery.}

It is a great advantage, when the area to be planted is large and is a great distance from the home nursery, to line out the seedlings, whether reared in the home nursory or bought from nurserymen, in a temporary 


\section{STOCKING THE GROUND}

nursery on the site for one or two years, according to the size of the plants required.

The plants become acclimatized, the cost of the cartage is greatly reduced, and the risk of damage to the roots, arising from exposure, is considerably lessened, as the time between lifting and planting is reduced to a minimum.

Planting with the cylindrical spade can be more economically done than when a long cartage is necessary, and the prospects of success are greater, as more of the soil will adhere to the roots. 


\section{CHAPTER VI}

TENDING THE PLANTATIONS

Cleaning the plants-Beating up-Weeding and thinning-Pruning -Cleaning ditches.

Cleaning the Plants.

Young trees on ground that is naturally dirty and covered with weeds should be cleaned at least once a year, but where growth of weeds is very rank, or where there is bracken, it is often absolutely necessary to do the work two or even three times; otherwise heavy rains may break it down on the tops of the young trees, either injuring their tender leading shoots or entirely smothering them.

When bracken is in the young and succulent stage, a very quick and effective method of dealing with it is to knock off the heads with a stick; this prevents strong growth afterwards.

If it is allowed to become hard and stalky, a stiff grass hook or a whin scythe must be used. The latter is a short, stiff-bladed tool, and is extremely useful for cutting other strong growths, such as Whin, Broom, young Birch, etc. It should only be used when the plants are at least 4 feet apart, and even then great care must be taken not to chop off the young trees. 
If grass only is to be dealt with, and the plants are fairly large, it is usually only necessary to clean round them to prevent them being choked.

If there is Heather, Whortleberry, or other such stiff growths on exposed sites, it is often an advantage to clear round the plants and chop off the top of the weeds between the rows a little lower than the height of the plants. The weeds then serve as a protection against severe winds.

Beating Up.

In very few cases is a plantation properly established in the first year. Drought, frost, or vermin will usually account for a percentage of deaths. The blanks thus caused must be refilled. In the first beating-up season, plants that have been left over for the purpose must be used. For instance, if the wood was planted with 2-year 1-year plants; 2-year 2-year must be used for beating up. In the next season 2-year 3-year plants will be required, so that even height growth may be preserved. If there are still blanks after that, in lightdemanding crops, shade-bearers must be used, or some faster-growing species. Usually three years is sufficient to establish a crop, but sometimes attacks by insects or fungi may cause large blanks. Agaricus melleus, the honey fungus, will often do incalculable damage in coniferous plantations. Hardwoods, as a rule, are immune from damage by this fungus, and these must be used to fill up the blanks. Sycamore, being quickgrowing, is particularly useful for the purpose. Where the damage is by insects-Pine weevil, for instance- 
some immune species must again be used, although in this particular instance it is hard to find a species that is immune, as they even gnaw hardwoods.

Where blanks are still found in older plantations, any self-sown trees should be allowed to grow to fill the spaces. Birch is often very useful in this respect.

In crops that have been sown, blanks will be found, and these should be filled up with plants taken from spots where they are too thick upon the ground. The cylindrical spade is extremely useful for this, as the plants may be lifted and carried direct to their new quarters with the minimum of disturbance.

\section{Weeding and Thinning.}

The object of planting trees closely together and keeping them in close canopy is to produce long, clean, straight and cylindrical stems.

If planted too far apart or thinned too heavily, thus admitting too much light, the resulting trees are short, tapering, and covered with branches. In self-sown forests the seedlings come up very thickly, and the struggle for the survival of the fittest begins almost at once. In a plantation this struggle begins as soon as close canopy has been formed-i.e., when the sidebranches have met and covered all the spaces between the trees-when each tree strives to outgrow its neighbours. The results are that first the lower branches are suppressed, then gradually the more vigorous trees dominate and, later, suppress the weakly ones.

To leave these dead and sickly trees in a plantation is 
to run the risk of insect damage, as the majority of beetles that do injury to forest trees use only dead or sickly trees as breeding-places. The most probable reason for this is that if they laid their eggs in the bark or cambium of flourishing trees the larvæ would be drowned by the strong flow of sap. Although the mature beetles of some species remain on the dead stems, the majority of the destructive ones fly to healthy trees, upon which they feed.

Trees in a sickly condition, too, are more liable to attack from different fungi, which, having obtained a foothold, will grow and produce spores which will infect other and healthier trees.

As a preventive measure, therefore, all dead and dying trees must be removed from the plantation as soon as possible. This work is called "weeding and cleaning."

All young trees that are cut out must be carried off the ground, and if not of useful size should be burned, as they may already have insect eggs upon them or be infected by fungi.

If the poles are large enough for use as stakes, etc., the bark should be stripped off and burned. If left on the ground, the branches and bark will serve as well for breeding-places as the poles.

Later on in the life of the plantation the struggle for existence goes on, as each tree for its development requires more individual growing space. If left alone, a percentage of the poles will die off and leave sufficient room for the others; but those trees that survive the struggle 
will be drawn up into long, weakly stems, unable to stand against wind or under heavy falls of snow.

To prevent this some of the poles must be taken out. This is called "thinning."

The principle of thinning may be said to be to allow sufficient room for the development of the best trees, without admitting too much light, which would prevent the killing of the side-branches and also prevent decay of the humus, thus depriving the trees of their source of nutriment.

The trees before thinning will be-(1) Dominant, those trees above the normal height; (2) dominated, healthy trees about the normal height, but overshadowed by the dominant class; (3) suppressed, including all dead and dying trees and those prevented from developing by the more vigorous trees.

The latter class should all be removed, except healthy but stunted trees, the removal of which might cause too large a break in the canopy.

The French method is to cut out all dead and sickly stems and leave all healthy but suppressed trees for the protection of the soil, only pruning or removing those that are doing injury to better trees. In the dominated class only those trees that are interfering with the growth of others need be removed.

Dominant trees, especially if of an inferior species, having been used as nurses to more expensive varieties, should be removed if the growth of their crowns is proving injurious to any of the latter trees.

The age at which to commence thinning varies with 
the different species. Fast-growing trees and lightdemanders, as a rule, need thinning earlier than the slower-growing ones and shade-bearers.

Larch and Ash, for instance, which grow very quickly and whose branches are easily suppressed, should be given a slight thinning about 15 years of age. Douglas Fir, although a shade-bearer, is a very quick grower, and should be lightly thinned at about 15 to 20 years to prevent them being overdrawn.

About 18 to 20 years is the age for thinning Pine woods, while Beech and Spruce seldom need thinning before 20 to 25 years, and Silver Fir from 25 to 30 years.

Nature is a good guide in the matter, and thinning should be done principally as a means of assisting Nature, by cutting out trees that are naturally in danger of suppression before injury is done to better trees.

Thinnings at all ages should be light and frequent.

In the working plan they should be so arranged that each plantation is attended to every five years or so, till the trees have attained their principal height growth. After that they may be less frequent, and may take the form of partial clearances to allow the trees to increase more rapidly in girth.

The number of trees to be taken out at each thinning depends upon the kind of tree and also upon the class of soil.

Shade-bearing trees, whose branches are usually very persistent, must be kept relatively closer than lightdemanders, and trees growing vigorously on good soil 
require more growing space than slower-growing trees on poor soil.

Hardwoods must be given more space than conifers, because the best hardwood timber has large annual rings, while the best coniferous timber has narrow rings.

The old rule in many places was to allow an average distance between the trees equal to one-third of their height; but however good this rule may have been when growing Oak for shipbuilding, it is of no use now, when timber is needed straight and free from knots.

According to Continental tables of thinnings, the average distance usually left between the trees is from one-eighth to one-sixth of their height when in the pole stage.

According to Maw in his book "The Practice of Forestry," the number of poles per acre at 45 to 50 years (after thinning) and at the end of a rotation on Quality II. soil should bo-

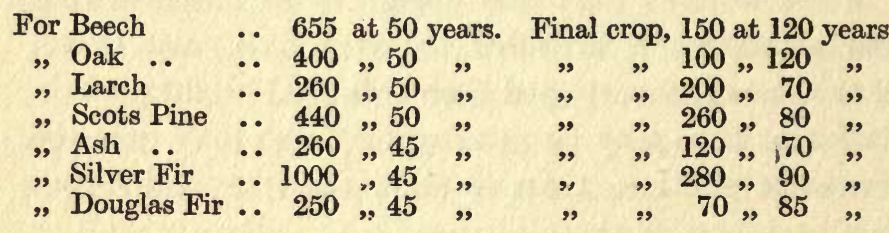

The figures for the final crops are, however, much lower than those given in Continental tables.

It is a great mistake to make haphazard thinnings; for instance, when a certain class of pole is needed for estate purposes, the temptation to go into a plantation and cut out the number required should be resisted, for 


\section{TENDING THE PLANTATIONS}

as a rule the very ones that should be taken are left, and those taken will be good poles that should be left to form the final crop. In this way large areas of woodland have been spoilt in the past.

Thinnings should be made regularly, and a certain percentage of the poles set aside for estate purposes.

In thinning mixed plantations, the species that are left as the final crop must be given the preference, and must be protected against the other species, although badly shaped or diseased trees of the principal varieties must be cut out and good trees of a subordinate variety left to take their places.

In selecting the poles to be taken out, it is better to mark all dead or dying ones first. In deciduous plantations they should be marked in summer, when they are more easily noticed.

While they are being felled the forester should work up behind the men and mark any other trees, such as those that are pressing too closely upon or otherwise injuring better trees. These are more easily selected after the worst trees have been taken out.

The marking may be done with a scribe, a tool which cuts from a tree a strip of bark, which should be left hanging, so that the trees marked may be more easily seen by the fellers and also by the forester when marking others. A scribe mark, however, in a pole wood is very difficult to discern at a little distance, owing to the density. In this case it is better to "blaze" or cut off a slice of bark from both the backs and fronts of the trees-those at the back to be easily seen by the fellers, 
and the others to serve as a guide to the forester, who can then see at a glance which trees he has already marked, and help him to avoid making mistakes.

In crowded plantations it is often impossible to use an axe for felling, so use should be made of a heavy billhook or a short cross-cut saw-the latter for preference. The side-branches should be trimmed off as high as possible while the pole is standing, and the pole then sawn off as close to the ground as possible.

The branches must be cut off flush with the stem with the axe or bill-hook, and the poles carried or dragged by horses, if too heavy to carry, to the nearest drive, where they should be placed in lots of 50 or 100 and sorted according to size and species.

After the crop has attained its principal height growth, thinnings or partial clearances are relatively lighter than in the pole stage, and are made to encourage those trees that are to be left as the final crop to increase in girth and volume.

They should be made from ten to thirty years before the crop is cleared.

\section{Pruning.}

If a plantation has been kept at a proper density, there should be no need of pruning, but where the canopy has been allowed to become too broken, preventing the side-branches from being killed off naturally, some such aid is necessary to produce good clean timber.

This applies more to hardwoods than to conifers, the green branches of which should really never be pruned, 
as doing so leaves wounds in which spores of fungi find lodgment.

Judicious pruning not only helps to produce clean timber, but encourages height growth and the formation of more cylindrical stems.

The greatest increase in girth always takes place below the lowest branches, so by removing the lower branches of a tree, either by close growing or by pruning, the higher portion of the tree increases relatively more in girth, producing a stem nearer to the shape of a true cylinder and more valuable, as there will be less waste in conversion than if it is very tapering in form.

Pruning should be done before the trees get too tall or the branches too thick, for when a heavy branch is cut off it takes a long time for the wound to heal over, and decay may set in, making a hole in the stem.

For the same reason, all branches should be cut off close to the stem and in line with it, because if a stump is left sticking out, even if it does not decay, it remains as a knot in the timber.

The young wood with which the wounds should be covered is put on with the downward flow of the sap, and it cannot get out to the end of a snag. Therefore the closer the cut is made to the stem, the sooner will it be healed, and the straighter will be the grain of the wood put on afterwards.

To prevent decay, and also to prevent lodgment of the spores of fungi, which are the principal causes of decay, all cuts should be covered with coal-tar or some other antiseptic. It is of no use putting this on after 
decay has set in, as the mycelium (or, as they may be called, the roots) of the fungus are already in the apparently sound wood around the hole.

As coal-tar will not adhere to the cut surfaces when the sap is running, it is best to do all pruning of live branches during the late autumn or winter months, but not in frosty weather.

Dead or dying branches should always be removed from ornamental trees, but the expense of doing this in a plantation would be too great.

Dead Larch branches may be easily broken off by means of a long pole, but even this is not to be strongly recommended, as snags are often left, which are, of themselves, too light to drop off, and cause knots in the wood. If the branches are left they will be pulled out of the sockets by their own weight.

Where underplanting is to be done, any wide-spreading branches on the trees left as the overcrop may be shortened to half their length or cut off close to the stem.

Pruning of standards in coppice woods is often necessary, not only to improve the trees themselves, but to lighten the shade on young coppice growths beneath. If a tree has very strong side-branches on all sides, rather than attempt to prune, it should be felled, and another sapling or store tree left to take its place.

In pruning small branches within easy reach, a sharp pruning knife is used, the cut being made in an upward direction. For small branches higher up, a pruning chisel is the best tool, as a clean cut close to the stem can be made. It is fitted to a light but rigid pole, and 
is placed against the underside of the branch, and sharp blows with a mallet are given to the lower end of the pole, which is usually fitted with an iron cap to prevent splitting. Care should be taken not to drive the chisel into the bark of the stem after severing the branch. Tree-pruners, or averuncators, are also very useful for high branches, but the latter cannot be cut off quite so close with these as with a chisel. For shortening straggling branches they are invaluable. The tree-pruner consists of a curved knife working against a double claw, which is hooked over the branch, the knife being worked by a lever pulling on a steel rod or cord.

For larger branches, one of heavier make is used, worked on the ratchet principle, and is extremely powerful.

Pole saws are used when the branches are too big for the pruners or chisel. The most useful ones are slightly curved, with the teeth facing downwards, so that all the cutting is done on the downward stroke. Branches cut off with the pole saw should previously be undercut with a chisel, and also, if heavy, should first be cut off 2 or 3 feet away from the stem, to prevent them, when nearly cut through, from breaking off and tearing the bark from the tree.

When a hand-saw is necessary, the undercut may be made with it, and the sawn piece cut out with a handbill.

Very large boughs should first of all be stripped of as many branches as possible, before being cut off 3 or 4 feet from the stem, as even when they are cut off at this 
point, if they are not lightened, they are apt to break away very quickly, tearing not only the bark, but also a strip of sapwood as well.

The undercut should be made as deep as the saw can be worked without risk of getting it fixed.

The stump must be cut off flush with the stem.

When a saw is used, it always leaves a rough surface, which must be smoothed off with a sharp knife, pruning hook, or chisel, to prevent lodgment of water.

As mentioned above, all cut surfaces should be covered with tar. To thin it down to make it easy of application a small quantity of paraffin may be used. It should be well brushed into all small cracks or crevices.

\section{Cleaning Ditches.}

To prevent the ditches being choked and thus waterlogging the soil, they should be cleaned whenever necessary. In some cases, with main drains particularly, this may be once or even twice a year, but in any case all drains should be looked to every two years. It is often quicker and cheaper to clean a ditch twioe in four years than to do it once during the same period. A light square-mouthed shovel about 9 to 10 inches wide is the handiest tool for the work, as it has more "lift" than a spade and holds the dirt better, which is a great help, especially if there is much water.

The soil or leaves taken out must be thrown well back from the edge of the ditch, and not placed on the edge, where its weight, by helping to break down the sides, may finally carry it back into the ditch. 
In ditches where there is a large quantity of water and an accumulation of leaves, a light five-grained fork should be used; but if the bottom is very soft, a five-grained drag must be used from the bank to take out the leaves, and a seoop for earth.

In wet ditches men should be provided with waders or long watertight elogs. All rubbish growing on the banks of ditches should be out, otherwise it will fall down and block the drain. 


\section{CHAPTER VII \\ CLEARING THE CROP}

Felling timber-Time for felling-Bark peeling-Measuring felled timber-Measuring standing timber-Measuring whole woodsHow to tell the age of trees.

Felling Timber.

With trees of pitwood size, this work is simple and straightforward, and young lads should be given their first opportunity of felling when such timber is cleared.

The work is practically the same as for heavier timber. and both may be explained together.

The tools used in felling and trimming out are-felling axe, lopping axe, hand-bill or bill-hook, felling saw and cross-cut saw, with saw-set, gauge and files, wedges and sledge-hammer.

For felling large trees with axe alone, the long-bladed English axe is best, as it is more easy to "get under" a tree with it than with the shorter-bladed wedge axe. The latter is most useful for poles, for lopping trees, and for "laying in" trees ready for felling with the saw. For heavy work, a good weight for an axe of any make is 7 pounds, lighter ones being used for cutting poles or branches.

The felling saw for big timber is usually 5 feet to 146 
5 feet 6 inches long, unless for exceptionally large trees. It should measure about $\mathbf{2}$ feet 6 inches longer than the diameter of the butt of the tree.

The teeth on these saws are of various patterns, but the one known as the rip-tooth or rag-tooth, for outting one way, is best for big hardwoods. Some saws are fitted with reversible handles, so that they may be used either for cross-cutting or felling, but the most useful handles for felling saws are the box handle for the cutting end and a spade handle for the feeding end.

The box handle is made to fit over the end of the saw, and is fixed by a wedge. From either side two handles project, so that two men may work, one on either side of the saw. The spade handle, as its name implies, is an old handle fitted to a piece of iron that is keyed to the saw.

For coniferous timber a needle-tooth saw or one with multiple teeth, having deep gulleys between each group of teeth, clear themselves better than the rip-tooth saws. Saws for hardwoods should have almost a straight face with a fine set, but for softwoods and conifers the more curved, or roach-belly, saws are best and need a wider set, as the wood is more spongy. All saws should be thicker in front than at the back, to reduce the pressure on them.

The saw sharpener and setter must take care to set the teeth on both sides of the saw equally, otherwise the side with the most set will draw the saw, making a curved cut and also making the work doubly hard. Automatic saw-sets are useful for hand-saws and thin cross-cuts, 
but with stiffer ones a specially made key should be used for setting, and a gauge used for correcting the set.

It is a mistake to bend just the top of the teeth over; the whole tooth should be slightly pulled out of line with the saw blade.

A badly set and sharpened saw means hard and also bad work.

For lopping trees a light axe or a heavy two-handed bill-hook is used on light boughs, and a cross-cut saw for severing the larger ones.

All limbs must be out off as close to the stem as possible, to make dragging and work on the saw bench easier. The trees should be cross-cut into the lengths required by the timber merchant or for estate purposes. The wedges are for driving into the saw-cut, behind the saw, to keep the weight of the tree off it, and help to throw the tree in the direction required. A grooved wedge will grip much better than a smooth one, and a little sand placed on the wedge will often make it grip better.

The first work to do when felling with axe and saw is to "lay in" the tree-i.e., to cut off as much as possible of the roots of the tree that are above ground, and to trim up the butt in line with the bole. With some conifers there is very little of this to do, although it is always wise to cut off the bark, as it "sucks" the saw. Hardwoods, however, often have very large "spurs" coming out of their butts. After the tree is "laid in" all round, a face must be made at the bottom of the butt, as close to the ground as possible and in the direction in which the tree is to fall. A "face" is a V-shaped cleft, 
which will vary in depth according to the size of the tree, and also to the degree that the tree may be leaning. A shallow face in a badly leaning tree would result in the latter splitting.

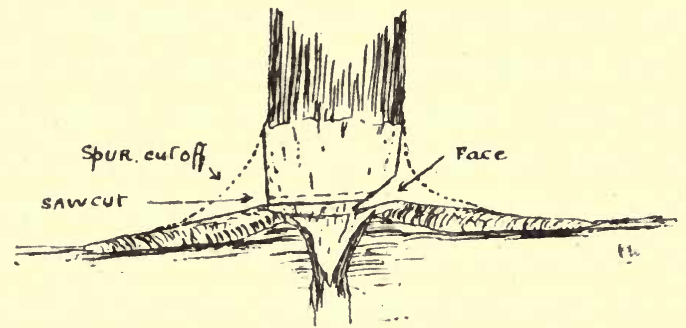

Fig. 14.-A Tree Laid in and Faced.

In laying in a tree, care must be taken to keep the work low and level, otherwise valuable timber may be wasted and sawing be made more difficult. A good axeman should be able to lay in perfectly level all round the tree.

There is an art in using an axe-in fact, it may be said that an axeman is born, but very seldom made. Some lads get into the way at their first attempt, others will be years at it, and still be as stiff and stilted as when they started. Axeing needs a natural swing and a lissom back.

The handle must not be gripped too tightly by the hand at the end, but just tight enough to prevent it slipping and to give force to the blow. The other hand should hardly grip at all, but be used to guide the axe.

The downward stroke in laying in is easily acquired, but in making the cutting out or level stroke the back 
must be well bent and the holding hand held at the same level as the axe-head, which must be driven into the wood in a slightly upward direction. This keeps the edge of the axe-cut out of the way of the saw, and prevents the sawyers knocking their knuckles upon it.

The saw-cut should be made about $\frac{1}{2}$ inch above the level axe-work. Sawyers should be "light-handed" and not force the tool too hard on to the wood. A heavy-handed man does not get through the work any quicker, but makes it harder for himself and his mates.

If a tree appears to be falling too much to one side, the cutting must be done faster on that side, leaving the strongest hold on the other, which will help to pull the tree straight. The wedges, too, should be driven in on the side to which the tree leans most, care being taken not to drive them on to the back of the saw.

In felling with the axe alone, the spurs are first trimmed up and a face made in the direction in which the tree is to fall, and to the depth of half the diameter of the tree. Axeing is then continued at the back of the tree until it falls. The cuts or faces must not be made too wide, otherwise a large percentage of valuable timber will be wasted. For this reason it is advisable to fell all trees above pole size with the saw.

When a tree forks into two large limbs, it should be felled so that it falls with equal weight upon both; otherwise, if it falls sideways, one or both of the limbs will be split, and very possibly the butt as well. Large spreading limbs should be cut off before the tree is felled, to avoid splitting the tree. 
If a tree is leaning backwards too far to be driven over with wedges, a rope must be used to assist. This is tied as high up as possible on the main stem, and on heavy trees should be worked with pulley blocks fastened to some other tree in front of the one to be felled. If there is no tree near enough, a stout post should be sunk 3 to 5 feet in the ground in a direction sloping away from the tree. Hand winches, made fast in the ground, are sometimes used to pull over big trees, but they are cumbersome tools, and a rope with double or treble blocks is as powerful.

When it is necessary to remove the roots of the trees, this is more easily done before they are severed from the butts. This operation is oalled grub felling, or pan felling when it is done to break up ironpan in the soil to assist drainage or to allow the roots of succeeding plantations to descend after moisture.

A rope is fastened to the tree as in ordinary felling, and the soil taken away from the roots, which are eut through with a grubbing axe or sharp mattock. When all side-roots have been cut, the tree is pulled over by means of pulley blocks or winches, the descending roots being pulled out, breaking up the pan for the benefit of the next orop.

The root system is then cut away from the butt.

After trees are trimmed out, the cordwood-i.e., branch wood below 6 inches in diameter for hardwoods and 3 inches for conifers-should be cut into lengths and stacked in " cords."

The contents of a "cord" of wood varies in different parts of the country, but usually about 126 or 128 cubic 
feet stacked 3 feet broad by 3 feet high by 14 feet long, or 8 feet long by 4 feet by 4 feet.

The small branches, or " brush," should be made into faggots or kids where there is a ready sale for them. These also vary in different parts of the country, usually being about 5 feet long and 3 to 4 feet in girth.

In making a faggot, a "withe" made of hazel or willow, a cord or wire with a loop at one end is laid on the ground, and the branch wood, cut to the proper length, is laid across it as straight as possible, until the faggot is large enough, when the loose end is passed through the loop and pulled tight, the branches being compressed by application of the foot, and the withe or cord secured.

They should be stacked or placed in a faggot shed until dry and fit to use for kilns or kindling wood.

\section{The Time for Felling.}

Timber that is felled when the sap is down is always considered to be of better quality than that felled in summer, when the sap is up.

Summer-felled timber, especially of coniferous trees, is more subject to attack by fungi. Therefore, as a rule, large timber should be felled in late autumn or the winter months.

The principal exception to this rule is when the trees are to be barked. Beech, when it is to be steamed for certain purposes, may be summer-felled.

As it is often difficult, owing to pressure of other work, to get all thinning done during the winter, some of this work may be left till the spring or summer. 


\section{Bark Peeling.}

Prior to the outbreak of war in 1914, the price of bark dropped so low that it did not pay to do any peeling. In wet seasons, when so much work was needed to harvest the bark, it was often a dead loss. This drop in price was due in a great measure to the import of large quantities of foreign bark and to the increased use of chemicals. Oak bark, however, which is richer in tannin than that of other trees, is still used for the very best leathers.

The bark with the largest percentage of tannin is that found on coppice shoots, the next best being that on the branches of trees, the rougher bark of the bole containing only a small percentage.

The bark of Larch, Spruce, Birch, Alder, and Willow, is also used for tanning different kinds of leather.

The best season for peeling is just when the sap is rising, generally in April, May, or early June, according to the species.

The tools used for the work are axe, saw, hand-bill, mallet, and peeling irons.

The bark should be stripped off the butt of the tree for about 3 feet before it is felled. After the tree is down, boys and women can strip the branches, while men with heavy peeling irons work on the bole. To strip the bark from the bole, it is cut through all round with a heavy bill or axe at every 2 feet 6 inches or 3 feet, and longitudinal cuts also made every 15 or 18 inches of the circumference, according to the size of the tree.

The large peeling iron is then inserted in the top 
cut, pushed under the bark, and a slight leverage applied.

This is continued along the length of bark, each successive application being a little farther in than the previous one, until the piece is detached. If the bark is very stiff to get off, it must be beaten with the mallet, when it should " run" much better.

There is less danger of splitting the bark if two men work at each length of bark.

On the boughs or on coppice shoots, the whole ring of bark may be detached in one piece, which is much better for harvesting.

The tool used on the boughs, and commonly called a "spoon," is light and fitted to a wooden handle, and about 1 foot in length over all, with a spoon-shaped head.

The tool for the thicker and stronger bark is all of iron, about 2 feet 6 inches or 3 feet long, with either a knob or a cross-handle. The spoon at the end is also much larger than in the one-handed tool (Fig. 15, A).

In peeling the boughs, all small branch wood below 1 inch in diameter is cut off and placed to one side. All branches near the ground are peeled and cut off, then the branches standing upright are cut partly through, bent down, and peeled.

Coppice shoots are usually cut off and supported by a forked stick driven into the ground, to make the work more easy.

If the bark on smaller branches is hard to strip, they should be cut off and laid upon the butt or the stool of the tree and beaten with the mallet. Too much use of 
the mallet is to be deprecated, as it spoils the quality of the bark.

If there is much moss or lichen on the bark, it must be scraped or brushed off. A three-cornered piece of steel fitted to the end of a short handle is generally used for seraping, but I have found that a brush with steel bristles
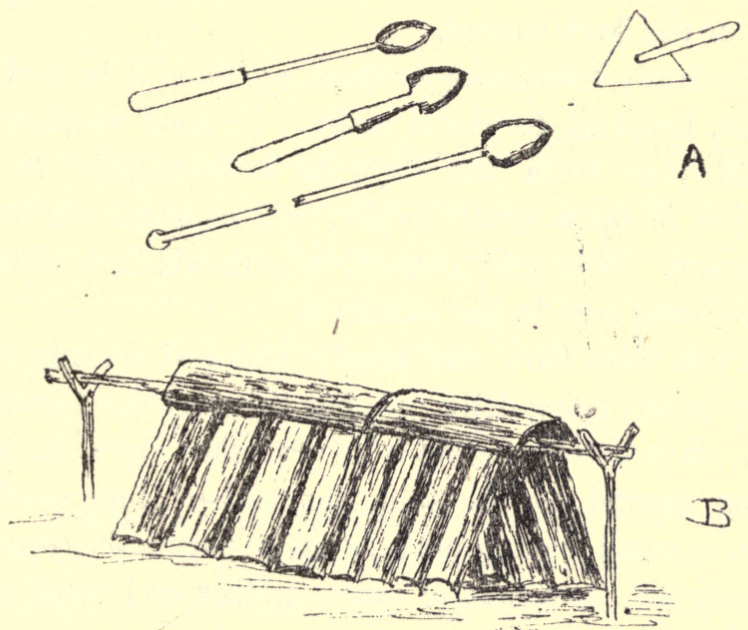

Fig. 15.

$A$, Barking tools ; and $B$, Bark rack.

gets into the crevices of the bark better and makes a cleaner job. This work can be done best before the bark is taken off.

After the tree is stripped, the bark should be carried or carted to an open space in the woods, or to an adjoining field, and racked up. To make racks, poles are laid along on forked sticks stuck upright in the ground, about 
2 feet high. Against these the bark is placed in a leaning position, keeping the rough side exposed (Fig. 15, B).

A small space should be left between the pieces to allow air to have free play. The larger pieces from the trunk are used as covers. If allowed to get very wet and mouldy, the quality of the bark deteriorates. If this should happen, the racks should be thrown open for a time or the bark turned.

It is ready for carting or stacking when it is hard and brittle, breaking to pieces easily. In good weather this should take from ten days to a fortnight. In wet weather it takes much longer, and constant turning is necessary. If it gets mouldy, it must again be brushed before being sent to the tanneries.

At one time bark was usually chopped up into small pieces before being delivered, but this is seldom practised now. It is better to send it as it seasons direct from the drying ground to the tanneries rather than stack it. There is small enough profit, even in favourable weather, without the extra cost of twice loading and carting and stacking.

\section{Measuring Felled Timber.}

The usual method adopted for measuring in this country is that known as the "square of $\frac{1}{4}$ girth measurement," which makes an allowance of $21 \frac{1}{2}$ per cent. for wastage, as compared with the true cubic contents.

In applying this, the girth is taken in inches midway between the ends of the log, allowance being made for bark, and the figure divided by 4 , giving the $\frac{1}{4}$ girth 
This figure is squared, multiplied by the length, and the product divided by 144 (the number of square inches in a square foot), which gives the answer in feet.

For instance, if a Scots Pine tree 50 feet long girths 48 inches at 25 feet, an allowance of $\frac{1}{12}$ being made for bark $=44$, the quarter of which is 11 .

The sum is as follows:

$$
\frac{11^{2} \times 50}{144}=\frac{121 \times 50}{144}=42 \text { feet } 0 \text { inch } 2 \text { parts. }
$$

To find the true contents, the diameter of the tree in the centre is found by callipers or tree compasses. For the same size tree as before the figures will be 50 feet long by 14 inches in diameter. The area of a circle 14 inches in diameter $=14^{2} \times 0.7854=153.938$ square inches.

$$
\frac{153.938 \times 50}{144}=53 \text { feet } 5 \frac{1}{2} \text { inches. }
$$

The figures for the square of $\frac{1}{4}$ girth measurementviz., 42 feet-is $21 \frac{1}{2}$ per cent. less than this figure.

Another way to arrive at the true contents is to multiply the square of $\frac{1}{4}$ girth by the length and divide by $113=\frac{121 \times 50}{113}=53$ feet 6 inches. 113 is $21 \frac{1}{2}$ per cent. less than 144.

To find the diameter of a tree when the girth is known, divide the latter figure by $3 \frac{1}{7}=\frac{22}{7}$; for instance, the above girth is $44 . \frac{44 \times 7}{22}=14$.

In finding the area of a circle, instead of multiplying by 0.7854 , which makes a long sum, 0.8 may be used, and 
2 per cent. deducted from the total. For example, as above, $14 \times 14 \times 0.8=156.8$; deduct 2 per cent. $=156.8$ $-3 \cdot 0=153.8$.

To convert square of $\frac{1}{4}$ girth figures to true contents, multiply by 100 and divide by $78 \cdot 6$. $(42 \cdot 0 \times 100)$ $+78 \cdot 6=53$ feet 5 inches.

To convert true contents to square of $\frac{1}{4}$ girth, multiply by 78.6 and divide by 100 .

(53 feet 5 inches $\times 78 \cdot 6)+100=42$ feet.

For girthing, special tapes are made showing the $\frac{1}{4}$ girth on one side in inches and quarters of an inch, and on the other side the contents of 1 lineal foot of tree for each $\frac{1}{4}$ girth. For instance, 1 lineal foot of 11 inches $\frac{1}{4}$ girth contains 0 feet 10 inches 1 part. All that is necessary to find the contents of the whole tree is to measure this figure by the length. 10 inches 1 part= $10_{12}^{\frac{1}{2}} \times 50=42$ feet 0 inches 2 parts.

A table at the end of the book gives the area of each $\frac{1}{4}$ girth, and by reference to this it is found that the area of a square 11 inches on the side is .840 square foot. This multiplied by $50=42.000$ square feet.

Instead of measuring the girth at the centre, it may be taken at each end, the figures added together and divided by 2 , giving the mean girth. For example, 16 inches $\frac{1}{4}$ girth at the butt plus 6 inches $\frac{1}{4}$ girth at the top $=22$, divided by 2 , gives 11 inches as mean $\frac{1}{4}$ girth.

The $\frac{1}{4}$ girth may be taken at many places on an irregularly shaped tree, and the sum of all the $\frac{1}{4}$ girths divided by their number gives the mean $\frac{1}{4}$ girth. 
Or the tree may be divided into two or more lengths, the length and $\frac{1}{4}$ girth of each taken, and the contents of all lengths added together to give the total cubic contents of the tree.

The allowance made for bark is usually 1 inch in 12 inches (or $\frac{1}{12}$ ) for thick or rough barked trees such as Oak, and $\frac{1}{2}$ inch in 12 inches (or $\frac{1}{24}$ ) for such thin-barked trees as Beech or Spruce.

\section{Measuring Standing Timber.}

The measuring of individual standing trees is usually done by judging the height and the girth at half-way, assisted by the use of poles of known length, or by the use of hypsometers or height measurers. When using a pole, which should be jointed and at least 20 feet in length, it is held against the tree, the man measuring standing back where he can see the full height of the bole, judging its height above the pole by comparison with the latter, and adding the known length to the length judged.

Many kinds of hypsometers are made, but they are all based upon the same principle-viz., that of equalangled triangles.

Faustman's mirror hypsometer and Weise's telescopic one are both very similar and easy to work.

In using the former, a base line is measured from the tree, say 20 yards, and a movable upright arm is set to figures indicating this distance. The observer then looks through an aperture in a small disc at one end and across a hair line stretched across a small frame at the other end, bringing the two points in line with the height to be 
measured. A plumb line suspended from the top of the movable arm marks off on a scale at the bottom the height in yards. This can be seen in a hinged mirror attached to the frame without moving the instrument. Whatever unit be taken in measuring the base line and setting the upright arm, the answer will be the same.

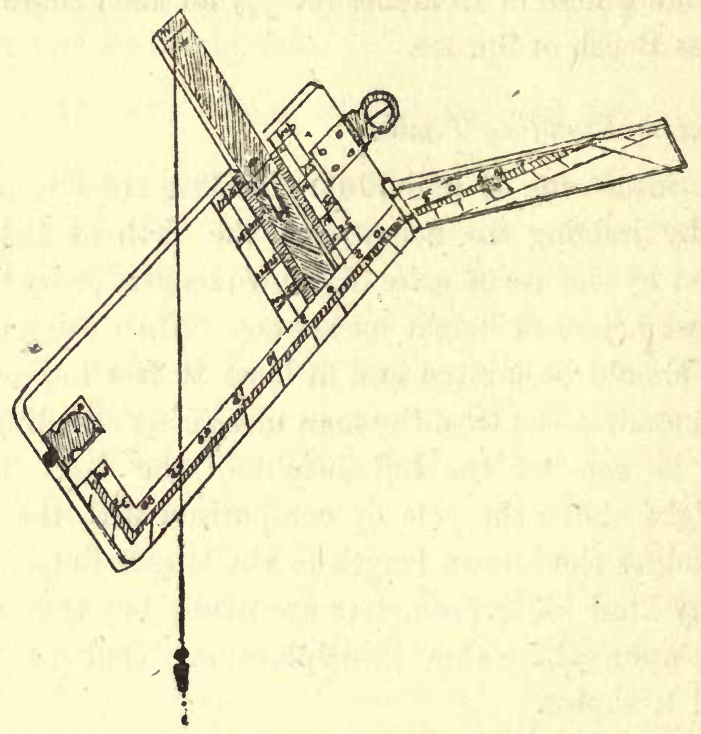

Fig. 16. -Fatstman's Hypsometer.

If metres, then the answer will be in metres. If yards or feet, the answer will be in yards or feet respectively.

With the telescope hypsometer, the movable arm is set on the same principle and the sight taken through the telescope. To allow the plumb line (a three-cornered steel rod) to remain in place until the answer is read off, 
the instrument is given a slight turn, when the rod catches in a toothed plate on which there is a scale of heights. Both these instruments fold up into a small space and can be carried in a pocket.

The centre $\frac{1}{4}$ girth or the diameter can be judged direct or arrived at in either of the following ways:

The measurements may be taken at breast height and an allowance made for the taper of the tree, or they may be taken at breast height and the length taken to where the $\frac{1}{4}$ girth is judged to be-say 3 inches. The two $\frac{1}{4}$ girths are added together and divided by 2 , to find the mean $\frac{1}{4}$ girth.

Measurements of Whole Woods.

This can be done by-(1) Measurement of all the trees; (2) measurement of sample trees; (3) measurement of sample plots.

By the first method, which can only be practised on small areas, or where there are several species and where the trees vary greatly in size, they are measured according to the methods explained above, and the totals of each class computed at the end.

When the area is large, the other methods are much quicker and quite as accurate.

When measuring sample trees, all the trees are counted and a number of trees over the whole area measured. From these figures the average stem is found by dividing the total number of cubic feet in those measured by their number. The figure for the average tree is multiplied 
by the number of trees on the area, which gives the total number of cubic feet.

In the third method, sample plots from $\frac{1}{2}$ an acre to 3 acres in extent are measured off, the trees counted, the average stem for each plot found, and the figures per acre arrived at from these.

This method is best where the growth of the trees varies in different parts of the wood.

If the crop is mixed, the contents of the different species must be calculated separately.

Taking as an example a mixed wood of 40 acres containing, say, 600 poles per acre, $\frac{2}{3}$ or 400 of which are Larch and $\frac{1}{3}$ or 200 Corsican Pine. The average Larch pole is found to contain 6 cubic feet, and the average Corsican Pine 8 cubic feet. Thus there are 2,400 cubic feet of Larch and 1,600 cubic feet of Corsican Pine per acre, and 96,000 cubic feet of Larch and 64,000 cubic feet of Pine on the whole area.

Also, if the growth or density of the crop varies much in different parts of the area, estimates should be made for each class or density. The best method of finding the average pole is by Weise's 40 per cent. rule. The poles are counted on each sample area and the $\frac{1}{4}$ girth or diameter taken at breast height (viz., 4 feet 3 inches). The measurements are divided up into inch classes, and the number for each class totalled up. Thus, if a sample area of 1 acre contained, say, 200 trees divided into 1 -inch classes, they would be tabulated as in the first two columns of the following table: 


\begin{tabular}{c|c|cc|c}
\hline Class. & $\begin{array}{c}\text { Number of } \\
\text { Poles in Each } \\
\text { Class. }\end{array}$ & $\begin{array}{c}\text { Average Pole in Each } \\
\text { Class. }\end{array}$ & $\begin{array}{c}\text { Cubic Contents } \\
\text { of Each Class. }\end{array}$ \\
\hline 5 & 10 & 4 & cubic feet. & 40 \\
6 & 17 & 6 &, & 102 \\
7 & 25 & 8 & $"$ & 200 \\
8 & 35 & $10 \frac{1}{2}$ & $"$ & 367 \\
9 & $44^{*}$ & $13 \frac{1}{2}$ &,$"$ & 594 \\
10 & 36 & 17 &, & 612 \\
11 & 28 & 23 &, & 644 \\
12 & 4 & 28 & $"$, & 112 \\
13 & 1 & 34 &, & 34 \\
\hline Totals & 2,00 & & - & 2705 \\
\hline
\end{tabular}

A count back of 40 per cent. from the highest inch class is made; 40 per cent. of 200 is 80 . Counting back 80 , we find that it brings us to the 9 -inch class, which contains the average pole. A number of poles of this class should then be felled and accurately measured, to arrive at the average cubic contents per tree. This figure is multiplied by the number of trees per acre, and the result multiplied by the number of acres of this class of timber. In the above table, the average pole in the 9 -inch class contains $13 \frac{1}{2}$ cubic feet which, multiplied by $200=2,700$ eubic feet in the acre measured.

An even more accurate method is to find the average pole of each class, and from that the cubic contents of each class; then add these figures together to give the total number of cubic feet on the area measured, as set out in the third and fourth columns of the above table. (These figures are fictitious, and must not be taken as a guide to the contents of any class of tree.)

* Class containing average pole by Weise's 40 per cent. rule. 
If it is not desirable to fell the sample poles, the average cubic contents may be computed by means of form factors. On the Continent, tables of form factors have been compiled, and this method is mostly used in calculating contents of trees, but unfortunately very little data is available in this country upon which to compile such tables. A form factor is a number representing the proportion which the contents of a tree bear to a true cylinder of the same height and girth or basal area at breast height.

The Continental tables are all worked on basal area, and no figures are available for $\frac{1}{4}$ girth.

To find the form factor for a tree ( $\frac{1}{4}$ girth measurement), the total length of the tree is measured, and also the $\frac{1}{4}$ girth at breast height. For example we will take a tree 50 feet high by $8 \frac{1}{2}$ inches $\frac{1}{4}$ girth. The length of timber is then taken, say 40 feet to where it is 3 inches in diameter; the $\frac{1}{4}$ girth at midway, 20 feet, is $6 \frac{1}{2}$ inches.

A cylinder 50 feet long by $8 \frac{1}{2}$ inches would contain 25 cubic feet. The actual contents of the tree are 11 cubic feet 8 inches.

25 feet $=300$ inches; 11 feet 8 inches $=140$ inches.

Therefore, the relation of the tree to a true cylinder erected on the same base is expressed by the fraction $\frac{140}{300}$, which, being reduced to decimal figures $=$

$$
\begin{aligned}
& 300) 1400(\cdot 46 \dot{6} \\
& \frac{1200}{2000} \text { or say } \cdot 47 \text {, the form factor. } \\
& \frac{1800}{2000}
\end{aligned}
$$


To find the cubic contents of the tree by the use of the form factor, the contents of the cylinder-viz., 25 cubic feet-is multiplied by the form factor

25

\section{$\cdot 47$}

$11 \cdot 75 \quad 11 \cdot 75=11$ cubic feet 9 inches.

To find out the form factor for a certain class, species, or size of tree, measurements of a large number should be taken, the form factor worked out for each stem, and all the results added together and divided by the number of poles measured, to arrive at the average factor.

The figures vary considerably for each tree.

When collecting some figures in a mixed wood thirtyfive years of age, I found that the factors for individual stems of Corsican Pine varied from $\cdot 59$ to $\cdot 40$, and for Larch from $\cdot 58$ to $\cdot 42$. The average for Corsican Pine was $\cdot 47$ and for Larch $\cdot 48$.

How to Tell the Age of Trees.

With hardwoods this is hardly possible while the trees are standing, but with conifers in the pole stage the age is found by counting the whorls or rings of branches from the top to the bottom, and allowing about two or three years for the space between the bottom whorl and the ground for the seedling stage. (Some species-Banks Pine, for instance-put on two or even three shoots in one year, making it impossible to tell their age by this method.) When the trees are felled, the age can be fairly accurately obtained by counting the annual rings from 
the bark to the centre, again allowing two or three years for the time the tree took to grow to the height where it was cut off.

Care must be taken not to count the summer rings, which are usually very faint. These are made at the time of flushing the summer foliage, or, as it is sometimes called, "the second sap."

If the rings get too narrow at any point, the last ring counted should be traced round until a spot is reached where they are wider. If they are very indistinct, a solution of aniline in methylated spirits should be brushed on the part where the rings are being counted. When the age of a whole wood is required, sample stems should be felled and their annual rings counted. 


\section{INSECT AND FUNGOID ENEMIES}

The following list is included in this book to serve as a rough guide to the young woodman, to help him recognize a few of the more common insects and fungi, with the hope that it may stimulate interest in the study of forest entomology and the diseases of trees. No attempt has been made at classification, but it is simply a list of the most common or interesting insects or fungi attacking the principal timber trees.

Beetles.

OAK.

Attelabius Curculionides.-Wing-cases bright brick red in colour, about $\frac{1}{4}$ inch long. Head black. Rolls leaves into thimble-cases, inside of which there is one egg.

Xyleborus Dispar.-Black, about $\frac{1}{8}$ inch long; bores into young trees to lay eggs, and makes galleries in the stems. Also attacks Beech.

Several other beetles attack the Oak, but they are not common.

Moths.

Cossus Ligniperda (Goat Moth).-Female moth dull grey, about $3 \frac{1}{2}$ inches across the wings. Male rather 
smaller. Appear in June or July. The larvæ are fleshcoloured, legs yellow, head black; 3 to $3 \frac{1}{2}$ inches long. Eggs are laid in the crevices of the bark, and the larvæ, after hatching out, eat their way into the timber, where they live for three or four years, honeycombing the tree. This moth also attacks Ash, Elm, Willow, or Poplar.

It gets its name from the smell arising from a dark brown liquid that oozes from its burrow. Caterpillars found in September.

Pygoera Bucephala (Buff-Tip Moth).-This moth is a beautiful one. Its forewings are mottled with all shades of grey tinged with brown, and each has a buff-coloured tip; hence the name. When the wings are folded the moth looks exactly like a broken twig, its head (also buffcoloured) and tips of the wings representing the broken parts. It measures from 2 to $2 \frac{1}{4}$ inches across the wings. The caterpillars are about $1 \frac{3}{4}$ to 2 inches long, and hairy, of a dull yellow colour, with nine black bands running round the body. They are usually found in clusters, and when in great number will soon defoliate a tree. They are found in August or September. The moths hatch out in the following May or June.

Orgyia Antiqua (Common Vapourer Moth).-The male moths are chestnut-brown in colour, with a crescentshaped spot on each forewing. The female is almost wingless. The caterpillar is common, and coloured with a mixture of brown, grey, red, and yellow, with little tufts of hair upon its back. It feeds upon the leaves of the Oak, and also most"other hardwood trees. 
Tortrix Viridana (Green Tortrix Moth).-The caterpillars of this moth are about the worst enemies of the Oak, as they often defoliate acres of Oak woods in May and June. They are dirty grey in colour, with four small black spots upon each segment, and are about $\frac{3}{4}$ inch long when full fed. The moth is a very pretty little insect. Its forewings are like bright green satin and lightly fringed. The hindwings are light grey. The width across the wings is about $\frac{7}{8}$ inch. Starlings and rooks will congregate in thousands to feed upon the caterpillars; which shows how useful these birds are.

\section{Gall Insects.}

The late Mr. Gillanders in his book "Forest Entomology" gives twenty-four different gall insects on Oak. These insects, or " midges," lay their eggs upon the leaves, flowers, twigs, or roots, and, by some process or other that has never really been explained, the sap forms a gall round the egg or the hatched larvæ, which enlarges as the latter grows. For each different gall insect there is a different-shaped gall. The most common ones are those of the following " midges":

Cynips Kollari (the Marble Gall).-The larvæ may easily be found by cutting open a marble.

Teras Terminalis (Oak-Apple).-Common in all parts of the country. The alternate generation of this insect causes a gall on the roots of the Oak-trees called Biorhiza aptera. This gall resembles the honeycomb of the bumble bee.

Dryophanta Divisa.-Small round galls on the veins on 
the underside of leaves. Bright red in colour, changing to brown.

Dryophanta Scutellaris.-The cherry gall, about the size of a small cherry, red and green in colour.

Aphilothrix Fecundatrix.-The hop gall, resembles a hop flower. Inside is a second gall shaped exactly like an acorn.

Neuroterus Numismatis.-The button gall. Circular, with deep depression in centre.

Neuroterus Lenticularis.-The spangle gall. Circular, raised in centre.

Neuroterus Fumipennis.-Smaller, but of a brighter red than the spangle gall, not raised in centre. Fungi.

Polyporus Sulphureus (Red Rot).-Infection takes place through a branch wound, causing the wood to become brown and dry. The sporophores are soft yellow beneath and reddish-yellow on the upper surface. This fungus also attacks Willow, Poplar, Alder, Acacia, and other hardwoods.

Polyporus Igniarius (White Rot).-Infection takes place through wounds on branches. The decaying wood is first turned a deep brown colour, and then yellowishwhite. The sporophores are hard, bracket-shaped, and often 12 inches across. Attacks most broad-leaved trees. Polyporus Fomentarius.-Attacks Oak, but is chiefly found in Beech. 
Beetles.

BEECH.

Orchestes Fagi.-Beetle slaty-black, $\frac{1}{10}$ inch long. Larvæ hatch from eggs laid on the midrib of leaf, and tunnel through the leaf. These galleries turn brown, giving the leaves the appearance of having been nipped by frost. The beetles eat holes in the leaf.

Agrilus Viridis.-Beetle $\frac{1}{4}$ inch long, bluish-green, metallic colour. Eggs laid near bottom of young trees. Larvæ feed for two years on the cambium, often killing the young plants. Also attacks Oak.

Plants attacked should be pulled up and burned before beetles hatch in June.

Moths.

Orgyia Pudibunda (Pale Tussock Moth).-Commonly called "Hop-dog." Female moth about 2 inches across wings, which are brownish or greyish-white, with a darker brown stripe across them, fainter on the hindwings than on the front ones. Caterpillar pale green, with three bands of velvety black round its body, with four yellowish tufts of hair upon its back and another near its tail. One of our prettiest caterpillars. They hatch from eggs laid about 10 or 12 feet from the ground, and feed upon the foliage in July, August, and September. The trees attacked should be grease-banded about 15 feet up, to prevent the caterpillars going up the stem to feed. 
Scale Insect.

Cryptococcus Fagi (the Felted Beech Scale).-The wingless females attach themselves to the bark, cover themselves with a white felt-like substance, and live beneath this, feeding upon juices extracted from the bark, which on badly attacked trees dries and cracks, the tree dying in consequence. This insect is about the most destructive enemy of the Beech. Affected parts should be brushed with paraffin emulsion.

\section{Fungi.}

Phytophthora Omnivora (Beech Seedling Fungus).-This disease attacks young seedlings, sometimes before they appear above ground, The stalks and young leaves become covered with brown patches, and soon wither or rot away. The ground that has been occupied by Beech seedlings attacked by this fungus should not be used for hardwoods again for several years.

Nectria Ditissima (the "Canker" Fungus). - This disease not only attacks Beech, but also Ash, Oak, Sycamore, or, in fact, almost every broad-leaved tree, but Beech and Ash principally. It usually follows injuries to the bark caused by scale insects, hail, frost, or sunburn. It is easily distinguished by the rough curledup edges of the bark round the canker spot, caused by the tree trying to heal the wound. In the late summer, white patches appear on the bark round the wound, and on these in the spring appear minute dark red globes. All wounded parts should be cut away, and the cut surface coated with tar. The white stage of the fungus can be 
killed by applying with a brush a solution of sulphate of iron-1 pound to a gallon of water (Board of Agriculture Leaflet No. 56).

Polyporus Fomentarius (the Tinder Fungus).-Droduces "white rot" on Beech and Oak. The mycelium penetrates the wood and grows in layers between the annual rings, which can be pulled apart easily and crumbled to dust. The sporophores are large and semicircular, light brown and hard above, soft beneath. When dry, was used for tinder in former years.

Bark Beetles.

ASH.

Hylesinus Fraxini.-Beetle about $\frac{1}{10}$ inch long, brownishgrey, with dark markings upon its elytra or wing-cases. A very pretty insect. The beetle makes a two-armed gallery between the bark and cambium, laying her eggs to right and left; the larvæ, on hatching out, eat galleries at right angles to main ones.

Hylesinus Crenatus.-Beetle dark brown or black, about $\frac{1}{4}$ inch long, with broad notched lines upon its wingcases. The beetle makes a gallery with either one or two arms, the larvæ making their galleries in all directions.

Hylesinus Oleiperda.-Beetle, generally found on the top branches of young trees, is $\frac{1}{10}$ inch long, black, covered with yellow hairs. Beetle makes galleries deeply cut into the wood of the branches; larval galleries very irregulay. Sickly trees are mostly attacked, although the beetles often attack healthy trees. Back-going trees should be cut out to reduce the risk of attack. 


\section{Moths.}

Zeuzera AEsculi (Wood Leopard Moth).-The moth, a rather pretty insect with white, almost transparent wings covered with blue-black spots, is about $2 \frac{1}{2}$ to 3 inches across the wings in the female, rather smaller in the male. The caterpillar is about 2 inches long when full fed, yellowish-white, and lives in this stage for two or three years, boring in all directions in the timber of Ash, Elm, Sycamore, Birch, and Willow. I have also found one specimen in a young Oak about twelve years old.

Scale Insect.

Apterococcus Fraxini (the Ash Scale).-The white feltlike scale is easily recognized on the bark of young Ash poles. If a stone is drawn across it, the insects are crushed and their blood tinges the bark with red. Scraping or scrubbing the bark with steel brushes is often effective, or the insects may be sprayed with paraffin emulsion in May.

\section{Fungi.}

Nectria Ditissima, described above, causes black heart in Ash.

Beetles.

\section{ELM.}

Scolytus Destructor (the Elm-Bark Beetle).-Beetle $\frac{3}{16}$ inch long, black thorax, with dark brown wing-cases. The female makes a long gallery, usually vertical, in which the eggs are laid. The larvæ, on hatching out, eat galleries in soft bark, curving towards either end of the mother-gallery. Cut out all dead and dying trees. 
Moths.

Cheimitobia Brumata (Winter Moth).-The wings of the male moth are about 1 inch to $1 \frac{1}{4}$ inches across. The front ones light browny-grey marked with faint transverse bands, and the hind ones pale grey. The female moth is practically wingless. The caterpillars are "loopers," green, with three yellow lines on each side, about an inch long when fully fed. They hatch in April and May. They do great damage to Lime and Sycamore as well as Elm. Grease-banding the trees prevents the female from climbing up to lay her eggs. The moth gets its name from the time of the year when it appearsviz., October to December.

Fungi.

Polyporus Fomentarius.-Described above.

Moths.

SYCAMORE.

Hybernia Defoliaria (the Mottled Umber Moth).-The male is a very pretty moth, with forewings mottled light brown and reddish-brown, and hindwings pale with a dark brown spot. The female is wingless. The caterpillar is reddish-brown on the back, with a black stripe down each side, below which the colour is greenish-yellow. Each segment has upon it a white spiracle surrounded with reddish-brown, and there are grey markings between each segment. They feed on the leaves of Sycamore, Lime, Hazel, Oak, and many other trees, and may be seen hanging by threads from the leaves in May and June. The moth appears in October. 
Fungi.

Nectria Cinnabarina (the Coral Spot Fungus).-This fungus takes its name from the colour of the small conidia cushions that break out upon the bark near infected spots. It mostly attacks dead branches, but the mycelium will spread from these to sound wood, and prevent the flow of sap, which kills the affected part. Damaged branches should be pruned off and coated with tar. Horse Chestnut, Lime, Maple, and Elm, are also attacked.

Beetles.

\section{POPLARS AND WILLOWS.}

Melasoma Populi.-Beetle nearly $\frac{1}{2}$ inch long, blackishblue body, brick-red wing-cases with a black tip. The larvæ hatch from eggs laid on the underside of leaves, and feed upon the latter, skeletonizing them. The beetles eat holes in the leaves.

Phyllodecta Vitellince.-A very pretty little beetle about $\frac{1}{8}$ inch long, metallic colourings from bluish-black to greenish-black with tinges of copper. The larvæ eat the leaves in the same manner as the former beetle.

Saw-Flies.

Croesus Septentrionalis.-The caterpillars feed upon Poplar, Alder, Willows, and other softwoods. They are bluish-green, with black dots in two rows along the body, and are about $1 \frac{1}{2}$ inches long. They are usually found in clusters. When disturbed, they always erect the hind portion of their body. 
Moths.

Dicranura Vinula (the Puss Moth).-This is one of our finest British moths, and the caterpillar is also one of our largest and finest. The moth is 3 inches or more across the wings and covered with silky hairs, brindled grey in colour, the body reminding one of a cat; hence the name. The caterpillars are very odd-looking creatures: bright green in colour, with a diamond-shaped, greenishbrown patch upon its back, and a hump over the fourth segment. It has a white line surrounding the brown patch, and a white spiracle on each segment and a brown spot upon the seventh. Its head is black, and appears as if surrounded by a hood, reddish in colour. It has a forked tail, from which, when aroused, two thin, threadlike organs are put out. It also assumes a fighting attitude, rearing its head and forelegs from the branch. They live upon the foliage of Poplars and Willows. The cocoon, inside of which pupation takes place, is hard and shell-like, made from " sawdust" nibbled from the branch upon which it is made.

Galls.

Many gall insects attack these trees, and they are sometimes attacked by a scale insect, Chionaspis salicis, which is also found on Ash.

Beetles.

PINES.

Hylobius Abietis (the Pine Weevil).-This insect is undoubtedly the most destructive insect in Britain. It not only attacks the Pines from which it gets its name, but 
practically every conifer, and does most damage in plantations up to six or seven years of age. The insect does damage in the mature stage by gnawing the bark and cambium of the young trees. The full-grown beetles measure about $\frac{1}{2}$ inch in length. This takes about two years. Smaller beetles may be found in company with the larger ones, these probably being those that emerged in the same summer as they are found. They are very dark brown or black, with small patches of yellow hairs upon the wing-cases, thorax, and abdomen. Their eggs are laid on roots of freshly felled trees or in sawdust heaps, and the larvæ hatch out about four weeks later, and bore galleries in the cambium and sapwood, pupating at the end of them.

When the beetles emerge in June and July, they fly to their feeding ground (viz., any coniferous plantation near). The best method of preventing attacks is to "grub fell" conifers and burn the roots, which may be full of eggs, larvæ, and beetles, before the latter emerge in the summer. Another, though not always advisable method is to allow the felled area to lie bare for three years before replanting, or planting any area near it.

The beetles may be trapped by heaps of sawdust or pieces of bark placed here and there throughout the infected area. These traps should be examined every morning.

The beetles may be collected from the young trees at feeding-time, generally in the afternoon when the sun is shining. When it is dull they may be found in any tuft of grass near the trees or in spaces between the stems and 
the soil, made by the trees being blown about by wind. When collected, they should be dropped into a bottle of paraffin or some other strong liquid.

'Other insects closely related to Hylobius abietis are Pissodes pini and Pissodes notatus. Both species may be found working with the former one. I have also found the clay-coloured weevil, Otiorrynchus picipes, on the same tree and in traps with $H$. abietis.

Hylurgus Piniperda (the Pine Beetle).-The beetle is about $\frac{1}{5}$ inch in length, dark bronzy-black in colour. The female lays her eggs under the bark of sickly trees or stems felled during the previous winter, and the larvæ, after hatching out, eat galleries at right angles to the mother one at first, afterwards in all directions. Little damage is done in this stage, as the galleries are almost wholly in the bark. After pupating, the beetles emerge from the bark of the breeding-place and fly to the leading shoots of young Pine-trees, bore into the pith, and eat their way up the centre of the shoot, which dies and falls off. It often spoils whole woods in this way.

The best method of preventing damage by this insect and other similar ones is to keep the woods free from dead wood. Pine-trees left lying for a time on a felled area should be peeled and the bark burned if there are any grubs or beetles in it.

Other boring beetles doing damage to Pines are-

Hylurgus Minor, Hylastes Palliatus, Hylastes Ater, which do damage to young trees as well as large timber.

Tomicus Bidentatus, a very small beetle that often does 
great damage to young trees. Easily recognized by its two tooth-like projections, one on each wing-case.

Tomicus Acuminatus, usually found on older trees, has three teeth upon each wing-case.

Tomicus Sexdentatus, not very common or very destructive, as it only attacks the bark of old Scots Pine. Has six teeth upon each wing-case.

Rhagium Bifasciatum, does not damage living trees, but is found on dead and very dry trees. It is a very fine beetle in a collection.

\section{Moths.}

Retinia Turionana (Pine-Bud Tortrix Moth).-Not a very common moth. Forewings red-brown with grey markings, hindwings grey. Caterpillar hollows out Pinebuds.

Retinia Buoliana (Pine-Shoot Tortrix Moth).-A very common and destructive insect. Caterpillar hatches from egg laid on the buds of Scots Pine, and eats its way up the young shoot, which dies in consequence. The moth is very pretty, with forewings yellowish-red with silvery markings, hindwings dark grey.

Retinia Resinella.-Not so common as the last moth. Forewings black-brown with silvery markings; hindwings pale brown-grey. Damage done to Pine-buds, the flow of resin from which causes the growth of a gall, twochambered, in which the larvæ pass the winter.

Trachea Piniperda (Pine Beauty Moth).-One of our prettiest moths; about $1 \frac{1}{2}$ inches across the wings. Forewings reddish-brown, marked with grey; hindwings dark 
grey-brown. The caterpillar varies in colour from light green to olive-green, with five white stripes upon its back, the lowest ones on either side being yellowish. They feed on twigs of Scots Pine.

Fidonia Piniaria (Bordered White Moth).-A very common moth in most parts of the country. It takes its name from the markings on the wings of the male. The centre of each wing is white and surrounded by a deep border of dark brown. The wings of the female are uniformly mid-brown. The caterpillar is sea-green, with a white line upon its back and a yellow one on either side.

Saw-Flies.

Lophyrus Pini (Pine Saw-Fly).-The caterpillars are most destructive, often defoliating whole plantations. They are dirty green in colour with black spots; about an inch long. They may be shaken from young trees or sprayed with Paris green.

Lophyrus Rufus (the Fox-coloured Saw-Fly)._Although not so common as the former insect, often does great damage. The caterpillar is a ruddy-brown, and only about $\frac{1}{2}$ inch long. They do similar damage to that by the larger caterpillar, and the same methods are used to exterminate them.

\section{Wood Wasps.}

Sirex Gigas (the Giant Wood Wasp).-The mature insect is a particularly fine one to have in a collection. The female is about $1 \frac{1}{2}$ inches long, with a wing expanse of $2 \frac{1}{2}$ inches, and is armed with a long ovipositor. The 
male is somewhat smaller. The body is banded black and yellow, and the wings are like yellow gauze. The larvæ live in logs of timber for two or three years, and the mature insects often emerge after the timber has been used for building, etc.

Spruce, Silver Fir, and Larch, are also attacked.

Sirex Juvencus.-This insect resembles the previous one in nearly all but colour, which is a steely blue.

Fungi.

Trametes Pini (the Stem-Rot Fungus).-This disease attacks Pines from forty years or so and upwards, and causes white rot in the heart of the trees. The mycelinm usually grows between the annual rings, separating them. The brown sporophores are very similar to an oystershell on top, softer underneath. All diseased stems should be cut out before becoming rotten.

Trametes Radiciperda (the Root Fungus).-Attacks the roots of Scots and Weymouth Pines, and also Spruce and Silver Fir, causing red rot, which spreads upwards, causing the tree to die and rot. The sporophores are usually found on roots just below the surface of the ground, between the scales of bark. The mycelium spreads in a white felty layer between the bark and the wood. Infection can take place by the contact of diseased roots with healthy ones, or the spores can be carried from one tree to another by mice. It is about the most destructive disease in our woods. The needles turn rustybrown on infected trees. Hardwoods should be planted on areas affected. 
Agaricus Melleus (the Honey Fungus).-The needles of trees affected by this disease also turn brown, but the sporophores, like mushrooms, are found at the base of young stems or upon old stools. The mycelium assumes different forms. Between the bark and the wood it appears as a white felty layer, changing into hard, brown, wire-like strands when the tree is dry. These strands or rhizomorphs grow out of the bark of the roots, and run through the soil until meeting with other roots, the bark of which they penetrate, spreading out again into mycelial layers of white felt. Another point of identity is the flow of resin that takes place at the base of the stem. This disease is found on hardwoods as a saprophyte, and is also said to be parasitic in some cases. It attacks almost all conifers.

Lophodermium Pinastri (the Leaf-shedding Fungus).The leaves of Scots and Austrian Pines turn brown and drop off. The trees appear as if badly frosted.

Peridermium Pini Acicola (the Pine-Needle Blister).Yellow blisters appear in rows on both sides of the needles.

Peridermium Pini Corticola (the Pine-Bark Blister or Canker).-This disease is very destructive to pole woods in many parts of the country. It infects wounds on branches, causing rupture of the bark and subsequent death, by preventing the flow of sap. 
Moths.

\section{LARCH.}

Coleophora Laricella.-The larvæ of this tiny moth bore into the leaves and suck the sap, the leaves shrivelling up in consequence. The wounds made offer lodgingplaces for the spores of Peziza Willkommii.

Saw-Flies.

Nematus Erichsonii (the Large Larch Saw-Fly).-Until recent years this insect has been rare and has been overlooked. The caterpillars do great damage to young trees, often entirely defoliating them. They are nearly an inch in length when fully fed, and are greyish-green in colour on the back and yellowish beneath, with brownish spiracles on the segments.

\section{Plant Lice.}

Chermes Laricio (the Larch Aphis).-This insect is well known because of its woolly covering, which is to be seen on the leaves and young bark of Larch in almost any wood. It is armed with a sucker, which exceeds in length the body of the insect, and through which it sucks the sap from the needles and bark. It not only injures the tree directly, but there is no doubt that the spores of the disease Peziza Willkommii find lodgment in the minute wounds made in sucking the juices. The alternate generation of this insect passes its life upon the Spruce, where it forms a gall similar to a cone. These galls 
should be collected and burned, and Larch-trees badly infected with aphides should be sprayed with paraffin emulsion.

\section{Fungi.}

Peziza Willkommii (the Larch Canker).-In very few districts is this disease entirely absent. Pure plantations of Larch are usually the worst. The fungus finds entrance to the tree through wounds of any kind made either by insects, rabbits, hail, or through carelessness when planting. It develops under the bark, which ruptures and exudes a large amount of sap. Year by year the canker enlarges, until sometimes it encircles the tree, causing death. Trees of any age up to forty years are attacked on the stem, while older trees may be attacked in the crown. Sometimes a tree may heal over the wound, but the timber near the canker spot is useless.

A prominent feature of the disease, and which makes its presence easily detected when there is no large canker, is the growth of the little Peziza cups, which are white outside and orange-red inside.

The disease is sometimes found on Scots Pine, but it seldom cankers the branches, and is more of a saprophyte than a parasite. To prevent the spread of this disease, Larch should seldom be planted pure, and then only in open and dry situations. The Novar method of combating the disease has already been explained-viz., cutting out the badly diseased stems and underplanting those left. Agaricus Melleus, Trametes Pini, and Polyporus Sulphureus, also attack Larch. 
Beetles.

\section{SPRUCE}

Trypodendron Lineatum bores into wood of recently felled trees, but the damage is usually confined to the sapwood. The beetle is a very pretty insect with nearly black thorax and yellowish-brown wing-cases, with three black bands or stripes running lengthwise.

Hylastes Palliatus also attack recently felled trees. Their galleries are usually made in the bark. The beetle is very small, and dark brown in colour.

\section{Plant Lice.}

Chermes Abietis (the Spruce Gall Aphis).-As mentioned before, this insect is the sexual form of the Larch aphis, and causes the growth of the cone-like galls on Sprucebranches.

\section{Fungi.}

Polyporus Vaporarius, P. Borealis, Trametes Pini, T. Radiciperda, and Agaricus Melleus, attack the Spruce as well as the Scots Pine and other conifers.

The young plants of all species are attacked by the cockchafer, Melolontha Vulgaris. The eggs are laid a few inches deep in the soil, and hatch in about six weeks. They live three or four years in the larval stage, and feed upon the roots of trees and grass. They are white in colour, and about $1 \frac{1}{2}$ inches long when full grown. The beetle is rich brown covered with a whitish down. It feeds upon the leaves of most hardwoods, and can be 
beaten down from the trees. Suggestions for the extermination of the larvæ have been made in Chapter II. Melolontha Hippocastani also does damage to young trees in plantations by eating the roots.

There are many more insects and fungi attacking the different trees, but I think the foregoing are the most common and easily found. Most of the insects mentioned are easily reared-a very interesting as well as instructive hobby.

For further instruction, “Forestry Entomology," by the late Mr. Gillanders, is the best book for beginners. 


\section{CHAPTER IX}

\section{MISCELLANEOUS WORK}

Hedges and their management-Measuring a plantation.

Hedges and their Management.

Hedges on an estate, either ornamental or useful, are usually in the care of the woods staff, and it may not be out of place to describe the methods adopted in the formation and management of them. If they are to be stock-proof they must be formed of plants that stock will not face or that will resist their weight. The plants must also be non-poisonous. If for shelter, they must be of plants that grow thick and bushy, or which retain their leaves throughout the winter. For ornamental hedges evergreen plants are mostly used, or those that flower profusely.

For stock-proof fences there is nothing to beat the common Quickthorn, either planted pure or mixed with Beech or Hornbeam. The prickly nature of the thorn prevents cattle trying to break through, and the Beech, which retains its leaves when trimmed annually, serves as shelter for stock. The stiff nature of the latter tree is also a great addition to the strength of a thorn hedge. Thorn and Holly, Holly and Beech, and Holly and 
Hornbeam, are also splendid stock-proof hedges, but Holly plants are usually dear and make these hedges expensive. These three hedges are not only strong and give good shelter, but are highly ornamental throughout the whole year. When shelter is needed for gardens, pleasure grounds, or nurseries, hedges of Privet alone, Privet and Thorn, Beech or Portugal Laurel, are most useful.

Ornamental hedges may be formed of a great variety of trees, the chief characteristic needed being their ability to stand pruning. Yew, Spruce, Thuja Lobbii, Cupressus Lawsoniana, C. macrocarpa, Box, Berberis Darwinii, Cotoneasters of different varieties, Myrobella Plum, Golden Privet, Holly (Green, Golden, or Silver varieties), Sweet-Briar Rose, Rosa rugosa, Laurels, Aucuba Japonica, and Laurestinus, all make very pretty hedges when kept properly trimmed.

\section{Preparing the Ground for Planting Hedges.}

The line of hedge should be marked out about 2 feet 6 inches wide for Thorn hedges, and from 3 feet 6 inches to 4 feet when bushy plants, such as Holly and Yew, are to be planted.

Starting at one end, the whole length should be bastard trenched as described in Chapter I., and all perennial weeds, such as couch, removed. On poor soil a good supply of leaf-mould should be added to the top layer of soil at the time of trenching.

If the soil is very wet, a closed drain should be put in about 15 feet away, to prevent roots from choking the 
pipes. For a plantation hedge an open drain may be necessary, but for farm hedges closed drains are better. The hedges should not be planted upon banks, as it keeps the plants too far away from the water-supply, and stock will break away the soil from the roots and injure them with their hoofs.

\section{Methods of Planting.}

Thorn hedges may be either single or double. When double, they sooner become fit to turn stock, and if kept properly brushed or trimmed seldom need "layering." The single-row hedge is cheaper to plant, and is more easily kept clean. With the latter, the plants should be put in about 4 inches apart, but with the double row they need be only about 6 inches apart, with 6 inches between the rows. The plants in each line should "cut" those in the other-i.e., be planted midway between them.

In favourable situations, hedges planted thus should be stock-proof in six or eight years.

The plants for a Thorn hedge should have been cut down a year after they were transplanted into nursery lines, to encourage them to throw out several shoots from the bottom, instead of forming one straight stem. After the ground has been trenched, a line should be stretched along at a foot from the edge of the trenched ground (if 2 feet 6 inches wide), and a trench made deep enough to receive the roots of the plants, as in transplanting.

The plants are inserted, the trench refilled, and the plants firmed up. The line is then transferred to points 6 inches away from this row, and operations repeated. 
If the hedge is to be a mixed one, one row may be of Thorn and the other of Beech, Hornbeam, etc., or they may be mixed by alternate plants. If the hedge is to be single, the trench must be taken out in the centre of the prepared ground.

A slight dressing of basic slag is a great help to the plants, or horn shavings may be dug in when trenching. The latter manure is slower in action, but is very good.

For ornamental hedges it is seldom necessary to plant double hedges. The plants, if large, are planted separately on the prepared ground, at distances varying with the kind of tree and their size.

Large transplants of Yew, Holly, Laurel, etc., may need 18 inches to 2 feet of space to grow well, while Privet, Box, etc., may do with from 6 to 9 inches.

\section{Protecting Hedges.}

Young Thorn hedges need protection against stock during the first six or eight years after being formed, and this can be fairly cheaply done by the use of woven fencing, which can be removed for use elsewhere when the hedge is strong enough.

Sheep particularly should be kept from young hedges, as their greasy wool will often kill off young shoots.

Against rabbits or hares protection must be given by wire-netting.

\section{Cleaning.}

From its earliest days a hedge should be kept free from weeds of any kind-viz., grass, ivy, or any self-sown 
plants, such as often spring up. Elder is particularly detrimental to hedges. The common hoe is useful for cleaning the ground on the outside of the hedge, or the ground may be "pointed," but the weeds between the plants must be pulled out by hand.

A hedge that is cleaned yearly will grow much better than one that is allowed to become choked with weeds, which deprive the plants of food and moisture and kill off lower shoots.

Nursery hedges must always be kept free from weeds, otherwise they will serve as harbour for vermin.

\section{Pruning or Switching.}

After the hedge has been planted for about three years, it should be topped-i.e., all long straggling shoots taken off. The side-shoots should also be shortened. This encourages the growth of the lower shoots and thickens the hedge.

After this, until it is of the required height and strength, a light brushing should be given every year to get it into shape.

When once a hedge is properly established, it should be treated more drastically. Thorn hedges and their mixtures should be cut back to the old wood every year, otherwise they will become too loose, and with too much top, which will result in the death of the lower branches.

Ornamental hedges also should be pruned hard.

If a Yew hedge is examined, it will be found that the green leaves are only on the last 6 inches or so of the branches. The rest of the branches are bare, and if the 
hedge is not pruned hard, this 6 inches creeps farther away from the centre every year, leaving the hedge loose and easily bent about by the weight of snow, etc.

Such hedges as Cotoneaster, Myrobella Plum, or Berberis, often need pruning twice a year, as they are apt to become straggly. The long straggling shoots should be taken off in the autumn if the hedge is not brushed properly.

The best tool to use for pruning any hedge is the hedgebill or switching bill, as when kept sharp it makes cleaner cuts and does not "pinch" the bark, as pruning shears do.

In using a hedge-bill the cutting must always be done with an upward stroke, never downward, or otherwise the branches are split and hacked off, not out, allowing water to obtain access and cause rot.

\section{Methods of Re-forming Hedges.}

When a Thorn hedge becomes too thin at the bottom, owing to too heavy a top growth or to weeds, etc., it is no longer proof against sheep or cattle, and some means of remedying this must be adopted, of which the most common are plashing, or layering, and stripping.

In some parts of the country stripping is resorted to regularly, but the hedges then are not switched annually. They are stripped once every six years or so, according to the rotation of the crops on the farm. Every hedge is stripped on one side when the field on that side is ploughed out of "ley," or on both sides when the fields on both 
sides are ploughed. The next crop being Oats, Barley, etc., and the succeeding ones roots, Oats, Hay, it is usually three or four years before stock can interfere with the hedge. (Sheep are netted when feeding off roots.) This gives the hedge plenty of time to become stockproof again. Stripping consists of cutting all branches back to the stem, and shortening the latter to about 3 feet. On old hedges it is a good plan to make cuts through the bark of the stems, about 6 inches from the bottom, to encourage the trees to throw out new shoots from the bottom. When these are strong enough, the old stems may be cut away.

To layer a hedge, all straggling branches are cut off and all dead or weakly shoots taken out. Stout stakes are driven in the line of hedge from 18 inches to 2 feet apart, and the long shoots that have been left are cut about halfway through at the bottom, with an upward cut, bent down and laced or twined between the stakes. Each succeeding layer is twined on the opposite sides of the stakes to the preceding one, and keeps it down in its place.

A properly plashed hedge should not "spring," but in some districts the tops of the layers are tied down with wire or tarred string, or " banisters "-i.e., light railsare nailed to the top of the stakes to prevent the layers springing up.

Another way to hold them down is to use " binders" -i.e., long Thorn or hazel rods, twined in and out of the stakes, in a similar manner to the layers, but horizontally instead of slanting. 
The use of wire is to be deprecated, as a man brushing the hedge afterwards may blunt his hedge-bill upon it and make him afraid to cut close.

After layering is finished, all rough ends must be trimmed off, the rubbish burned, and the ditches, if any, cleaned out.

If there are gaps in the hedge, layers should be pegged down into the soil, as explained in " Nursery Work," and covered with soil, or the gaps must be planted up with strong transplants.

The hedge should be brushed annually until it again becomes too thin or too loose, and then left to grow long shoots to use as layers. In some districts hedges are layered regularly every ten years or so. They are brushed annually for six years and left to grow for four years. Another method adopted for renewing hedges is to cut the old stumps halfway through, as for plashing, but they are bent over at right anc $->$ to the line of hedge instead of in line with it. Tht, are staked and wattled, making a very good protecting fence until the young shoots coming from the stools are strong enough to form a hedge by themselves.

\section{How to Measure a Plantation.}

To estimate for the number of plants required, it is necessary to know the area of the ground to be planted. Also, when valuing a wood, it is necessary to know how many acres there are. This may usually be found by reference to an Ordnance Survey map. but often it is 
necessary to take the measurements from the area itself.

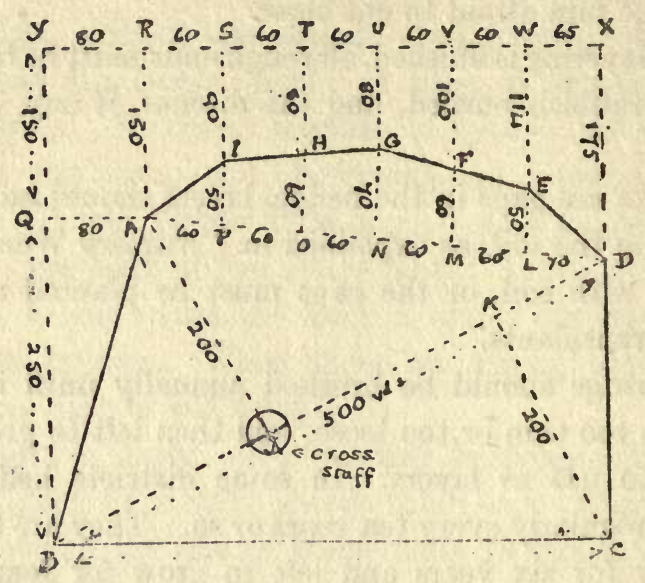

Frc. 17.

The above plan represents a piece of ground with three straight sides and a curved one.

When there are no trees to obstruct the view, the measuring is done on the actual area, but when the ground is fully stocked with trees this is impossible. The area then must be measured from the outside. I will first try to show how the area is measured from the inside, and later by the other method

In measuring land, it is not wise to trust to the possibility of any two sides being parallel, or any angle being a right angle. It is best to make one's own right angles. Base lines must first be poled off and measured. 
In the above sketch, the first base line is from $B$ to $D$.

Poles are set up in line between these points, the distance measured, and found to be 500 yards.

A cross-staff is then used to find out where a straight line from $A$ would meet $B D$ at right angles. These lines are called offsets. The commonest form of cross-staff consists of a block of wood having in it two saw-cuts, exactly at right angles to each other, fixed to a pole about 5 feet long. The latter should be pointed and shod with iron to make it easy to stick in the ground.

This instrument is set up on line $B D$, where it is judged that the line from $A$ will meet it at right angles. A sight should be taken through a saw-cut, getting it in line with $B$ and $D$, then a sight taken through the other saw-cut. If this does not point straight to the offset staff erected at $A$, the cross-staff must be moved to right or left as required until it does.

A special instrument called an "optical square" is made. With it a man walking along line $B D$ and looking at $D$ through the instrument would see the offset staff at $A$ reflected in a small mirror when he arrived at the spot where the line should cut $B D$.

The mirror is set at an angle of 45 degrees with the main line of sight, so that any object reflected in it is exactly at right angles with the line of sight.

When the correct spot, $J$, is found and marked, the line $J A$ is measured-viz., 200 yards. The cross-staff is 
then moved along the line, and the point $K$ found in the same manner.

There remains the curved part of the area to be measured.

The line $A D$ is poled off, measured, found to be 370 yards, and used as a base line.

Perpendiculars or offsets must be set up at intervals along this line-say every 60 yards, starting from $A$.

This makes five offsets, leaving 70 yards between the points $L$ and $D$. (To erect a perpendicular from a given point, set up the cross-staff so that on looking through one of the saw-cuts the ends of the line can be seen. Then the other saw-cut will point out the direction of the perpendicular or offset.)

These offsets are measured and noted. PI 50 yards, $O H \quad 60$ yards, $N G \quad 70$ yards, $M F \quad 60$ yards, $L E 50$ yards.

The booking may be done in different ways, but the best way, in my opinion, is to draw a rough plan of the area, and marking upon it the points and distances as they are measured.

The area of the ground may then be worked out in sections from these figures.

The area of a triangle is found by multiplying the base by the perpendicular height and dividing by 2 .

The area of a trapezoid (a figure with two sides parallel) $=$ mean length of parallel sides multiplied by the perpendicular distance between them.

The figures may be set out thus: 


$$
\begin{aligned}
\text { Triangle } \quad A B D=\frac{500 \times 200}{2}=50,000 \text { square yards. } \\
\Rightarrow \quad B C D=\frac{500 \times 200}{2}=50,000 \quad " \\
\Rightarrow \quad A I P=\frac{50 \times 60}{2}=1,500 \quad "
\end{aligned}
$$

Trapezoid IHPO $=\frac{60+50}{2} \times 60=3,300 \quad$ "

$$
\begin{aligned}
\prime \quad H G O N & =\frac{60+70}{2} \times 60=3,900 \\
, \quad G F N M=\frac{70+60}{2} \times 60 & =3,900 \\
, \quad F E M L & =\frac{60+50}{2} \times 60=3,300 \\
\text { Triangle } E L D & =\frac{50 \times 70}{2}=\frac{1,750}{117,650}, "
\end{aligned}
$$

117,650 square yards divided by 4,840 , the number of square yards in one acre, gives $24 \cdot 398$ acres as the area of the ground.

The area of the irregular figure containing the four trapezoids may be found by taking the mean length of the two extreme offsets $P I$ and $L E$-viz., 50. Add to this the sum of the other offsets-viz., 190-making 240; multiply this figure by the extreme length of the figure - viz., 240-and divide by the number of spaces between the offsets-viz., $4=14,400$.

To measure the same ground from the outside, it is necessary to erect a square or parallelogram of known dimensions upon one of the sides.

Taking the line $B C$ as the base, it is measured and found to be 445 yards. From $B$ and $C$ perpendiculars are set 
up long enough to include the whole ground-say 400 yards in this case.

These lines are poled off, and also the line $Y X$ joining them. The contents of the parallelogram thus formed is $445 \times 400=178,000$ square yards.

Then, using $B Y$ as a base line, an offset is made at $Q$ to $A$.

The distance from $B$ to $Q$ is 250 yards, and the length of $Q A 80$ yards.

Then, on base line $Y X$ an offset is made from $R$, which is found to be 80 yards from $Y$, to $A$, which is measured -viz., 150 yards.

Every 60 yards offsets are made and measured-viz., SI 90 yards, TH 80 yards, UG 80 yards, VF 100 yards, $W E 114$ yards, the distance between $W$ and $X$ being 70 yards, and from $X$ to $D 176$ yards.

The figures for this are as follows:

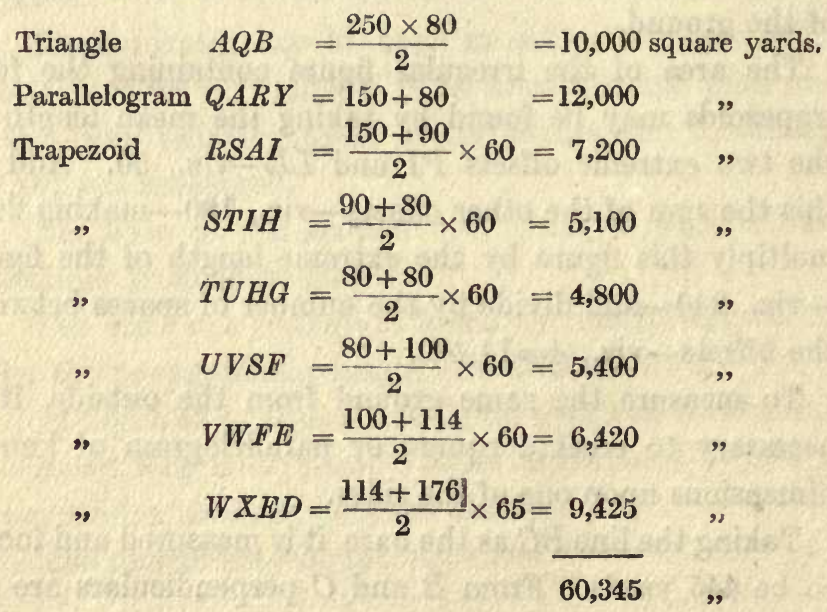


This figure must be deducted from the area of the parallelogram-viz., 178,000 square yards, which leaves 117,655 square yards, or $24 \cdot 308$ acres.

I have given these figures in yards as a link is too small a unit for such a small plan as the above, but for actual measuring the chain of 22 yards, or 100 links, is more convenient. A tape marked in links is generally used, being lighter and handier than a steel chain. A chain is made of 100 links, each 7.92 inches long (792 inches in one chain, divided by $100=7 \cdot 92$ ). It is $\frac{1}{80}$ of a mile, $\frac{1}{10}$ of a furlong; a square chain is a $\frac{1}{10}$ part of an acre. Ten square chains, therefore, make 1 acre, and the computation of areas is thus made simple. The links being decimal parts of a chain, the measurements may be written $5 \cdot 50$ chains, or 75 links as $\cdot 75$ of a chain.

All calculations are then made by decimal arithmetic.

In using the chain or tape on a line previously poled out, the surveyor stands at the starting-point of the line, holding one end of the chain. His assistant, holding the other end, and carrying ten pins or arrows, walks along the line until reaching the full extent of the chain, which he stretches tight and straight. At this point he places a pin upright in the ground in a line between the points to be measured. He is guided in this by signs from the surveyor. He then moves on to the end of the next chain length, where he again puts in a pin. When this is properly placed, the surveyor picks up the first pin and moves on to the next.

This continues until the ten pins have been used and picked up by the surveyor. The chain is left lying 
stretched out while the assistant goes back for the pins. No. 1 pin is then put in at the end of the eleventh chain. The pins should be counted at every change, to make sure none has been dropped.

The line must not be measured parallel with the surface of the ground, but the chain must always be held level.

When working downhill the assistant should hold his end up at a level with that held by the surveyor, and when working uphill the surveyor must hold his end up.

When measuring steep hillsides, it is better to use a shorter unit of measurement than the chain to ensure the tape being held level. The offset staffs should be painted in black-and-white bands, to be easily seen at a distance. 


\section{APPENDIX}

TABLES of linear measure, square measure, cubic measure, capacity measure, liquid measure, angular measure, avoirdupois weight, metric system.

Calculation of areas.

Fencing Notes.-Wire gauges, staple gauges, weight of nails.

Draining Notes.-Re draining tiles, angles of slope, natural slopes of earth, depth of drains, number of tiles per acre.

Plantation Tables and Notes.-Planting in squares, triangles and lines, insecticides, number of plants per square yard in nursery lines.

Timber Notes.-Timber measure, average composition of dry wood, measuring timber, timber weights, areas of $\frac{1}{4}$ girths, areas and circumferences of circles, technical properties of timber, how to use the slide rule.

Calendar of work. 


\section{MEASURES OF LENGTH.}

LINEAR MEASURE.
12 lines......... $=1$ inch.
12 inches $. . . \ldots . .=1$ foot.
$7 \cdot 92, \quad \ldots . . .=1$ link.
3 feet $. . . \cdots \cdots=1$ yard.
$5 \frac{1}{2}$ yards $\ldots \ldots .=1$ pole.
40 poles $\ldots \ldots \ldots=1$ furlong.
8 furlongs $\ldots \ldots=1$ mile.
3 miles $\ldots \ldots \ldots=1$ league.

The hand in terms of which horses are measured $=4$ inches.

Gunter's chain of 66 feet ............... $=100$ links.

The fathom used for recording soundings $\ldots . . .=6$ feet.

One cable's length ................... $=120$ fathoms.

One Admiralty knot ................... $=6080$ feet.

One nautical mile ................... $=1870$ yards.

\section{INCH TABLE.}

One inch $\ldots \ldots \ldots \ldots=12$ lines.

\begin{tabular}{|c|c|c|c|}
\hline & & & of a link \\
\hline & $\cdots \cdots \cdots \cdots$ & & 25 of a link \\
\hline & & & $\frac{1}{12}$ or 0833 of $a$ foo \\
\hline & 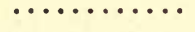 & & or 0277 of a yard. \\
\hline & $x^{2}+2$ & & 254 of \\
\hline & $\cdots \cdots$ & & 2.542 centimetres \\
\hline & & & $25 \cdot 42$ millimetres. \\
\hline
\end{tabular}

.0833 of an inch ............ = 1 line.

7.92 inches $. . . \ldots \ldots \ldots \ldots \ldots . . .6=1$ link.

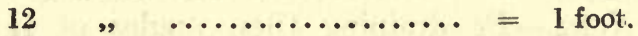

$36 \quad " \quad \ldots \ldots \ldots \ldots \ldots \ldots \ldots \ldots . . . \cdots=1$ yard.

$198 \quad " \quad \ldots \ldots \ldots \ldots \ldots \ldots \ldots \ldots . . .1$ pole.

$792 " \quad \ldots \ldots \ldots \ldots \ldots \ldots \ldots . .1$ chain.

.03937 of an inch ............

$.3937, \quad \ldots \ldots \ldots \ldots \ldots \ldots \ldots . . .1$ centimetre.

3.937 inches $\ldots \ldots \ldots \ldots \ldots \ldots \ldots . . .6=1$ decimetre.

$39.371, \quad \ldots \ldots \ldots \ldots \ldots \ldots . .=1$ metre.

LINK TABLE.

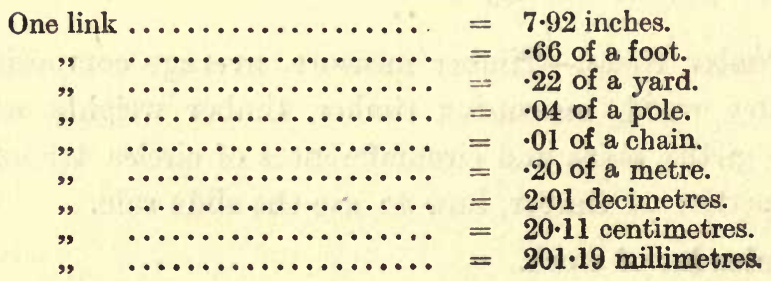




\section{LINK TABLE.}

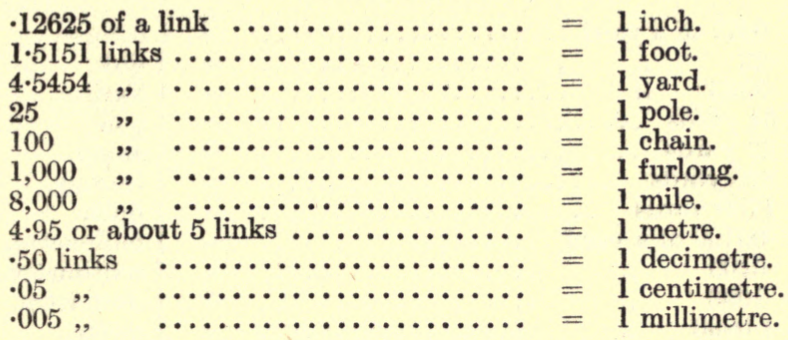

FOOT TABLE.

One foot

$=12$ inches.

,"
,",
,"
,"
,"

$=1.5151$ links.

$=\frac{1}{3}$ or $\cdot 3333$ of a yard.

$=-0606$ of a pole.

$=.01515$ of a chain.

$=\cdot 3048$ of a metre.

$=3.048$ decimetres.

$=30.48$ centimetres.

,

$=305$ millimetres.

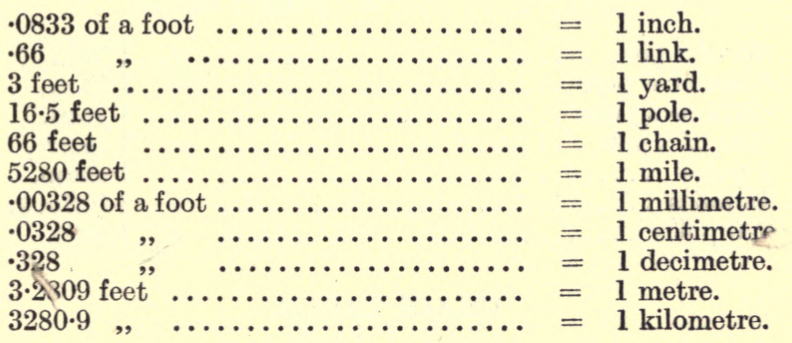

YARD TABLE.

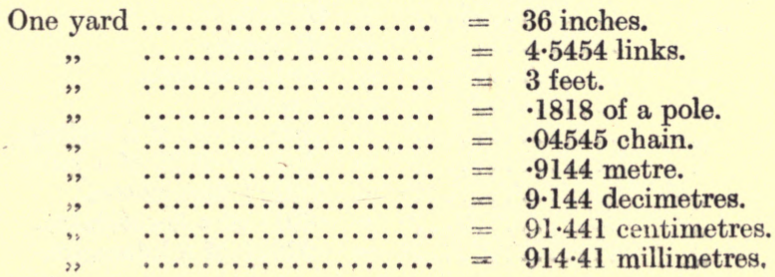


YARD TABLE.

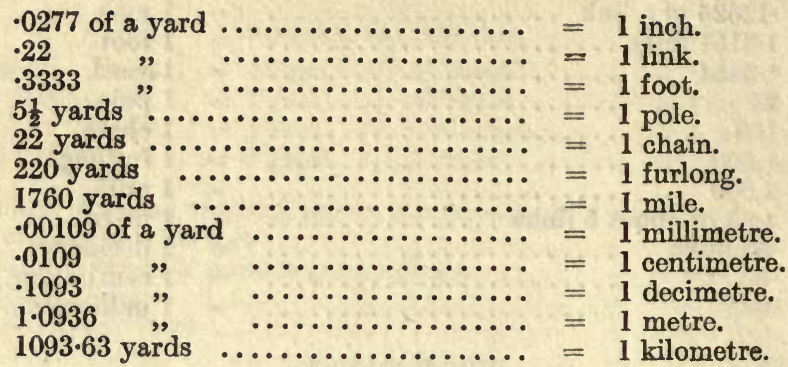

POLE TABLE.

One pole

",
",
",

$=198$ inches.

25 links.

$16 \frac{1}{2}$ feet.

$5 \frac{1}{2}$ yards.

$\frac{1}{4}$ or $\cdot 25$ of a chain.

$\frac{1}{40}$ or .025 of a furlong. $\frac{1}{2} 0$ or 00312 of a mile. 5.02911 metres.

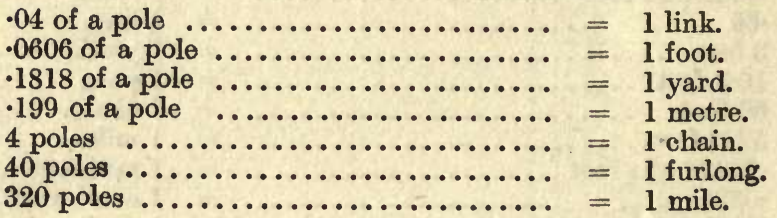

CHAIN TABLE.

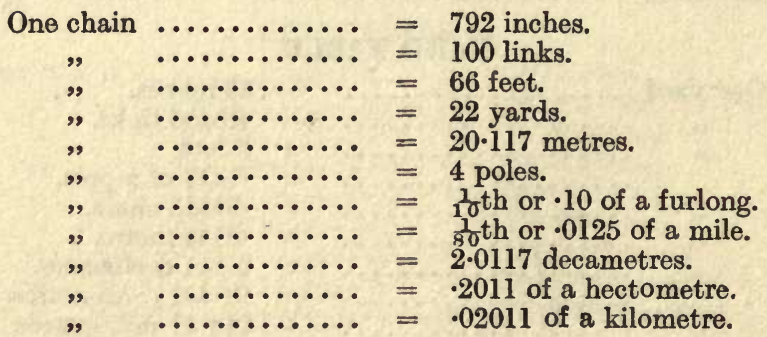


CHAIN TABLE.

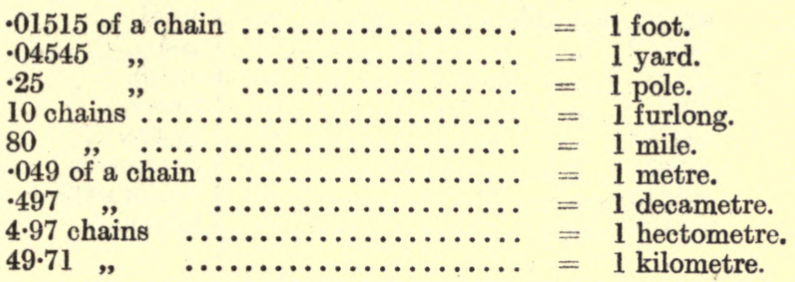

FURLONG TABLE.

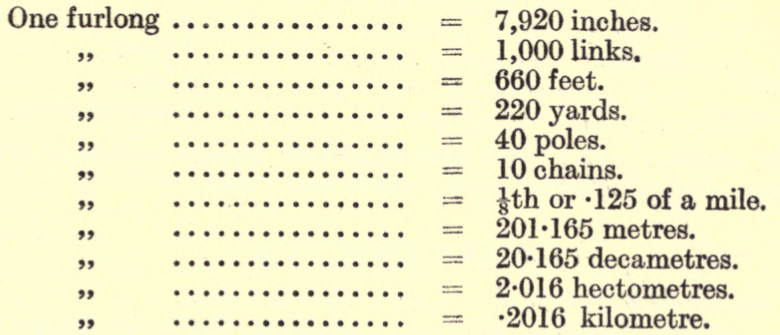

8 furlongs

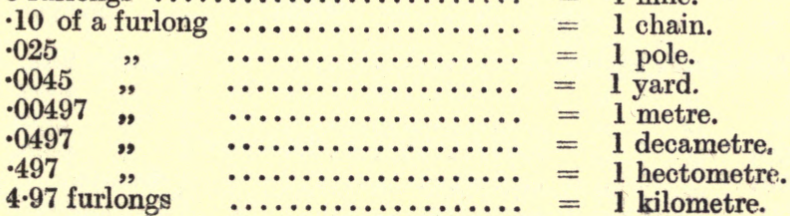

MILE TABLE.

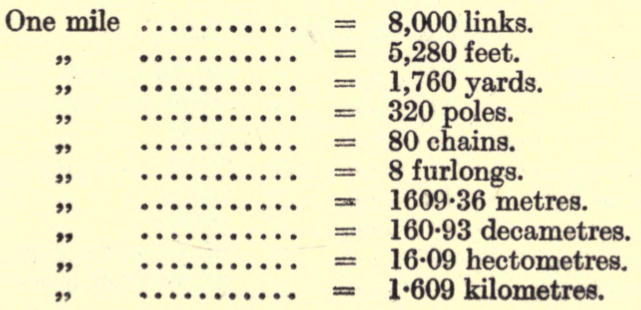




\section{MILE TABLE.}

\begin{tabular}{|c|c|c|c|c|}
\hline \multicolumn{2}{|c|}{.00057 of a mile } & & & rd. \\
\hline .00312 & & & $=$ & 1 pole. \\
\hline 012 & " & . $\ldots \ldots \ldots \ldots$ & $=$ & $1 \mathrm{c}$ \\
\hline$\cdot 12$ & ", & ....... & $=$ & ong. \\
\hline & " & ……...... & $=$ & 11 \\
\hline & & ... & $=$ & 1 \\
\hline & ", & & $=$ & 1 kilome \\
\hline
\end{tabular}

\section{MEASURES OF SURFACE.}

144 square inches

9 ", feet

$30_{4}^{1}$ " yards

40 " poles

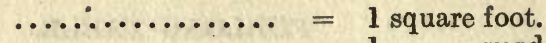

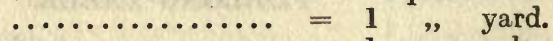

.............. $=1$ pole.

.............. 1 rood.

$$
\begin{aligned}
& \text {.................. }=1 \text { acre. }
\end{aligned}
$$

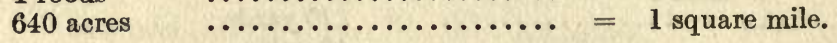

The square chain a tenth part of an acre, square links may readily be expressed in terms of acres, roods, and poles.

\section{SQUARE INCH TABLE.}

One square inch........$=016$ of a link.

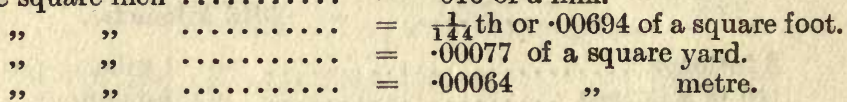

62.726 square inches $\ldots \ldots \ldots \ldots \ldots \ldots . .1$ square link.

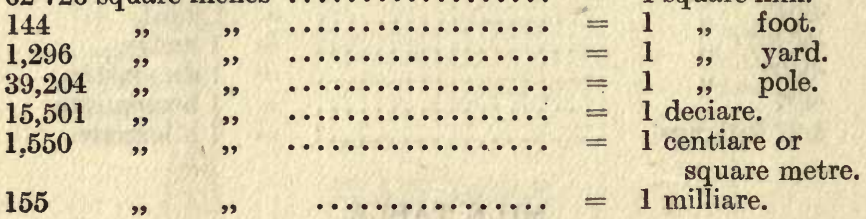

SQUARE LINK TABLE.

One square link

9
9
9
9
9

$=62 \cdot 726$ square inches.

$=.4356$ of a square foot.

$=.0485, "$, yard.

$=.0422, \quad, \quad$ metre.

$=.0001 \%$, chain.

$=.00004 \%$ rood.

$=.00001$ of an acre.

$=0000042$ of a hectare. 


\section{SQUARE LINK TABLE.}

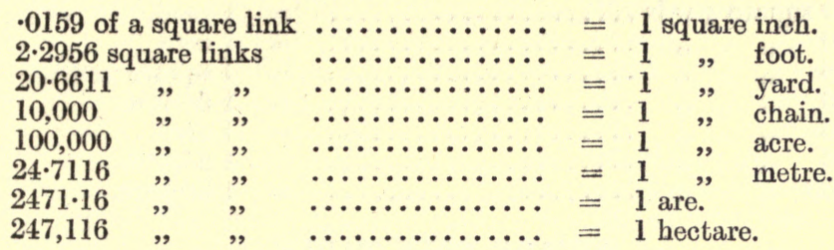

SQUARE FOOT TABLE.

One square foot ............ = 144 square inches.

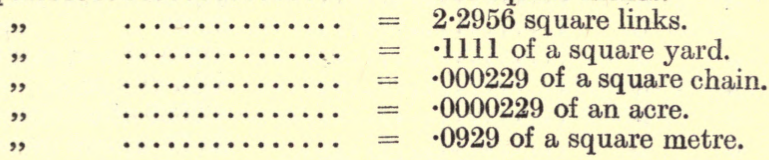

.00694 of a square foot $\ldots . \ldots \ldots \ldots \ldots . .=1$ square inch.

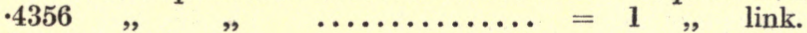

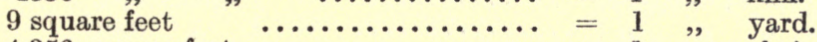
$4,3 \tilde{5} 6$ square feet $\ldots \ldots \ldots \ldots \ldots \ldots \ldots . .=1$, chain.

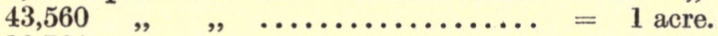

$10.764 \quad, \quad, \quad \ldots \ldots . . . . . . . . . .=1$ square metre.

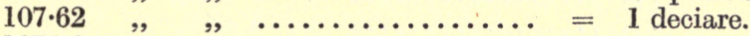

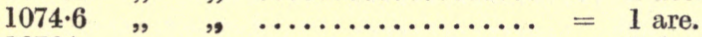

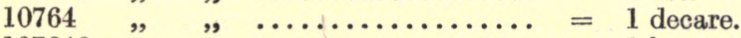

$107640 \quad, \quad, \quad \ldots \ldots \ldots \ldots \ldots \ldots \ldots . \ldots=1$ hectare.

\section{SQUARE YARD TABLE.}

One square yard $\ldots \ldots \ldots \ldots \ldots=1,296$ square inches.

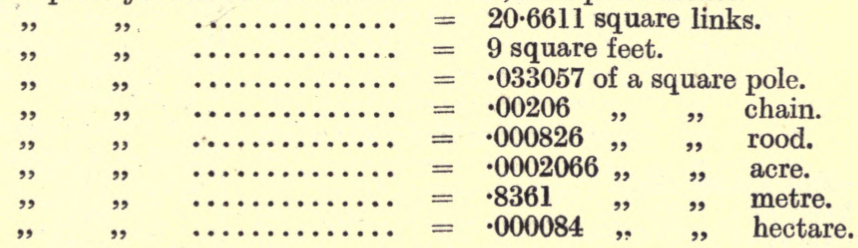

.00077 of a square yard............$=1$ square inch. $.0485 \% \quad " \quad \ldots . . . . . . . . . .=1 \%$ link.

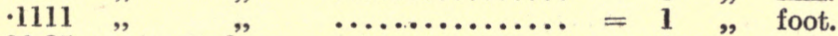

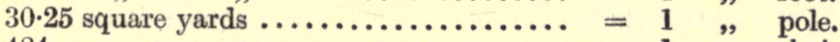
484 
SQUARE YARD TABLE.

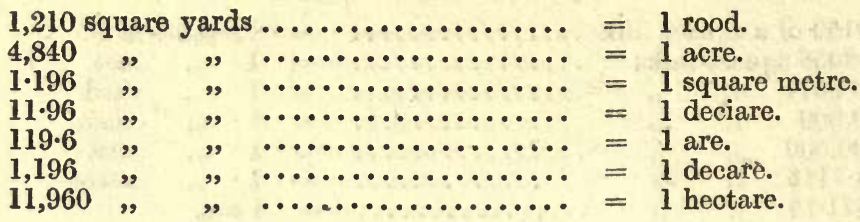

SQUARE POLE TABLE.

One square pole

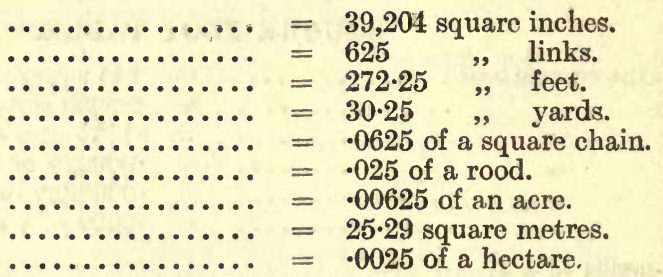

.0016 of a square pole ............. $.00367, ", \quad$ " $" . . . . . . . . .=1$, foot.

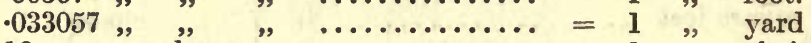
16 square poles ................. $=1$, chain. 40 160 "

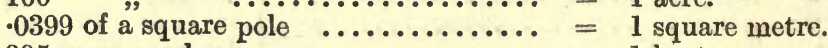
395 square poles

$=1$ hectare.

\section{SQUARE CHAIN TABLE.}

One square chain
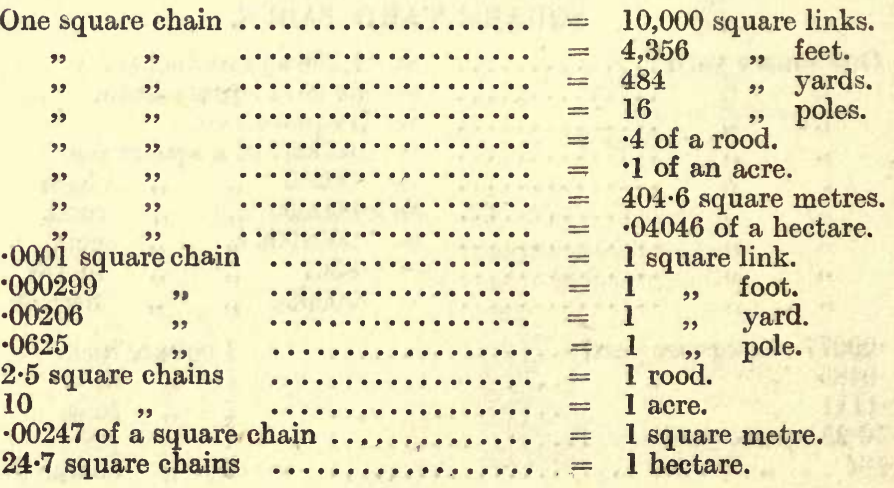
ROOD TABLE.

One rood

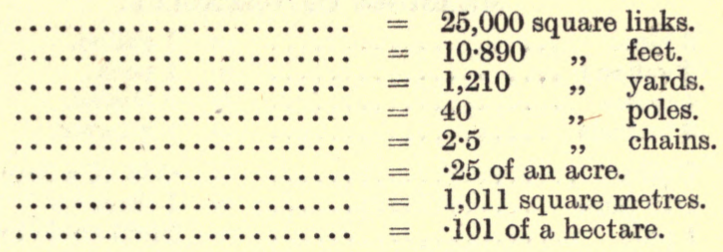

.00004 of a rood $\ldots \ldots \ldots \ldots \ldots \ldots \ldots . . .1$ square link.

$.0000918, "$ "............... $=1$ foot.

$.000826, ", \ldots \ldots \ldots \ldots \ldots \ldots \ldots \ldots \ldots \ldots \ldots .1 \%$ yard.

$.025 \quad " \quad, \quad \ldots \ldots \ldots \ldots \ldots \ldots \ldots . .1 \%$, pole.

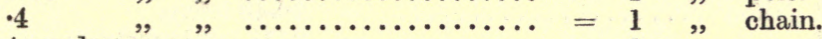

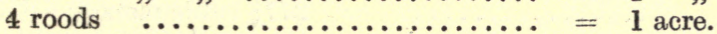

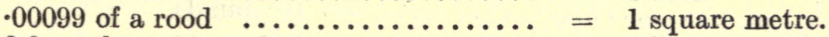

9.9 or about 10 roods $\ldots \ldots \ldots \ldots \ldots \ldots=1$ hectare.

ACRE TABLE.

One acre

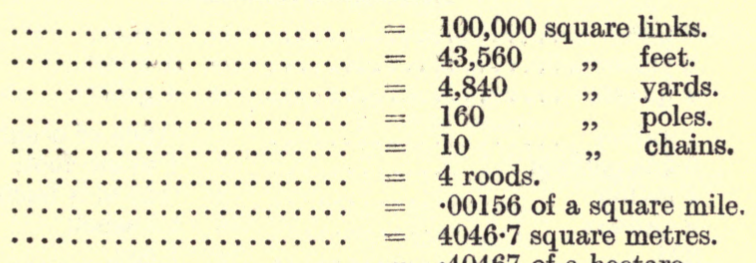

" $\quad$................. $=40467$ of a hectare.

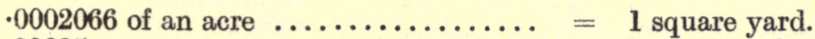

$.00625 \quad " \quad, \ldots \ldots \ldots \ldots \ldots \ldots \ldots=1 \%$ pole.

$\cdot 1 \quad, \quad, \quad \ldots \ldots \ldots \ldots \ldots \ldots \ldots=1$, chain.

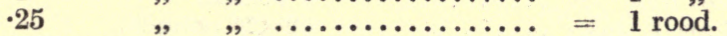

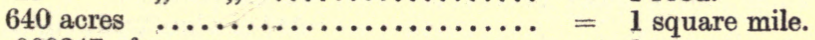

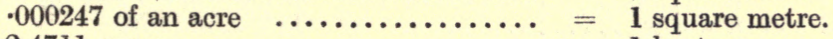

2.4711 acres

$=1$ hectare.

\section{SOLID OR CUBIC MEASURE.}

1,728 cubic inches $\ldots \ldots \ldots \ldots \ldots \ldots=1$ cubic foot.

27 cubic feet $\quad \ldots \ldots \ldots \ldots \ldots \ldots \ldots=1, y$. yard.

1 cubic inch $\quad$...............

$1, " \quad \ldots \ldots \ldots \ldots \ldots \ldots . . .16 .386$, centimetres.

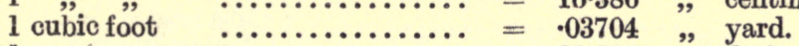

$1, " \quad \ldots \ldots \ldots \ldots \ldots \ldots . . .28 .315$, decimetres.

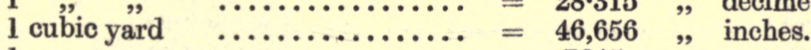

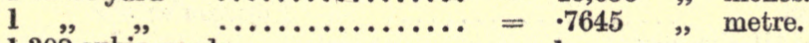

1.308 cubic yards $\ldots \ldots \ldots \ldots \ldots \ldots . ., "$ " $"$ 


\section{MEASURE OF CAPACITY.}

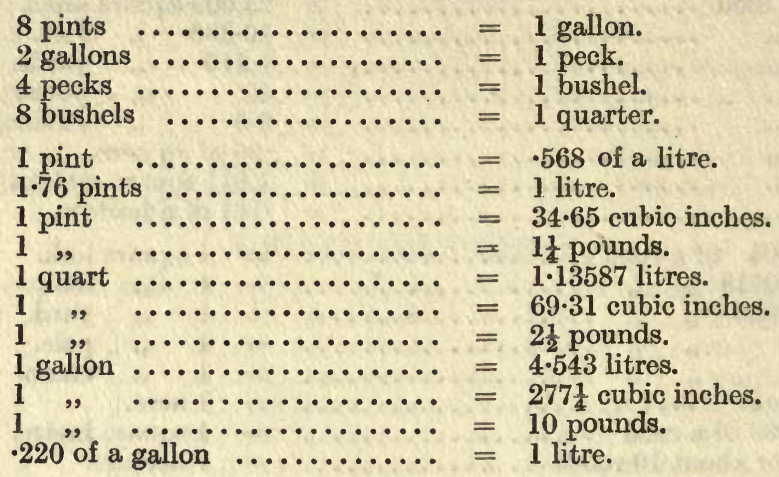

LIQUID MEASURE.

\begin{tabular}{|c|c|c|}
\hline 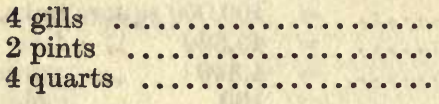 & $\begin{array}{l}= \\
= \\
=\end{array}$ & $\begin{array}{l}1 \text { pint. } \\
1 \text { quart. } \\
1 \text { gallon. }\end{array}$ \\
\hline 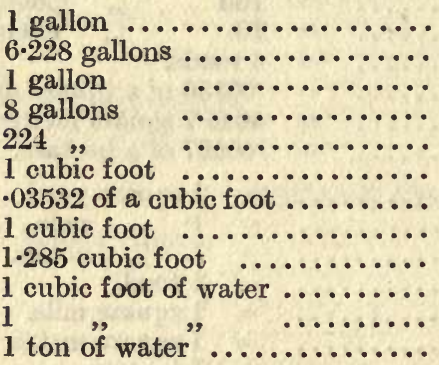 & $\begin{array}{l}= \\
= \\
= \\
= \\
= \\
= \\
= \\
= \\
= \\
= \\
=\end{array}$ & $\begin{array}{l}-1605 \text { of a cubic foot. } \\
1 \text { cubic foot. } \\
.125 \text { of a bushel. } \\
1 \text { bushel. } \\
1 \text { ton. } \\
28 \cdot 33 \text { litres. } \\
1 \text { litre. } \\
.778 \text { of a bushel. } \\
1 \text { bushel. } \\
62.425 \text { pounds. } \\
.557 \text { of a hundredweight. } \\
35.9 \text { cubic feet. }\end{array}$ \\
\hline
\end{tabular}

ANGULAR MEASURE.

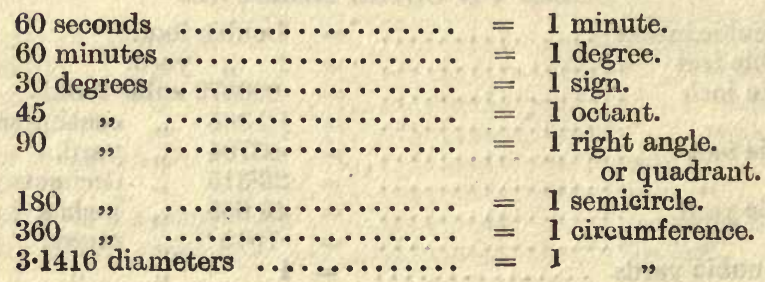




\section{AVOIRDUPOIS WEIGHT}

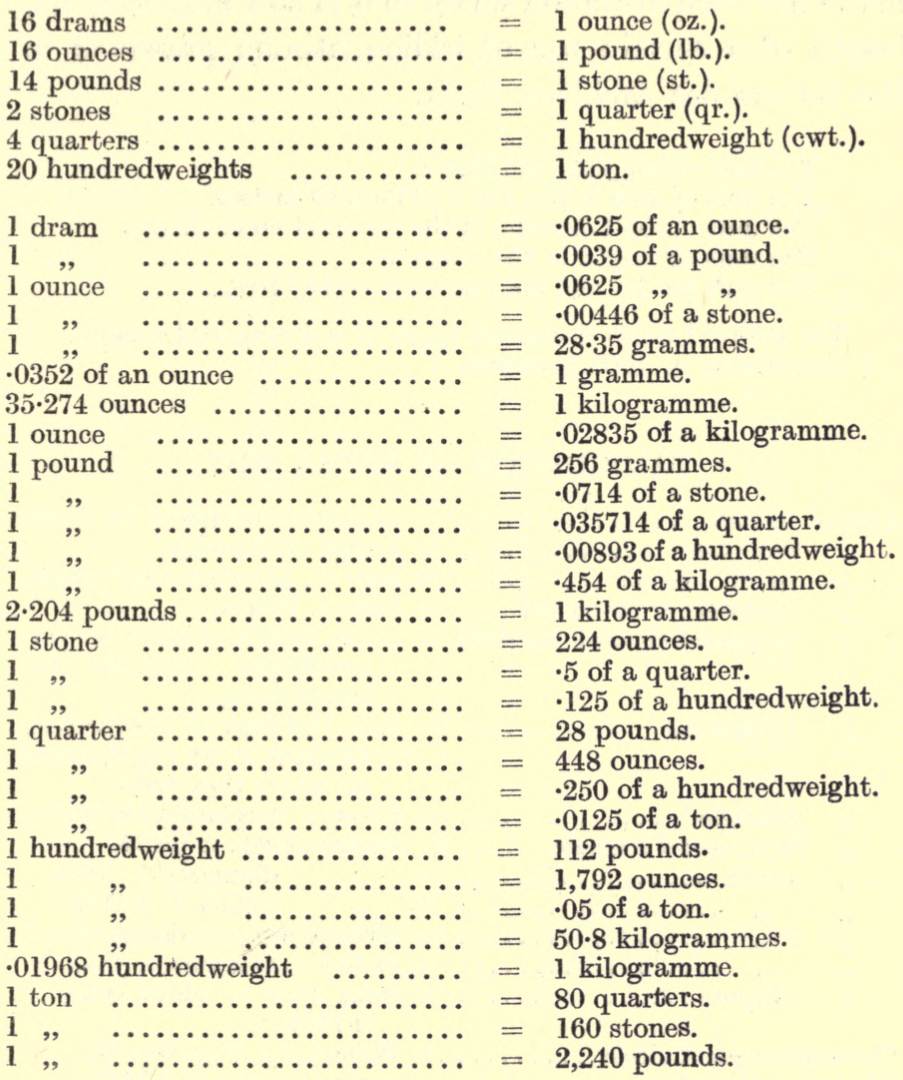

\section{METRIC SYSTEM.}

The metric system is based upon the "metre," which was originally intended to be equal to the one tenmillionth part of the distance from the pole to the equator. 
Subsequent measurements, however, prove that the metre has been made too small, so it is now defined as the length of a certain bar of iridio-platinum preserved in the Bureau des Archives, Paris.

The unit of length is the Metre.

The unit of area is the Are $=100$ square metres.

The unit of solid measure is the Stere $=1$ cubic metre.

The unit of weight is the Gramme.

The unit for dry and fluid measure is the Litre.

The litre $=1$ cubic decimetre ( $\frac{1}{10}$ th of a metre) and weighs 1 kilogramme $=1000$ grammes.

CALCULATION OF AREAS, ETC.

Area of square $\ldots \ldots \ldots \ldots \ldots \ldots=$ any side multiplied by itself.

" rectangle $. . . \ldots \ldots \ldots . .$. . length $\times$ breadth.

" parallelogram ......... = base $\times$ perpendicular height.

$"$ rhombus or rhomboid ... = base $\times$ height.

$" \quad$ trapezoid $(2$ sides parallel $)=$ mean length of sides $\times$ perpendicular distance between them.

trapezium

$=$ half the sum of the perpen. diculars $x$ by the diagonal on which they fall.

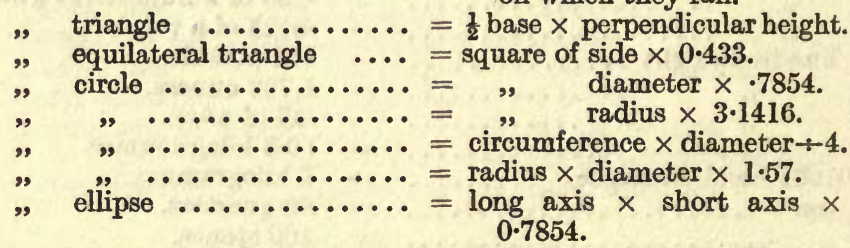

Circumference of circle $\ldots \ldots \ldots .=$ diameter $\times 3.1416$ or ${ }^{22}$.

Diameter of circle $\quad . . \ldots \ldots . .=$ circumference $\times 0.3183$.

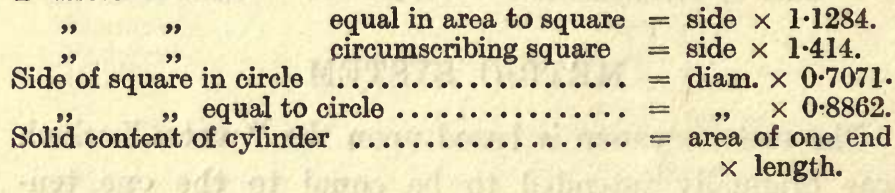




\section{FENCING NOTES.}

WIRE GAUGES AND LENGTHS PER CWT.

\begin{tabular}{|c|c|c|c|}
\hline $\begin{array}{c}\text { Gauge } \\
\text { Number. }\end{array}$ & Gauge. & $\begin{array}{c}\text { Strand Wire. } \\
\text { Number of Yards } \\
\text { per Cwt. }\end{array}$ & $\begin{array}{c}\text { Plain Wire. } \\
\text { Number of Yards } \\
\text { per Cwt. }\end{array}$ \\
\hline $\begin{array}{r}1 \\
2 \\
3 \\
4 \\
5 \\
6 \\
7 \\
8 \\
9 \\
10 \\
11 \\
12 \\
13 \\
14 \\
15 \\
16 \\
17 \\
18 \\
36\end{array}$ & 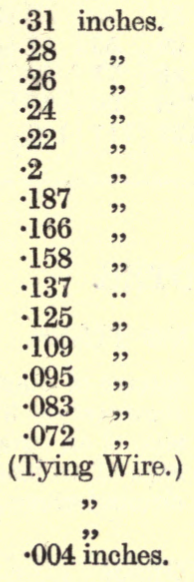 & $\begin{array}{l}155 \text { yards. } \\
183 \text { " } \\
220 \text { " } \\
260 \text { " } \\
311 \text { " } \\
380 \text { " } \\
452 \text { " } \\
546 \text { " } \\
675 \text { " } \\
854 \quad "\end{array}$ & 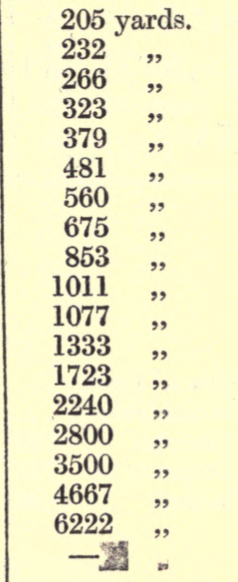 \\
\hline
\end{tabular}

Barb wire, barbs 6 inches apart, 2-ply, 560 yards per cwt.

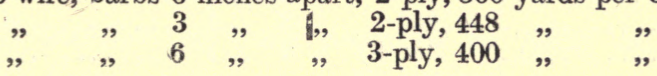

USUAL GAUGES OF NETTING STAPLES.

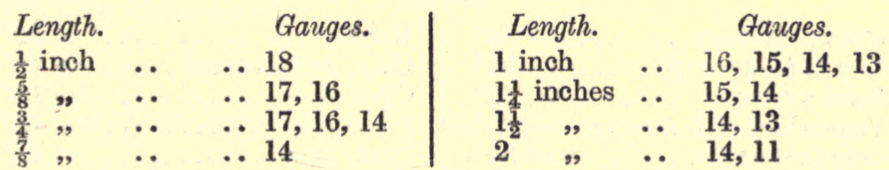


NUMBER OF WIRE NAILS PER POUND.

\begin{tabular}{|c|c|c|c|c|c|c|c|c|c|c|c|c|}
\hline Size. & $\mid \begin{array}{c}\text { Gauge } \\
\text { Number } \\
\text { of Wire. }\end{array}$ & $1^{\prime \prime}$ & $1 \frac{1}{2}^{\prime \prime}$ & $2^{\prime \prime}$ & $\left.2 \frac{1}{2}\right)^{\prime \prime}$ & $3^{\prime \prime}$ & $3 \frac{1}{2}{ }^{\prime \prime}$ & $4^{\prime \prime}$ & $5^{\prime \prime}$ & $6^{\prime \prime}$ & $7^{\prime \prime}$ & $8^{N}$ \\
\hline 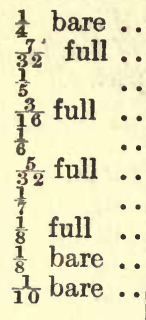 & $\begin{array}{r}3 \\
4 \\
5 \\
6 \\
7 \\
8 \\
9 \\
10 \\
11 \\
12\end{array}$ & $\begin{array}{r}76 \\
90 \\
106 \\
123 \\
149 \\
172 \\
207 \\
248 \\
314 \\
411\end{array}$ & $\begin{array}{r}50 \\
60 \\
71 \\
82 \\
100 \\
115 \\
138 \\
165 \\
209 \\
274\end{array}$ & $\begin{array}{r}38 \\
45 \\
53 \\
62 \\
75 \\
86 \\
103 \\
124 \\
157 \\
205\end{array}$ & $\begin{array}{r}30 \\
36 \\
42 \\
50 \\
60 \\
69 \\
82 \\
99 \\
125 \\
164\end{array}$ & $\begin{array}{r}25 \\
30 \\
35 \\
41 \\
50 \\
57 \\
69 \\
83 \\
105 \\
137\end{array}$ & $\begin{array}{r}22 \\
26 \\
30 \\
35 \\
43 \\
49 \\
59 \\
71 \\
90 \\
117\end{array}$ & $\begin{array}{r}19 \\
23 \\
26 \\
31 \\
37 \\
43 \\
52 \\
62 \\
79 \\
103\end{array}$ & $\begin{array}{l}15 \\
18 \\
21 \\
25 \\
30 \\
35 \\
41 \\
50 \\
- \\
-\end{array}$ & $\begin{array}{l}13 \\
15 \\
18 \\
21 \\
25 \\
29 \\
- \\
- \\
-\end{array}$ & $\begin{array}{l}11 \\
13 \\
15 \\
18 \\
- \\
- \\
- \\
- \\
-\end{array}$ & $\begin{array}{l}10 \\
11 \\
- \\
- \\
- \\
- \\
- \\
-\end{array}$ \\
\hline
\end{tabular}

\section{DRAINING NOTES.}

\section{NOTES $R E$ DRAINING TILES.}

Area of circle $\ldots \ldots \ldots \ldots \ldots \ldots=$ square of diameter $\times \cdot \mathbf{7 8 5 4}$.

Circumference $. . \ldots \ldots \ldots \ldots \ldots . .6$ diameter $\times 3.14159$.

Diameter $\times \cdot 8862 \ldots \ldots \ldots \ldots=$ side of an equal square.

Diameter $\times \cdot 7071 \ldots \ldots \ldots \ldots=$ side of an inscribed square.

Radius $\times 6.28318 \ldots \ldots \ldots=$ circumference.

\section{ANGLES OF SLOPES}
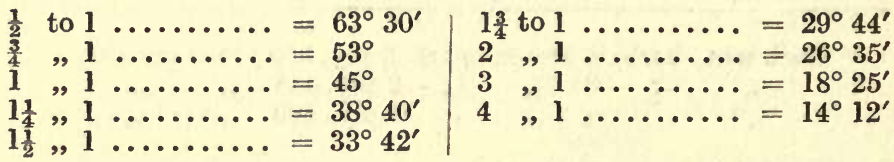

\section{NATURAL SLOPES OF EARTH WITH HORIZONTAL} LINE.

Gravel average $\ldots \ldots \ldots=40^{\circ}$ Dry Sand average ..... $=38^{\circ}$ Sand average $\ldots . . .=22^{\circ}$ Vegetable earth average $=28^{\circ}$ Compact earth ....... $=50^{\circ}$ Shingle ............ $=39^{\circ}$
Rubble ............ $=45^{\circ}$

Clay, well drained ..... $=45^{\circ}$

Clay, wet .......... $=16^{\circ}$

Peat, loose .......... $=15^{\circ}$

Peat, firm ......... $=45^{\circ}$ 


\section{DEPTH OF DRAINS.}

Stiff clay $\ldots \ldots \ldots \ldots \ldots \ldots .2$ feet 6 inches deep. 15 feet apart.

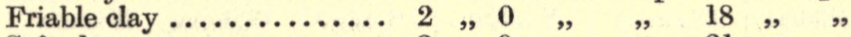

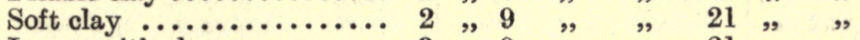

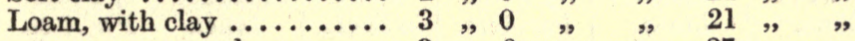

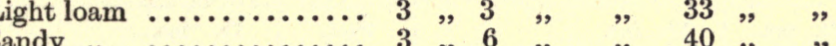

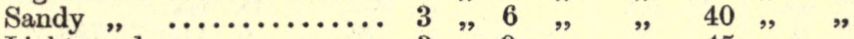

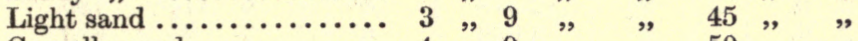

Gravelly sand $\ldots \ldots \ldots \ldots \ldots .4 \quad, \quad 0 \quad, \quad, \quad 50, \quad$,

NUMBER OF 12-INCH PIPES REQUIRED PER ACRE AT DIFFERENT DISTANCES BETWEEN DRAINS.

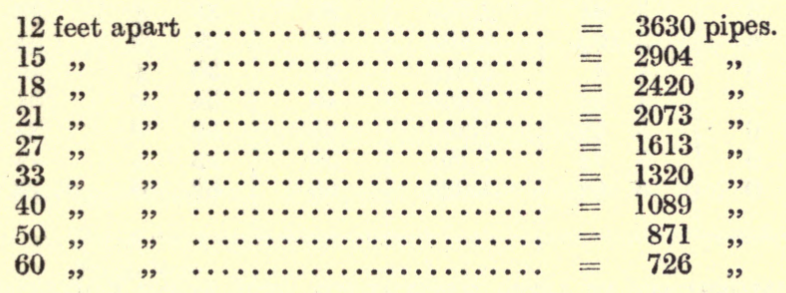

\section{PLANTATION TABLES AND NOTES.}

PLANTING IN SQUARES.

To find number of trees required to plant an acre: Divide the square feet in an acre $(43,560)$ by the square of the distance apart of the plants in feet for instance $\frac{43,560}{6 \times 6}=1,210$ trees.

Quincunx $=$ double the number. 
DISTANCE BETWEEN LINES IN EQUILATERAL TRIANGLE PLANTING AND NUMBER OF PLANTS PER ACRE.

\begin{tabular}{|c|c|c|c|c|c|c|c|}
\hline \multicolumn{2}{|c|}{$\begin{array}{c}\text { Distance } \\
\text { Apart in } \\
\text { Lines. }\end{array}$} & $\begin{array}{l}\text { Distance } \\
\text { between } \\
\text { Lines. }\end{array}$ & $\begin{array}{l}\text { Number } \\
\text { of Trees } \\
\text { Per Acre. }\end{array}$ & \multirow{2}{*}{$\begin{array}{c}\text { Distance } \\
\text { Apart } \\
\text { in Lines. }\end{array}$} & \multicolumn{2}{|c|}{$\begin{array}{c}\text { Distance } \\
\text { Between } \\
\text { Lines. }\end{array}$} & $\begin{array}{l}\text { Number } \\
\text { of Trees } \\
\text { Per Acre. }\end{array}$ \\
\hline Ft. & ins. & Ft. ins. & & & Ft. & ins. & \\
\hline $\begin{array}{l}2 \\
2\end{array}$ & $\begin{array}{l}0 \\
6\end{array}$ & $\begin{array}{ll}1 & 83 \\
2 & 2\end{array}$ & $\begin{array}{r}12,578 \\
8049\end{array}$ & 8 & $\begin{array}{l}6 \\
7\end{array}$ & $\begin{array}{r}11 \frac{1}{4} \\
01\end{array}$ & 785 \\
\hline 3 & 0 & 271 & 5,590 & 10 & 8 & 8 & 502 \\
\hline 3 & 3 & $29 \frac{3}{4}$ & 4,763 & 11 & 9 & $6 \frac{1}{2}$ & 416 \\
\hline 3 & 6 & $\begin{array}{ll}3 & 0 \frac{4}{4}\end{array}$ & 4,106 & 12 & 10 & $5^{2}$ & 349 \\
\hline 3 & 9 & $33^{2}$ & 3,577 & 15 & 13 & 0 & 223 \\
\hline 4 & 0 & $\begin{array}{ll}3 & 5 \frac{1}{2}\end{array}$ & 3,144 & 20 & 17 & 4 & 125 \\
\hline 4 & 3 & $38 \frac{1}{4}$ & 2,785 & 25 & 21 & 8 & 80 \\
\hline 4 & 6 & $310 \frac{3}{4}$ & 2,484 & 30 & 26 & 0 & 55 \\
\hline 5 & 0 & $44^{4}$ & 2,012 & 35 & 30 & 4 & 40 \\
\hline 5 & 6 & $49 \frac{1}{4}$ & 1,663 & 40 & 34 & 8 & 31 \\
\hline 6 & 0 & $5 \quad 2 \frac{1}{2}$ & 1,398 & 45 & 39 & 0 & 24 \\
\hline 6 & 6 & $5 \quad 7 \frac{1}{2}$ & 1,191 & 50 & 43 & 4 & 19 \\
\hline 7 & 0 & $60 \frac{3}{4}$ & 1,026 & 60 & 52 & 0 & 13 \\
\hline
\end{tabular}

NUMBER OF PLANTS REQUIRED PER ACRE SQUARE PLANTING.

\begin{tabular}{c|c|c|c}
\hline Feet Apart. & Number of Plants. & Feet A part. & Number of Plants. \\
\hline 1 & 43,560 & 7 & 888 \\
$1 \frac{1}{2}$ & 19,360 & $7 \frac{1}{2}$ & 775 \\
2 & 10,890 & 8 & 680 \\
$2 \frac{1}{2}$ & 6,969 & $8 \frac{1}{2}$ & 602 \\
3 & 4,840 & 9 & 537 \\
$3 \frac{1}{4}$ & 4,124 & 10 & 435 \\
$3 \frac{1}{2}$ & 3,555 & 11 & 360 \\
$3 \frac{3}{4}$ & 3,097 & 12 & 302 \\
4 & 2,722 & 15 & 193 \\
$4 \frac{1}{2}$ & 2,151 & 20 & 108 \\
5 & 1,742 & 25 & 69 \\
$5 \frac{1}{2}$ & 1,440 & 30 & 48 \\
6 & 1,210 & 35 & 35 \\
$6 \frac{1}{2}$ & 1,031 & 40 & 27 \\
\hline
\end{tabular}


NUMBER OF PLANTS PER ACRE IN LINE PLANTING.

\begin{tabular}{|c|c|c|c|}
\hline $\begin{array}{c}\text { Distance } \\
\text { Between Lines. }\end{array}$ & $\begin{array}{c}\text { Distance } \\
\text { Between Plants } \\
\text { in Lines. }\end{array}$ & Growing Space. & $\begin{array}{c}\text { Number of } \\
\text { Plants } \\
\text { Per Acre. }\end{array}$ \\
\hline $\begin{array}{l}4 \text { feet } \\
5 \quad " \\
5 \\
6 \quad " \\
6 \quad " \\
7 \\
7 \\
7 \Rightarrow\end{array}$ & $\begin{array}{l}3 \text { feet } \\
3 \quad, \\
4 \quad, \\
4 \quad, \\
5 \quad, \\
4 \quad, \\
5 \quad, \\
6 \quad,\end{array}$ & $\begin{array}{l}12 \text { feet } \\
15 ", \\
20 ", \\
24 ", \\
30 ", \\
28 ", \\
35 " \\
42 ",\end{array}$ & $\begin{array}{l}3,630 \\
2,904 \\
2,178 \\
1,815 \\
1,452 \\
1,555 \\
1,244 \\
1,037\end{array}$ \\
\hline
\end{tabular}

\section{LIST OF INSECTICIDES.}

Bordeaux Mixture. For plant diseases caused by fungi.

Copper sulphate (bluestone) $\ldots \ldots \ldots \ldots \ldots, 1$ pound.

Fresh lime ...................... 1

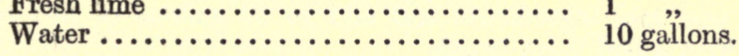

Slake 1 pound of lime in 1 gallon of water and 1 pound of bluestone in 1 gallon and add to 10 gallons of water, mix well, strain through fine sieve, and spray trees affected.

Combination Bordeaux Mixture and Paris Green. Spray against fungi and leaf-eating insects.

Copper sulphate .......... 4 level tablespoonfuls.

Quicklime ............... 4 ,"

Paris green .............., 1 , ,

Water $. . \ldots \ldots \ldots \ldots \ldots \ldots, 2$ gallons.

Prepare like Bordeaux mixture and stir in Paris green before spraying.

Paris Green, Dry. Dust on leaf-eating insects.

Paris green ................... 1 pound.

Flour or other dust ............... 100 pounds.

Mix thoroughly. 
Paris Green, Liquid. Spray for leaf-eating insects.

Paris green ................... 1 pound.

Water ................... 150 gallons.

Lime (fresh slaked) $\ldots \ldots \ldots \ldots \ldots \ldots 2$ pounds.

Lime-Sulphur Wash. Spray for scale.

Fresh lime

10 pounds.

Flowers of sulphur

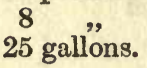

Slake lime with some of the water, gradually stir in sulphur Boil with fire, stirring frequently, until colour is dark orange. Strain through fine mesh wire into spray pump. Apply to trees before leaves open.

Paraffin, Sulphur, Turpentine, and Soft Soap. Mixture for scale

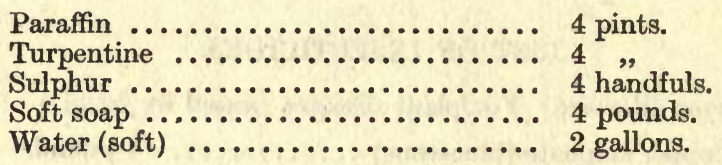

Boil and mix ingredients and add to 16 gallons of soft water Apply with a stiff paint-brush.

Paraffin with Soap. For aphides.

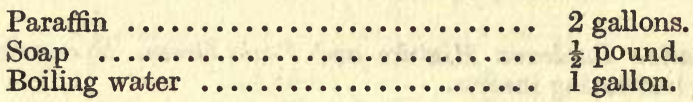

Dissolve soap in water, add paraffin and stir for 10 minutes. Dilute with 30 gallons of water.

Pyrethrum Mixture. For slugs, etc.

Insect powder ................. 1 ounce.

Flour $. . \ldots \ldots \ldots \ldots \ldots \ldots \ldots \ldots, 5$ ounces. bed.

Mix thoroughly, let stand, dust on plants or lay in lines round 


\section{NURSERY NOTES.}

NUMBER OF PLANTS IN NURSERY LINES PER SQUARE YARD AT GIVEN DISTANCES.

\begin{tabular}{|c|c|c|c|c|c|}
\hline $\begin{array}{l}\text { Distance } \\
\text { Apart. }\end{array}$ & $\begin{array}{c}\text { Number } \\
\text { Per Sq. } \\
\text { Yard. }\end{array}$ & $\begin{array}{c}\text { Distance } \\
\text { Apart. }\end{array}$ & $\begin{array}{c}\text { Number } \\
\text { Per Sq. } \\
\text { Yard. }\end{array}$ & $\begin{array}{c}\text { Distance } \\
\text { Apart. }\end{array}$ & $\begin{array}{c}\text { Number } \\
\text { Per Sq. } \\
\text { Yard. }\end{array}$ \\
\hline Inches. & & Inches. & & Inches, & \\
\hline $2 \times 6$ & 108 & $3 \times 6$ & 72 & $6 \times 12$ & 18 \\
\hline $2 \times 7$ & 92 & $3 \times 8$ & 54 & $9 \times 12$ & 12 \\
\hline $2 \times 8$ & 81 & $3 \times 10$ & 43 & $9 \times 18$ & 8 \\
\hline $2 \times 9$ & 72 & $3 \times 12$ & 36 & $12 \times 12$ & 9 \\
\hline $2 \times 10$ & 65 & $3 \times 14$ & 30 & $18 \times 18$ & 4 \\
\hline $2 \times 11$ & 59 & $4 \times 8$ & 40 & $18 \times 36$ & 2 \\
\hline $2 \times 12$ & 54 & $4 \times 10$ & 32 & - & - \\
\hline $2 \times 14$ & 46 & $4 \times 12$ & 27 & - & - \\
\hline
\end{tabular}

\section{TIMBER NOTES.}

TIMBER MEASURE.

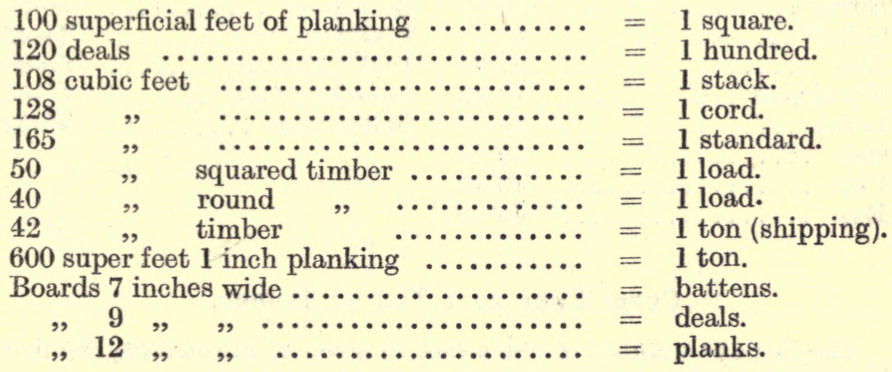

AVERAGE COMPOSITION OF DRY WOOD.

Carbon .............. 50 per cent.

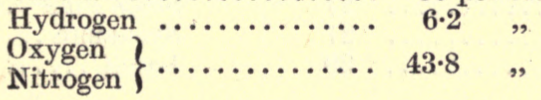

Moisture in freshly felled timber ........... 25 to 60 per cent. Moisture in air dried timber $\ldots \ldots \ldots \ldots \ldots 10$ to 20 per cent. 


\section{MEASURING TIMBER.}

Quarter Girth.-Square the $\frac{1}{4}$ girth, multiply by length and divide by $144=$ total number of cubic feet in log.

True Contents. - Square the $\frac{1}{4}$ girth, multiply by length and divide by 113; or multiply the area by the length and divide by 144 .

To convert $\frac{1}{4}$ girth measurements to true contents, multiply by 100 and divide by 78.6 .

To convert true contents to $\frac{1}{4}$ girth, multiply by 78.6 and divide by 100 .

\section{TIMBER WEIGHTS.}

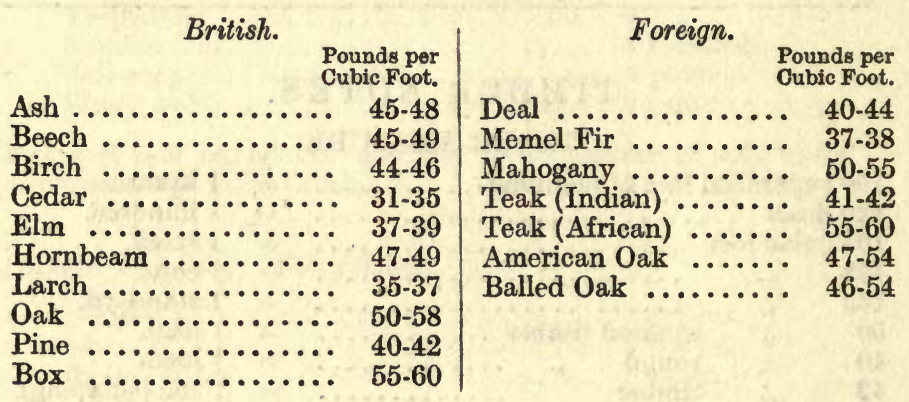

\section{Cubic Fret to 1 Ton of Timber.}

The average number of cubic feet to a ton of unconverted timber is as follows:

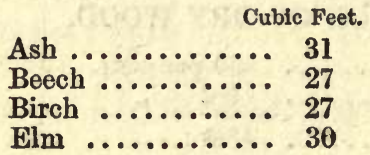
Cubic Feet.
Oak .......... 24
Scots Pine ....... 28
Sycamore ........ 26
Larch .......... 32

About 45 per cent. of the total weight of unseasoned timber consists of water. 
AREAS OF QUARTER GIRTHS.

\begin{tabular}{|c|c|c|c|c|c|}
\hline $\begin{array}{l}\text { Quarter } \\
\text { Girth. }\end{array}$ & Area. & $\begin{array}{l}\text { Quarter } \\
\text { Girth. }\end{array}$ & Area. & $\begin{array}{l}\text { Quarter } \\
\text { Girth. }\end{array}$ & Area. \\
\hline $\begin{array}{l}6 \\
61 \\
6 \frac{1}{2} \\
6 \frac{1}{4} \\
7 \\
7 \frac{1}{4} \\
7 \frac{1}{2} \\
7 \frac{1}{4} \\
8 \\
8 \frac{1}{4} \\
8 \frac{1}{2} \\
8 \frac{3}{4} \\
9 \\
9 \frac{1}{4} \\
9 \frac{1}{2} \\
9 \frac{3}{4} \\
10 \\
10 \frac{1}{10} \\
10 \frac{1}{2} \\
11 \\
11 \frac{1}{4} \\
11 \frac{1}{2}\end{array}$ & $\begin{array}{c}.250 \text { or } \frac{1}{4} \\
.2722 \\
.294 \\
.317 \\
.340 \text { or } \frac{1}{3} \\
.364 \\
.390 \\
.417 \\
.444 \\
.472 \\
.501 \text { or } \frac{1}{2} \\
.531 \\
.562 \\
.594 \\
.626 \\
.659 \\
.694 \text { or } \frac{2}{3} \\
.730 \\
.766 \\
.803 \\
.840 \\
.878 \\
.918\end{array}$ & $\begin{array}{l}11 \frac{3}{4} \\
12 \\
12 \frac{1}{4} \\
122 \\
12 \frac{1}{4} \\
13 \\
13 \frac{1}{13} \\
13 \frac{1}{2} \\
13 \frac{3}{4} \\
14 \\
14 \frac{1}{14} \\
14 \frac{1}{2} \\
14 \frac{3}{4} \\
15 \\
15 \frac{1}{4} \\
15 \frac{1}{2} \\
16 \frac{3}{4} \\
16 \frac{1}{2} \\
166 \\
17 \\
17 \frac{3}{4} \\
17 \frac{1}{2}\end{array}$ & $\begin{array}{c}.959 \\
1.000 \\
1.042 \\
1.085 \\
1.129 \\
1.174 \text { or } 1 \frac{1}{6} \\
1.219 \\
1.265 \text { or } 11 \\
1.313 \\
1.361 \\
1.410 \\
1.460 \\
1.511 \text { or } 1 \frac{1}{2} \\
1.5662 \\
1.615 \\
1.668 \\
1.722 \\
1.777 \text { or } 1 \frac{3}{4} \\
1.890 \\
1.948 \\
2.006 \text { or } 2 \\
2.086 \\
2.126\end{array}$ & $\begin{array}{l}17 \frac{3}{4} \\
18 \\
18 \frac{1}{2} \\
19 \\
19 \frac{1}{2} \\
20 \\
20 \frac{1}{2} \\
21 \\
21 \frac{1}{2} \\
22 \\
22 \frac{1}{2} \\
23 \\
23 \frac{1}{2} \\
24 \\
25 \\
= \\
= \\
= \\
= \\
=\end{array}$ & $\begin{array}{c}2 \cdot 187 \\
2 \cdot 250 \text { or } 21 \\
2 \cdot 376 \\
2 \cdot 506 \text { or } 2 \frac{1}{2} \\
2 \cdot 640 \\
2 \cdot 777 \\
2 \cdot 917 \\
3 \cdot 062 \text { or } 3 \\
3 \cdot 209 \\
3 \cdot 362 \\
3 \cdot 516 \text { or } 3 \frac{1}{2} \\
3 \cdot 673 \\
3 \cdot 835 \\
4 \cdot 000 \text { or } 4 \\
4 \cdot 340 \\
= \\
= \\
= \\
= \\
=\end{array}$ \\
\hline
\end{tabular}

To find contents of a tree, multiply length by area of quarter girth. Example:

Tree 18 feet long $\times 25$ inches quarter girth $=18 \times 4 \cdot 340=78 \cdot 120$ feet. 
AREAS AND CIRCUMFERENCES OF CIRCLES.

\begin{tabular}{|c|c|c|c|c|c|}
\hline Diameter. & $\begin{array}{l}\text { Circum- } \\
\text { ference. }\end{array}$ & $\begin{array}{l}\text { Area. } \\
\text { Square } \\
\text { Inches. }\end{array}$ & Diameter. & $\begin{array}{l}\text { Circum- } \\
\text { ference. }\end{array}$ & Area. \\
\hline 2 & $6 \cdot 2831$ & $3 \cdot 1416$ & 17 & $53 \cdot 407$ & 226.98 \\
\hline $2 \frac{1}{2}$ & $7 \cdot 8539$ & 4.9087 & 18 & $56 \cdot 548$ & $254 \cdot 47$ \\
\hline 3 & $9 \cdot 4247$ & 10.9956 & 19 & $59 \cdot 690$ & 283.53 \\
\hline 4 & $12 \cdot 5664$ & $12 \cdot 566$ & 20 & $62 \cdot 831$ & $314 \cdot 16$ \\
\hline $4 \frac{1}{2}$ & $14 \cdot 1372$ & 15.904 & 21 & $65 \cdot 973$ & $346 \cdot 36$ \\
\hline 5 & $15 \cdot 7080$ & $19 \cdot 635$ & 22 & $69 \cdot 115$ & $380 \cdot 13$ \\
\hline $5 \frac{1}{2}$ & $17 \cdot 2788$ & $23 \cdot 758$ & 23 & $72 \cdot 256$ & $415 \cdot 48$ \\
\hline 6 & $18 \cdot 8496$ & $28 \cdot 274$ & 24 & $75 \cdot 398$ & $452 \cdot 39$ \\
\hline $6 \frac{1}{2}$ & $20 \cdot 4240$ & $33 \cdot 183$ & 25 & 78.539 & $490 \cdot 87$ \\
\hline 7 & 21.991 & $38 \cdot 485$ & 26 & $81 \cdot 681$ & 530.93 \\
\hline $7 \frac{1}{2}$ & $23 \cdot 561$ & $44 \cdot 179$ & 27 & $84 \cdot 823$ & $\mathbf{5 7 2 . 5 6}$ \\
\hline 8 & $25 \cdot 327$ & $50 \cdot 265$ & 28 & $87 \cdot 964$ & $615 \cdot 75$ \\
\hline $8 \frac{1}{2}$ & $26 \cdot 703$ & $56 \cdot 745$ & 29 & $91 \cdot 106$ & 660.52 \\
\hline 9 & $28 \cdot 274$ & $63 \cdot 617$ & 30 & $94 \cdot 247$ & $706 \cdot 86$ \\
\hline $9 \frac{1}{2}$ & $29 \cdot 845$ & $70 \cdot 882$ & 31 & $97 \cdot 389$ & $754 \cdot 77$ \\
\hline $10^{\circ}$ & $31 \cdot 416$ & $78 \cdot 540$ & 32 & $100 \cdot 531$ & $804 \cdot 25$ \\
\hline $10 \frac{1}{2}$ & $32 \cdot 986$ & $86 \cdot 590$ & 33 & $103 \cdot 673$ & $855 \cdot 30$ \\
\hline $11^{2}$ & $34 \cdot 557$ & $95 \cdot 033$ & 34 & $106 \cdot 814$ & $907 \cdot 92$ \\
\hline $11 \frac{1}{2}$ & $36 \cdot 128$ & $103 \cdot 87$ & 35 & 109.956 & $962 \cdot 11$ \\
\hline 12 & $37 \cdot 699$ & $113 \cdot 10$ & 36 & 113.097 & $1017 \cdot 9$ \\
\hline 13 & $40 \cdot 840$ & 132.73 & 37 & $116 \cdot 239$ & $1075 \cdot 2$ \\
\hline 14 & 43.982 & 153.94 & 38 & $119 \cdot 381$ & $1134 \cdot 1$ \\
\hline 15 & $47 \cdot 123$ & $176 \cdot 71$ & 39 & $122 \cdot 522$ & $1194 \cdot 6$ \\
\hline 16 & $50 \cdot 265$ & $201 \cdot 06$ & 40 & $125 \cdot 664$ & $1256 \cdot 6$ \\
\hline
\end{tabular}


TECHNICAL PROPERTIES OF TIMBER.

Durability (according to Gayer).

Most durable: Pedunculate Oak, resinous Larch, resinous Scots Pine, Sessile Oak, Black Pines, Acacia, Sweet Chestnut, Elm.

Durable: Ash, Larch grown at low elevations, Scots Pine of quick growth with small summer zones of wood and less resinous, Spruce from lofty elevations, silver Fir.

Least durable: Conifers of very rapid growth and poor in resin, Beech, Hornbeam, Maple and Sycamore, Alder, Birch, Aspen, Lime, Weymouth Pine, Poplar, Willow.

Hardness (Nördlinger).

Very hard: Boxwood, Hawthorn, Blackthorn.

Hard : Acacia, Maple, Sycamore, Hornbeam, Pedunculate Oak.

Moderately hard: Ash, Plane, Elm, Beech, Sessile Oak.

Soft : Spruce, Silver Fir, Alder, Horse Chestnut, Birch, Larch, Austrian Pine, Scots Pine, Sallow.

Very soft: Weymouth Pine, all Poplars, most Willows, Lime.

Utility as firewood (Gayer).

Having greatest heating power : Hornbeam, Beech, Birch, Acacia, resinous Scots Pine, Austrian Pine.

Having considerable heating power: Maple, Sycamore, Ash, English Elm, resinous Larch, ordinary Scots Pine, Oak, 
Having fair heating power : Scots Elm, Spruce, Silver Fir, Sweet Chestnut, Cembran Pine.

Having little heating power: Weymouth Pine, Lime, Alder, Aspen, Poplar, Willow.

Hardness in sawing (Gayer).

Hardest to saw: Poplar, Willow, Lime, Birch, Aspen, Sallow.

Medium : Oak, Alder, Larch, Maple, and Sycamore.

Easy to saw: Scots Pine, Spruce, Silver Fir.

Fissibility (Nisbet).

Easy to split: Spruce, Silver Fir, Weymouth and Scots Pine, Larch, Alder, Lime.

Less easy to split: Oak, Beech, Ash, Sweet Chestnut, Austrian Pine.

Hard to split: Hornbeam, Elm, Sallow, Birch, Maple, Sycamore, Poplar.

\section{THE USE OF THE SLIDE RULE.}

The slide rule consists of 4 scales- $A, B, C, D$.

$A$ and $D$ are fixtures, $C$ and $D$ are on a piece of ivory or wood which slides in a groove between $A$ and $D$.

$A, B$, and $C$ are marked exactly the same, while $D$, commonly called the " girt line," is marked differently.

By the proper manipulation of these 4 scales it is possible to multiply, divide, to square, or extract the square root; also to find the superficial contents of a board or plank or the contents of timber in the round. 
Multiplication by Sliding Rule.

Set 1 upon $A$ to the multiplier upon $B$, then against the multiplicand upon $A$ will be found the product upon $B$.

Example: Product of $24 \times 12$.

As 1 on $A: 12$ on $B:: 24$ on $A=288$ on $B$ (answer).

Division.

Set the divisor on $A$ to 1 upon $B$, then against the dividend on $A$ is the quotient on $B$.

\section{Example: $432 \div 12$.}

As 12 on $A: 1$ on $B:: 432$ on $A: 36$ on $B=$ answer.

To Square a Number.

Set 1 upon $D$ to 1 on $C$, then against the number upon $D$ will be found the square upon $C$.

Example: Square of 25.

As 1 on $D: 1$ on $C:: 25$ on $D: 625$ on $C=$ answer.

To Extract the Square Root of any Number.

Set 1 on $C$ to 1 on $D$, then against the number on $C$ is the root on $D$.

Example: Square root of 144.

As 1 on $C: 1$ on $D:: 144$ on $C: 12$ on $D=$ answer. 
To Find the Superficial Contents of a Board.

As 12 upon $B$ is to the breadth in inches upon $A$, so is the length in feet upon $B$ to the content upon $A$ in feet and fractional parts.

Example: 12 feet 6 inches long $\times 15$ inches.

Set 12 on $B$ to 15 on $A$, look at $12 \frac{1}{2}$ on $\mathrm{B}$, answer opposite on $B=15 \cdot 7$ (answer).

To Find the Cubic Contents of Round Timber by Square of $\frac{1}{4}$ Girth Measurement.

Length on $C$ against 12 on $D$, then against the $\frac{1}{4}$ girth on $D=$ answer on $C$.

Example: 20 feet long $\times 8 \frac{1}{2}$ inches $\frac{1}{4}$ girth.

Set 20 on $C$ against 12 on $D:: 8 \frac{1}{2}$ on $D: 10$ on $C$.

\section{PRINCIPAL WORK FOR EACH MONTH.}

It is not possible to lay down hard and fast rules as to when certain work should be done, as so much depends upon the locality, and upon the weather.

In the South of England work of most kinds is more forward than in the North of England or in Seotland.

The man on the spot should be the best judge as to when planting, felling, bark peeling, or seed-sowing should be done. 


\section{PRINCIPAL WORK FOR EACH MONTH 229}

The following notes may serve as a general guide:

\section{January.}

Planting should be continued from December in open weather.

Felling and thinning can be done in hard weather. Cones of conifers should be collected from good trees as they are felled.

Ground in the nursery from which plants have been lifted should be dug roughly and manured for green crop.

Any pipe draining that is necessary should be done during the winter months when the wettest spots are most discernible.

\section{February.}

Planting may be continued, also felling and thinning.

Digging or ploughing in nursery.

Plant thorn hedges, also prune or plash existing ones; watch recently planted areas, and tread up plants that have been loosened by frost and thaw or wind.

The seed of Thorn and Holly, collected and stored sixteen months previously, should be ready to sow at end of month or early in March.

\section{March.}

Planting should be finished, except for Douglas Fir, Maritime Pine, and Corsican Pine, which may be planted towards the end of the month.

Transplanting in nursery should be done when the weather is fine and the soil suitable. 
Oak, Beech, Sycamore, and Chestnut seeds may be sown. Woodland drives and nursery roads should be repaired after the heavy traffic is finished for the season.

Continue pruning and plashing of hedges.

April.

Continue lining out transplants. Make seedbeds and sow seeds of conifers towards end of month in localities where late frosts are not prevalent. Sow manuring crops. Start " pointing" in nursery, edge up paths and generally tidy up the nursery.

Finish hedging. In southern districts bark peeling may be started.

May.

Sow seeds in frosty localities early in month.

Bark peeling and harvesting.

Hoe nursery lines as soon as annual weeds appear or in very dry weather, when seed beds should be mulched.

\section{June.}

Clean ditches, repair fences, switch bracken in plantations while it is still succulent. Weeding and thinning left from winter may be done at convenient times during the summer months. Hoeing, handweeding, mulching and watering must be attended to in nursery.

Towards end of month collect Elm seed and sow at once. 
July.

Clean plantations, hedges and ditches. Mow drives. Mark poles to be thinned out during following winter. Make cuttings of privet for hedges.

August.

Clean and tend young plantations; continue cleaning ditches.

Start clearing, fencing, and draining the area to be planted in the following winter.

Open pits for planting on stiff soils.

Hoe and point between transplant lines in nursery and handweed seed beds.

\section{September.}

Take cuttings of most shrubs. Layer shrubs.

Finish cleaning plantations and preparing ground for planting.

\section{October.}

Beat up blanks in plantations.

Collect seed of Ash, Alder, Beech, Birch, Maple, and Sycamore.

Start planting hardwoods as soon as leaf is off and weather favourable, and where the soil is not too stiff.

\section{November.}

Planting on dry soils should be done to take advantage of winter rains. 
In hard weather felling and thinning should be commenced, and also any pruning of green limbs that is necessary.

Collect seed of Oak, Spruce, Silver Fir, Thorn, and Holly, also Beech and Ash if late in ripening.

Ash, Thorn, and Holly seed should be stored, mixed with sand in a pit or clamp to rot the outer covering.

Collect leaves for compost heap.

\section{December.}

Continue planting in open weather and felling during frosty spells. Hedge pruning.

Towards the end of the month, pits that have been opened in stiff soils, should be suitable for the reception of plants. Attend to recently planted areas after thaws and high winds. Collect seeds of conifers from December onwards to March from good trees that have been felled.

General Work for the Whole Year.

Repairing fences. Keeping the mouths of drains and ditches clear of rubbish. Watching plantations for signs of insect or other damage. 


\section{INDEX}

A

Acons dibbler, 41

Acre table, 211

Advantages of pure plantations, 110

of mixed plantations, 111

Age of trees, how to tell, 165

Angles of slopes, 216

Angular measure, 212

Areas, calculation of, 214

of quarter girths, 223

and circumferences of circles, 224

Ash scale, 174

bark beetles, 173

Avoirdupois weights, 213

B

Bark peeling, 153

tools, 155

Bavarian drill board, 39

Beating up plantations, 133

Beech, felted, scale, 172

leaf-mining beetle, 171

seedling fungus, 172

Bordeaux mixture, 219

Bordered-white moth, 181

Buff-tip moth, 168

Button gall, 170

C

Calendar of work, 228

Canker fungus, 172

Capacity measure, 212

Cardot's seedling pricker, 62

Chaining, 201

Chrin table, 207

Cherry gall, 170
Circumferences and areas of oircles, 224

Clay-coloured weevil, 179

Cleaning plantations, 133 hedges, 191

Clearing planting area, 73 the crop, 147

Cockchafers, 186

Composition of wood, 221

Coral-spot fungus, 176

Crops, green, 50 manuring and cleaning, 51

Cross staff, 197

D

Dibbler, acorn, 41

Distance at which to plant, 129

Ditch cleaning, 144

Division of planting area into compartments, 104

Division of nursery into beds, 18

Draining plantations, 80 nursery, 19 tools, 21 notes, 216

Drains, depth of, 217

Drain pipes per acre, 217

Drives in plantations, 104

Durability of timber, 225

Dry wood, composition of, 221

\section{E}

Elm-bark beetle, 174

F

Felling timber, 147 time for, 152

Felted beech scale, 172 
Fencing plantations, 88 notes and tables, 215

Fences, maintenance of, 102

Fissibility of timber, 226

Foot table, 205

Form factors, 163

Formation of a nursery, 13

Forty per eent. rule (Weise's), 162

F'ox-coloured saw-fly, 181

Fungi and insects, 167

Furlong table, 207

\section{G}

Gall insects, 169

Gates, 103

Gauges of wire, 215

of staples, 215

Giant wood-wasp, 181

Goat moth, 167

Green-cropping, 51

H

Hardness of timber, 225

in sawing, of timber, 226

Heating power of timber, 225

Hedges, and their management, 189

thorn, beech, etc., 189

ornamental, 189

protection of, 191

cleaning, 191

pruning, 192

re-forming, 193

Honey fungus (Agaricus melleus), 183

Hop gall, 170

Inch table, 204

Insects and fungi, 167

Insecticides, 219

K

Kooping plants clean, 63

L

Larch aphis (Chermes laricis), 184 saw-fly, 184 canker, 185
Leaf-shedding fungus, 183

Levelling, 81

Lifting seedlings and transplants, 55

Lime-sulphur wash, 220

Lining out seedlings, 55

Link table, 204

Liquid measure, 212

M

Marble gall, 169

Measurement of plantation areas, 195

Measuring timber, felled, 156 standing, 159

whole woods (contents of), 161

Measures $n^{2}$ length, 204

s arface, 208

solid or cubic, 211

of capacity, 212

liquid, 212

angular, 212

Methods of mixing trees, 112

Metric system, 213

Mile table, 207

Mixed plantations, 111

Mixtures of trees, 113

Mottled umber moth, 175

Mound planting, 80

\section{$\mathrm{N}$}

Natural slopes of earth, 216

Number of plants in nursery lines, 221

Nursery, formation of, 13 size of, 15

division of, 18

trenching, 22

roads and paths, 24

fences and hedges, 26

notes, 221

\section{0}

Oak galls, 169

Oak-apple gall, 169

Oak leaf-rolling beetle, 167

Optical square, 197

Ornamental hedges, 189 
$\mathrm{P}$

Palo tussock moth, 171

Paraffin emulsion, 220

Paris green, 219

Pine weevil, 177

beetle, 179

beauty moth, 180

saw-lly, 181

needle blister, 183

bark blister, 183

shoot tortrix moth, 180

bud tortrix moth, 180

Plantations, pure or mixed, 109 weeding and thinning, 134

Plantation fences, 88 notes and tables, 217

Planting area, preparation of, 73 division of, 104

Planting, in pits, 119

notch, 121

with dibbling iron, 123 planting hoe, 123 cylindrical and semi-circular spades, 124

in squares (number per acre), 217

in equilateral triangles, 218

in lines, 219

Plashing hedges, 193

Pole table, 206

Preparation of nursery ground, 55 of planting area, 73

Propagation of trees by cuttings, 45

Protection of hedges, 191 of seed-beds, 42

Pruning nursery plants, 66 trees, 140

hedges, 192

Puss moth, 177

Pyrethrum mixture, 220

Q

Quarter-girth measurements, 222 areas, 223

$\mathbf{R}$

Rapidity of growth, 110

Red rot, 170

Roads and paths in nursery, 24
Rood table, 211

Root fungus, 182

Rotation of crop, 125

$\mathrm{S}$

Soarcements, 25

Seed, collection of, 28

extraction of, 30

storage of, 31

buying, 32

germinative capacity of, 32

sowing, 36

Seed-beds, size of, 34

making, 35

weeding, 47

protection of, 42

Seedlings, lifting, 48

lining out, 55

Seedling pricker (Cardot's), 62

Shadebearing trees, 109

Shelter belts, 125

Size of nursery, 15

of plants, 129

Slide rule (how to calculate by), 226

Slopes of earth (natural), 216

angles of, 216

Soil preparation, draining, 19 pitting, ploughing, etc., 75

improving trees, 109

Solid measure, 211

Sowing seeds in nursery, 36

on forest land, 115

lath, 40

Spades, cylindrical, etc., 71

Spangle gall, 170

Species for different soils, 107

Spruce gall aphis (Chermes abietis), 186

Square measure, 208

Staples, gauges of, 215

Stem rot fungus, 182

Stocking the planting area, 107

Suppression of side branches, 110

$\mathbf{T}$

Tables, inch, square inch, etc., 204

Tending plantations, 133

Temporary nursery (advantage of), 131 


\section{FORESTRY WORK}

Thorn hedges, 189

Timber felling, 146 measuring, 156

notes and measures, 221

weights, 222

technical properties of, 225

durability of, 225

hardness of, 225

in sawing of, 226

utility as firewood, 225

fissibility of, 226

Transplanting, time for, 54

Transplants, lining out, 55

lifting, 69

Trees to plant pure, 112

Trenching nursery, 22

$\mathrm{U}$

Underplanting, 127
V

Vapourer moth, 168

\section{W}

Weights and measures, 204

Weise's 40 per cent. rule, 162

White rot, 170

Willow-leaf beetle, 176

Winter moth, 175

Wire ga uges and lengths, 215 nails (number per pound), 216 netting fences, 100

Wood-leopard moth, 174

Working plan (necessity of), 11

Woven-wire fencing, 100

Y

Yard table, 205 

THIS BOOK IS DUE ON THE LAST DATE STAMPED BELOW

AN INITIAL FINE OF 25 CENTS WILL BE ASSESSED FOR FAILURE TO RETURN THIS BOOK ON THE DATE DUE. THE PENALTY WILL INCREASE TO 50 CENTS ON THE FOURTH DAY AND TO $\$ 1.00$ ON THE SEVENTH DAY OVERDUE.

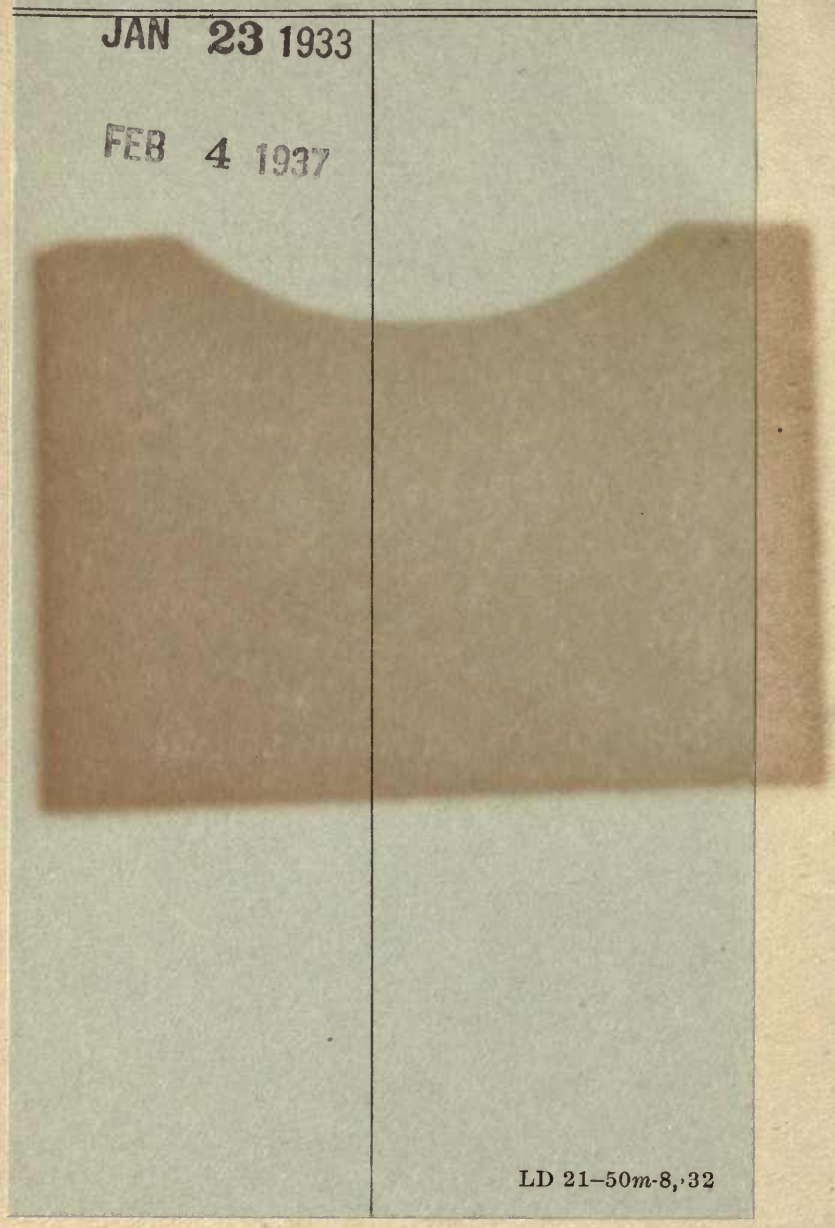


U.C. BERKELEY LIBRARIES

c03264906 4

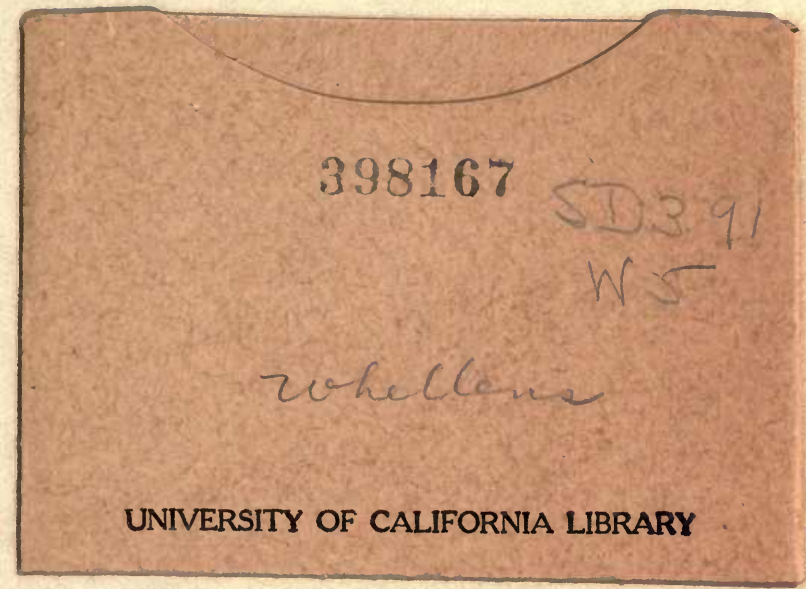


